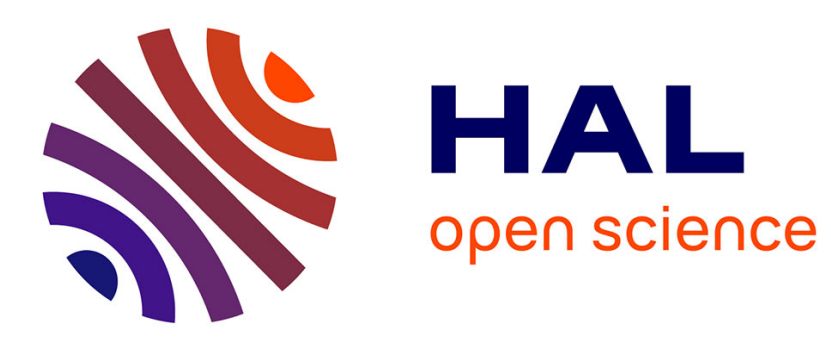

\title{
Plastidial and cytosolic thiol reductases participate in the control of stomatal functioning
}

\author{
Jean-luc Montillet, Damien Rondet, Sabine Brugière, Patricia Henri, \\ Dominique Rumeau, Jean-philippe Reichheld, Yohann Couté, Nathalie \\ Leonhardt, Pascal Rey
}

\section{To cite this version:}

Jean-luc Montillet, Damien Rondet, Sabine Brugière, Patricia Henri, Dominique Rumeau, et al.. Plastidial and cytosolic thiol reductases participate in the control of stomatal functioning. Plant, Cell and Environment, 2021, 44 (5), pp.1417-1435. 10.1111/pce.14013 . hal-03186495

\section{HAL Id: hal-03186495 \\ https://hal.science/hal-03186495}

Submitted on 27 Apr 2021

HAL is a multi-disciplinary open access archive for the deposit and dissemination of scientific research documents, whether they are published or not. The documents may come from teaching and research institutions in France or abroad, or from public or private research centers.
L'archive ouverte pluridisciplinaire HAL, est destinée au dépôt et à la diffusion de documents scientifiques de niveau recherche, publiés ou non, émanant des établissements d'enseignement et de recherche français ou étrangers, des laboratoires publics ou privés. 


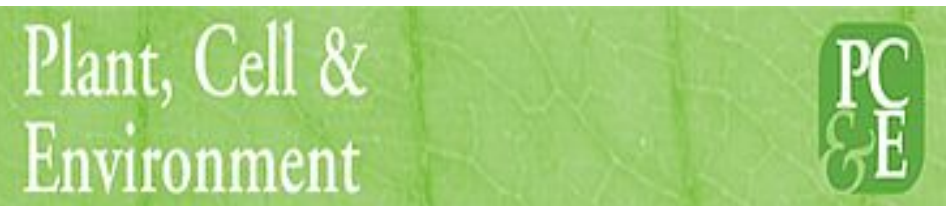

\section{Plastidial and cytosolic thiol reductases participate in the control of stomatal functioning}

\begin{tabular}{|c|c|}
\hline Journal: & Plant, Cell \& Environment \\
\hline Manuscript ID & Draft \\
\hline Wiley - Manuscript type: & Original Article \\
\hline $\begin{array}{r}\text { Date Submitted by the } \\
\text { Author: }\end{array}$ & $n / a$ \\
\hline Complete List of Authors: & $\begin{array}{l}\text { Montillet, Jean-Luc; CEA, DRF, BIAM, PPV } \\
\text { Rondet, Damien ; CEA, DRF, BIAM, PPV } \\
\text { Brugiere, Sabine; CEA, DRF, IRIG, BGE } \\
\text { Henri, Patricia; CEA, DRF, BIAM, PPV } \\
\text { Rumeau, Dominique; CNRS7265, DRF, BIAM, PPV } \\
\text { Reichheld, Jean-Phillipe; CNRS, LGDP } \\
\text { Couté, Yohann; CEA, DRF, IRIG, BGE } \\
\text { Leonhardt, Nathalie; CEA Cadarache, DRF, BIAM, SAVE } \\
\text { Rey, Pascal; CEA, DRF, BIAM, PPV }\end{array}$ \\
\hline Environment Keywords: & $\mathrm{CO} 2$, oxidative stress \\
\hline Physiology Keywords: & signaling, stomata \\
\hline Other Keywords: & redox signaling, thiol reductase \\
\hline Abstract: & $\begin{array}{l}\text { Stomatal movements via the control of gas exchanges condition plant } \\
\text { growth in relation to environmental stimuli through a complex signaling } \\
\text { network involving reactive oxygen species that lead to post-translational } \\
\text { modifications of Cys and Met residues, and alter protein activity and/or } \\
\text { conformation. Thiol-reductases (TRs), which include thioredoxins, } \\
\text { glutaredoxins (GRXs) and peroxiredoxins (PRXs), participate in signaling } \\
\text { pathways through the control of Cys redox status in client proteins. Their } \\
\text { involvement in stomatal functioning remains poorly characterized. By } \\
\text { performing a mass spectrometry-based proteomic analysis, we show that } \\
\text { numerous thiol reductases, like PRXs, are highly abundant in guard cells. } \\
\text { When investigating various Arabidopsis mutants impaired in the } \\
\text { expression of TR genes, no change in stomatal density and index was } \\
\text { noticed. In optimal growth conditions, a line deficient in cytosolic } \\
\text { NADPH-thioredoxin reductases displayed higher stomatal conductance } \\
\text { and lower leaf temperature evaluated by thermal infrared imaging. In } \\
\text { contrast, lines deficient in plastidial 2-CysPRXs or type-II GRXs exhibited } \\
\text { compared to WT reduced conductance and warmer leaves in optimal } \\
\text { conditions, and enhanced stomatal closure in epidermal peels treated } \\
\text { with abscisic acid or hydrogen peroxide. Altogether, these data strongly } \\
\text { support the contribution of thiol redox switches within the signaling } \\
\text { network regulating guard cell movements and stomatal functioning. }\end{array}$ \\
\hline
\end{tabular}




\section{SCHOLARONE ${ }^{\mathrm{m}}$ Manuscripts}


Jean-Luc Montillet ${ }^{1}$, Damien Rondet ${ }^{1,2}$, Sabine Brugière ${ }^{3}$, Patricia Henri ${ }^{1}$, Dominique Rumeau ${ }^{1}$,

5

6 1'Aix Marseille Univ, CEA, CNRS, BIAM, Plant Protective Proteins Team, F-13108, Saint

7 Paul-Lez-Durance, France

$8 \quad{ }^{2}$ Laboratoire Nixe, F-06905 Sophia-Antipolis, France

9 3Univ. Grenoble Alpes, CEA, INSERM, IRIG, BGE, Grenoble, France

${ }^{4}$ Laboratoire Génome et Développement des Plantes, CNRS, Université Perpignan Via

Domitia, F-66860 Perpignan, France

${ }^{5}$ Aix Marseille Univ, CEA, CNRS, BIAM, SAVE Team, Saint Paul-Lez-Durance, France F-

* Corresponding author: Pascal Rey; pascal.rey@cea.fr 


\section{Abstract}

Stomatal movements via the control of gas exchanges condition plant growth in relation to environmental stimuli through a complex signaling network involving reactive oxygen species that lead to post-translational modifications of Cys and Met residues, and alter protein activity and/or conformation. Thiol-reductases (TRs), which include thioredoxins, glutaredoxins (GRXs) and peroxiredoxins (PRXs), participate in signaling pathways through the control of Cys redox status in client proteins. Their involvement in stomatal functioning remains poorly characterized. By performing a mass spectrometry-based proteomic analysis, we show that numerous thiol reductases, like PRXs, are highly abundant in guard cells. When investigating various Arabidopsis mutants impaired in the expression of $T R$ genes, no change in stomatal density and index was noticed. In optimal growth conditions, a line deficient in cytosolic NADPH-thioredoxin reductases displayed higher stomatal conductance and lower leaf temperature evaluated by thermal infrared imaging. In contrast, lines deficient in plastidial 2CysPRXs or type-II GRXs exhibited compared to WT reduced conductance and warmer leaves in optimal conditions, and enhanced stomatal closure in epidermal peels treated with abscisic acid or hydrogen peroxide. Altogether, these data strongly support the contribution of thiol redox switches within the signaling network regulating guard cell movements and stomatal functioning.

Summary statement: The contribution of thiol reductases to the signaling network governing stomatal functioning remains poorly known. Using proteomics, we show that numerous thiol reductases are abundant in a guard cell-enriched fraction, and we unveil a stomatal phenotype in Arabidopsis mutants for thiol reductases.

Keywords: Arabidopsis thaliana, glutaredoxin, guard cell, peroxiredoxin, proteomics, thiol reductase, signaling, stomata, thioredoxin. 


\section{Introduction}

The movements of stomata, pores delimited by two guard cells, govern gas exchange and transpiration at the leaf surface. Plant growth is thus conditioned by stomatal opening, which allows $\mathrm{CO}_{2}$ supply for photosynthetic assimilation, and ensures appropriate hydration and temperature in leaf tissues (Hetherington and Woodward, 2003; Berry et al, 2010). During stomatal movements, the turgor and volume of vacuole in guard cells change due to osmolyte fluxes thanks to the fine regulation of channels and carriers in plasma and vacuole membranes (Kim et al, 2010; Roux and Leonhardt, 2018). These movements result from the sensing of environmental stimuli (primary input signals), the production of secondary signals such as hormones and the signal transduction via numerous messengers including kinases, calcium ions and reactive oxygen species (ROS) (Murata et al, 2015; Kollist et al, 2014).

Stomatal opening is mainly caused by blue light and photosynthetic active radiations (Shimazaki et al., 2007; Kollist et al, 2014). In comparison, multiple primary stimuli promote stomatal closure to limit water loss in response to the varying environment that plants face (Kim et al, 2010; Murata et al, 2015). Abscisic acid (ABA) plays a central role in this process notably via the production of ROS, which are recognized signaling molecules in stomatal movements (Kwak et al, 2003; Song et al, 2014; Sierla et al, 2016). ROS fulfill signaling functions in development and responses to environment by reacting with antioxidant molecules, lipids and proteins (Foyer and Noctor, 2016). Oxidation of sulfur-containing amino acids, Cys and Met, leads to redox post-translational modifications and switches altering enzymatic activity, protein conformation or subcellular distribution (Delaunay et al, 2002; Tada et al, 2008; Geigenberger et al., 2017).

Plant thiol reductases (TRs), which display catalytic Cys, accomplish key biological functions including signaling by controlling Cys and Met redox status in partner proteins (Rouhier et al, 2015; Geigenberger et al, 2017; Rey and Tarrago, 2018). They belong to 
multigene families (Tarrago et al, 2009; Meyer et al, 2012; Liebthal et al, 2018), and those considered here include thioredoxins (TRXs), glutaredoxins (GRXs), methionine sulfoxide reductases (MSRs) and the related thiol peroxidases: peroxiredoxins (PRXs) and glutathione peroxidases (GPXs) named by analogy to mammalian counterparts albeit using preferentially TRXs as reductants (Navrot et al, 2006). Plant TRXs are well-characterized small disulfide reductases carrying a Cys-Xxx-Xxx-Cys active site. Plastidial isoforms regulate photosynthetic metabolism in relation with light and redox pressure (Schürmann and Buchanan, 2008; Courteille et al, 2013; Naranjo et al, 2016). Cytosolic h-type TRXs are supplied in reducing power by NADPH-TRX reductases (NTRs), and participate in the mobilization of seed reserves upon germination or in responses to biotic constraints (Sweat and Wolpert, 2007; Hägglund et al, 2016). GRXs are oxidoreductases closely related to TRXs using glutathione (GSH) as an electron donor (Rouhier et al, 2008). Among TRX and GRX targets, thiol peroxidases play essential signaling roles via the control of peroxide concentration or direct thiol oxidation in protein partners (Day et al., 2012; Rhee and Woo, 2011; Stöcker at al., 2017). Thus, plastidial 2-CysPRXs participate in photosynthesis deactivation during the light-dark transition (Yoshida et al., 2018). Their signaling function is further supported by their ability to interact with more than 150 proteins (Cerveau et al, 2016a). Plant TRXs and GRXs, by modifying the Cys redox status in a very broad set of proteins (Rouhier et al, 2005; Montrichard et al, 2009), are involved in multiple metabolic, developmental and stress-related processes (Rey et al., 2005; Vieira Dos Santos and Rey, 2006; Bashandy et al., 2010: Knuesting et al, 2015; Rouhier et al, 2015; Liebthal et al, 2018). However, their involvement in stomatal functioning remains elusive. In a pioneer work, Jahan et al. (2008) reported enhanced ABA-induced stomatal closure in Arabidopsis GSH-deficient plants. Proteomic analyses showed high abundance of several TRs in Arabidopsis and B. napus guard cells (Zhao et al., 2008; Zhu et al., 2009; 2010), and identified potential TR partners in these cells (Zhu et al., 2014; Zhang et al., 2016). Of note, 
GPX3 based on the phenotype of Arabidopsis mutants and on its ability to interact with ABArelated signaling actors was presumed to act as both a ROS scavenger and a redox transducer in guard cells (Miao et al, 2006). Changes in stomatal functioning have been also reported in plants modified for the abundance of plastidial 2-CysPRXs (Mao et al., 2018), mitochondrial TRXs o1 and h2 (Calderon et al., 2018; da Fonseca et al., 2019), or cytosolic GRXS17 (Hu et al., 2017).

Altogether, these data suggest that thiol redox switch, via the action of TRs, is a major component of the cell guard signaling network. However, the knowledge on this process is still very poor due to the limited data regarding the presence and abundance of TRs in guard cells. In this work, we characterized the proteome of a fraction highly enriched in guard cells and we present a detailed analysis of the expression of Arabidopsis $T R$ genes. We found that numerous TRs are abundant in this fraction, and uncovered a stomatal phenotype for mutants deficient in NTRs, PRXs or GRXs. Finally, we discuss the potential functions of TRs in the signaling pathways governing stomatal movements.

\section{Material and methods}

\section{Plant material}

Arabidopsis plants were grown in the "Phytotec" platform (CEA, DRF, BIAM) from sowing in soil in standard conditions under an 8-h photoperiod and a photon flux density of 200 $\mu \mathrm{mol}$ photons. $\mathrm{m}^{-2} \cdot \mathrm{s}^{-1}$ with a temperature regime of $22 / 18^{\circ} \mathrm{C}$ (day/night) and a relative humidity of $55 \%$ as reported in Cerveau et al. (2016b). The genotypes used were wild-type Col-0, two T-DNA mutant lines for TRXh3 (SAIL_314_G04 and SALK_111160), two T-DNA mutant lines for TRXo1 (SALK_143294C and SALK_042792), one T-DNA mutant line for PRXQ (SAIL_742_G10), one T-DNA mutant line for GRXS17 (SALK_021301), one double T-DNA mutant line for 2-CysPRXA and 2-CysPRXB (Cerveau et al., 2016b), one double T-DNA mutant 
129 line for NTRA and NTRB (Reichheld et al., 2007), several lines either impaired for or overexpressing GRXS14 and/or GRXS16 (Rey et al., 2017), and the ost2-2D mutant (Merlot et al., 2007). Arabidopsis leaf genomic DNA from trxh3 and prxq mutants was extracted using the Phire plant direct kit (Thermofisher) to perform PCR using appropriate primers corresponding to 5' and 3' ends of coding sequences, Taq DNA polymerase (Life Technologies), and the GeneAmp PCRSystem 2700 (Applied Biosystems). The absence of expression in homozygous plants was checked at the protein level. Rosette weight measurements were performed following 5 or 6 weeks of growth in standard conditions. Plants expressing promoter-GUS reporter constructs were previously described (Reichheld et al., 2002; Reichheld et al., 2007). GUS histochemical staining was performed according to Reichheld et al. (2007).

\section{Preparation of fractions enriched in guard cells from leaf epidermis}

Epidermis were prepared from six week-old plants grown in standard conditions. Leaves (35 g) were ground at max speed for $3 \mathrm{~min}$ in $1 \mathrm{~L}$ bowl of a Waring Blender ${ }^{\mathrm{TM}}$ containing about $200 \mathrm{ml}$ deionised water and a handful of crushed ice. The suspension was filtered through 100$\mu \mathrm{m}$ nylon sieve, and then rinsed off thoroughly with deionised water. The obtained retentate was rapidly dried on paper towels, suspended in $10 \mathrm{mM}$ Tris-Mes buffer $\mathrm{pH} 6.0$ containing 30 $\mathrm{mM} \mathrm{KCl} 0.5 \mathrm{M} \mathrm{NaCl}$ and $0.5 \mathrm{mM}$ SDS ( $1 \mathrm{~g}$ material in $5 \mathrm{~mL}$ buffer). The suspension was gently stirred at room temperature for $15 \mathrm{~min}$ before filtration $(100 \mu \mathrm{m})$, rinsed with deionised water and dried on paper towels. After rapid freezing in liquid $\mathrm{N}_{2}$, samples were stored at $-20^{\circ} \mathrm{C}$ before protein extraction and analyses.

\section{Protein extraction from leaf and epidermis fractions}

Protein extracts, prepared according to Wang et al., (2006) from $0.5 \mathrm{~g}$ of leaf or epidermis, and sampled from three independent plant cultures were mixed to gain a representative sample 
of each type of material. Protein concentration was determined using the "Protein Quantification BCA Assay" kit (Interchim). The resulting protein pellets were resuspended in sodium phosphate buffer $0.1 \mathrm{M} \mathrm{pH} 7.2$ containing $0.15 \mathrm{M} \mathrm{NaCl}$ and $1 \%$ SDS, diluted (1:4) in 4 $\mathrm{X}$ Laemmli buffer and heat-denatured $5 \mathrm{~min}$ at $95^{\circ} \mathrm{C}$.

\section{Mass spectrometry-based proteomic analyses}

Twenty-five micrograms of proteins were stacked in a single band in the top of a SDSPAGE gel (4-12\% NuPAGE, Life Technologies) and stained with Coomassie blue R-250 before in-gel digestion using modified trypsin (Promega, sequencing grade) as previously described (Salvetti et al., 2016). Resulting peptides were fractionated by tip-based strong cation exchange and analysed by nanoliquid chromatography coupled to tandem mass spectrometry as previously described (Farhat et al. 2020).

RAW files were processed using MaxQuant (Tyanova et al., 2016) version 1.5.8.3. Spectra were searched against the Uniprot database (Arabidopsis thaliana reference proteome, February 2017 version), the frequently observed contaminants database embedded in MaxQuant, and the corresponding reversed databases. Trypsin was chosen as the enzyme and two missed cleavages were allowed. Precursor and fragment mass error tolerances were set at their default values. Peptide modifications allowed during the search were: Carbamidomethyl (C, fixed), Acetyl (Protein N-term, variable) and Oxidation (M, variable). Minimum number of peptides, razor + unique peptides and unique peptides were set to one. Maximum false discovery rates were set to 0.01 at PSM and protein levels. The match between runs option was activated. Quantification of proteins was based on unique + razor peptides. For sample comparison, intensity-based absolute quantification (iBAQ) values were loaded into ProStaR (Wieczorek et al., 2017). Peptides and proteins identified in the reverse and contaminant databases were discarded. After $\log 2$ transformation, iBAQ values were median normalized, and their log2(fold change) 
179 between conditions calculated, after missing value imputation (replacing missing value by the

180

181

\section{Bioinformatics and data processing}

Minimum number of peptides, razor + unique peptides and unique peptides were set to one. Maximum false discovery rates were set to 0.01 at PSM and protein levels. The match between runs option was activated. Quantification of proteins was based on unique + razor peptides. For comparison of samples, intensity-based absolute quantification (iBAQ) values were loaded into ProStaR (Wieczorek et al., 2017). Peptides and proteins identified in the reverse and contaminant databases were discarded. After $\log 2$ transformation, iBAQ values were median normalized and their $\log 2$ (fold change) between conditions calculated.

\section{Electrophoresis and immunoblot analysis}

Proteins were SDS-PAGE separated in reducing conditions, and either stained using Coomassie blue (Imperial ${ }^{\mathrm{TM}}$ Protein Stain, Thermo Scientific) or electroblotted onto $0.45 \mu \mathrm{m}$ nitrocellulose (Pall Corporation) for immunoblot analysis. Primary antibodies raised against At2-CysPRX (Broin et al., 2002), poplar PRXQ (Rouhier et al., 2004), AtPRXII-B (Bréhelin et al., 2003), AtTRX h3 (Reichheld et al., 2007) and AtGRXS14 (Rey et al., 2017) were used diluted $1: 10,000,1: 1000,1: 10,000,1: 10,000$ and 1:800, respectively. Antibodies against hyperoxidized 2-CysPRX (LF-PA0004; AbFrontier, Seoul, Korea) were diluted 1:3,000. The serum against spinach RubisCO (kindly provided by Dr. GH Schmid, University of Bielefeld, Germany) was diluted 1:10,000. Bound antibodies were detected using either a goat anti-rabbit secondary antibody coupled to a fluorescent molecule at a dilution of 1:10,000 (Alexa Fluor 680, Invitrogen) using the 'Odyssey Infrared Imager' at $680 \mathrm{~nm}$ (Licor, Lincoln, NE, USA) or an anti-rabbit immunoglobulin G coupled to alkaline phosphatase (Sigma). 


\section{Chlorophyll content determination}

One-cm diameter leaf disks were taken from well-expanded adult leaves and crushed in

207

208

209

210

211

212

213

\section{Preparation of adaxial and abaxial leaf epidermis for stomatal counting.}

Adaxial (upper) and abaxial (lower) epidermis were prepared according to a protocol derived from the "Tape-Arabidopsis Sandwich" reported by Wu et al., (2009). The upper or lower epidermal surface was stuck on a strip of Time tape (Time Med, IL., USA) while the opposite surface was affixed to a strip of Scotch Crystal tape (3M, Minn., USA). The Scotch Crystal tape was then sharply removed, and put in a Petri dish containing $10 \mathrm{mM}$ Tris-Mes buffer $\mathrm{pH}$ 6.0, $30 \mathrm{mM} \mathrm{KCl}$ to avoid tissue desiccation. Then with the help of a microscope cover slip, the strip has been scraped off to get rid, the best as possible, of mesophyll tissues. Stomata were counted with the help of a Leica LMD6000 microscope. Stomatal index was calculated using the formula $S /(E+S), S$ being the number of stomata per area unit and $E$ the number of ordinary epidermal cells in the same area.

\section{Measurements of stomatal aperture}

The abaxial side of half leaf blades from two 4-5-week-old plants of the same genotype grown in standard conditions was stuck on cover slips and peeled. Samples were then placed in Petri dishes containing $20 \mathrm{~mL}$ of buffer containing $10 \mathrm{mM}$ MES/Tris $\mathrm{pH}$ 6.0, $30 \mathrm{mM} \mathrm{KCl}$. After $30 \mathrm{~min}$ in the dark, epidermal peels (except controls) were transferred under light $(300 \mu \mathrm{mol}$ photons. $\mathrm{m}^{-2} \cdot \mathrm{s}^{-1}$ ) at $22^{\circ} \mathrm{C}$ for $2.5 \mathrm{~h}$ in order to ensure that most stomata were open before 
treatments. For promotion of closure, $20 \mu \mathrm{L}$ of stock solutions of ABA in ethanol and of $\mathrm{H}_{2} \mathrm{O}_{2}$ in water were directly diluted in the buffer in contact with peels. Thereafter, samples were incubated in the light for $2.5 \mathrm{~h}$ before aperture measurements according to Merlot et al., (2007). To avoid bias results, double blind experiments were performed, so that, experimenters in charge of measurements were not informed of genotype or treatment. Values reported are the means \pm SD of two independent experiments, for which 60 aperture widths were measured each time. Error bars represent standard deviations of the means.

\section{Porometry measurements}

Stomatal conductance of fully expanded leaves was measured on 6-week old well drained plants grown in standard conditions. Measurements were carried out using a hand-held AP4 porometer (Delta-T Devices, Cambridge, UK) on the abaxial leaf side in the middle of the light period, and two to four hours after watering by flooding. Usually, eight measurements per plant were made on 6 to 12 independent plants per genotype. Due to variations in calibration resulting from slight differences in the moisture of the paper used as a reference, differences were noticed in the level of conductance in WT plants between experiments despite very similar growth and measurement conditions. All experiments and repetitions for characterizing one genotype and corresponding WT plants were carried out using the same calibration reference.

\section{Infrared determination of leaf temperature}

Plants were cultivated on soil as described above for up to 6 weeks in a dedicated phytotron, in which low relative humidity $(45 \% \pm 5 \%)$ and low wind speed were applied the day before infrared thermographic imaging to ensure optimal contrast between lines. Images were acquired using a Thermacam PM250 infrared camera as described by Costa et al., (2015). 


\section{Results}

\section{Analysis of $T R$ gene expression in guard cells by transcriptomics}

As a first step, using transcriptomic data from guard and mesophyll cell protoplasts representing a large part of Arabidopsis genes (Yang et al., 2008), we extracted those available for $T R$ genes. Based on relative expression values, we noticed that most TR transcripts are present in both cell types (data not shown), and observed that a number of them displayed a ratio between the two values higher than 2 , indicating preferential expression in one cell type. This was noticed for NADPH-Thioredoxin Reductase A (NTRA), which encodes the reducer for cytosolic TRXs and exhibits higher transcript level in guard cells (Fig. S1A). Regarding TRX genes (Fig. S1A), we observed that $T R X h 3$ exhibits compared to others the highest expression in guard cells, and a substantially higher transcript level compared to mesophyll cells. Most interestingly, nine other TRX genes $(h 2, h 4, m 3, o 1, o 2, T D X, C L O T, N R X 1$ and LILIUM-1), coding for various typical or unusual isoforms located in the main subcellular compartments, exhibited higher expression in guard cells, while two ( $h 5$ and CDSP32) were preferentially expressed in mesophyll cells. Regarding other $T R$ genes (Fig. S1B), we noticed that GRXs $S 15$ and ROXY10, $P R X I I-B$ and $G P X 2$, and MSRs $A 1$ and $A 4$ displayed a transcript abundance higher in guard cells compared to mesophyll cells. To deepen some of these microarray data, we analyzed gene expression by promoter-GUS histochemistry (Fig S2). GUS staining was clearly observed in guard cells of PrTRXh2-, PrTRXh3-, PrPRXII-B- and PrNTRB-GUS lines, confirming the expression of these $T R$ genes in guard cells.

\section{Preparation of a guard cell-enriched fraction}

We then investigated $T R$ gene expression in guard cells by implementing a proteomic approach. We did not used protoplasts since during preparation, redox homeostasis is dramatically impaired (Papadakis and Roubelakis-Angelakis, 1999), leading to changes in the 
expression, abundance, redox status and conformation of TRs. To obtain a fraction enriched in guard cells, we treated epidermis from Arabidopsis plants as described in Experimental Procedures. Microscope observations of this fraction revealed the presence of intact guard cells, predominantly broken and open pavement and trichome cells, and some pieces of xylem vessels (data not shown). The presence of chloroplasts served as an indication of cell integrity. Vigorous shearing of leaf tissues and extensive washing of epidermis kept intact only guard cells, which are protected from mechanical constraints due to their cell wall thickness. We therefore assumed that a significant part of proteins in this extract, notably the soluble pool, originates from guard cells. To estimate the enrichment, we counted guard cells in both epidermal sides of all leaves of 6-week old plants, measured the sizes of representative guard cells to estimate their average volume, and determined the protein concentrations in whole leaves and in broken epidermis. Based on these measurements (Table S1), the total GC volume has been rated at $0.13 \%$ of the leaf volume, and assuming that protein concentration $\left(2 \mathrm{mg} . \mathrm{g}^{-1}\right.$ leaf $\mathrm{FW}$ ) is identical regardless of cell type, we estimated this content in GC to $0.0026 \mathrm{mg} \cdot \mathrm{g}^{-1}$. Given that the protein concentration in grinded epidermis was $0.028 \mathrm{mg} \cdot \mathrm{g}^{-1} \mathrm{FW}$, the inference is that $9.3 \%$ come from guard cells. Therefore, we calculated an enrichment factor of 71 (9.3:0.13) in broken epidermis that was thus termed guard cell-enriched (GCE) fraction. Finally, we compared the protein patterns of leaf and GCE fractions by SDS-PAGE (Fig. 1A), and observed clear differences, such as dramatically decreased abundance of RubisCO subunits at 50 and $13 \mathrm{kDa}$ in the GCE fraction. This was confirmed in immunoblots, where a much higher band intensity was observed for both subunits in the leaf extract (Fig. 1B). In contrast, the intensity of two bands at 22 and $75 \mathrm{kDa}$ was more elevated in the GCE fraction (Fig. 1A). 
The GCE fraction, along with a whole leaf extract prepared in a similar manner, were analyzed by mass spectrometry-based proteomics, leading to the characterization of 4842 proteins identified with two peptides and quantified in at least in one of the two samples, representing 4694 and 4248 proteins in GCE and leaf fractions, respectively (Table S2). To estimate the relative abundance in each sample, we ranked proteins according to their computed intensity-based absolute quantification (iBAQ, Schwanhäusser et al., 2011) values. The iBAQ values were also used to compare the abundance of each protein between GCE and leaf fractions. The functional categorization of the genes encoding the $25 \%$ most abundant proteins in each fraction has been determined using the Gene Ontology annotation retrieval tool available on the TAIR site (https://www.arabidopsis.org/tools/go_term_enrichment.jsp). The comparison uncovered some striking differences (Fig. 2), such as under-representation (- 9 to $16 \%$ ) of proteins related to plastid, chloroplast and thylakoid functioning in the GCE fraction, consistent with the elimination of photosynthetic mesophyll cells during the preparation.

We also noticed enrichment $(+9 \%)$ in the GCE fraction of extracellular and cell wall proteins (Fig. 2), partly due to the presence of many cell phantoms originating from the pavement. With the help of the reports of Irshad et al., (2008), Duruflé et al., (2019) and Showalter et al., (2010) that characterized Arabidopsis cell wall proteome using bioinformatic and proteomic approaches, we reckoned 322 proteins contributing to cell wall structure or function (Table S3). A majority (85\%) is more abundant in the GCE fraction, $16 \%$ being not detected in leaf. Of note, based on microarray data (Yang et al., 2008), more than one third of the genes encoding these proteins were found preferentially expressed in GC (ratio of expression GC/MC higher than 2). Regarding extracellular proteins (Table S3), seven germins and germin-like proteins (GLPs) are more abundant in the GCE fraction, two (GLP1-6 and GLP5-1) being the first and the fifth most abundant proteins, respectively. GLPS are 
glycoproteins associated with the extracellular matrix, encoded by 32 genes in Arabidopsis, and involved in responses to osmotic constraints ( $\mathrm{Li}$ et al., 2016). Among cell wall proteins more abundant in the GCE fraction (Table S3), we noticed the presence of a large number of GDSLtype esterases/lipases, 18 out of 45 putative ones, which are notably involved in biotic stress responses (Lai et al., 2017), and of 17 expansins out of the 36 genes identified in Arabidopsis (Lee et al., 2001). Expansins interact with cell wall carbohydrates, cellulose and hemicellulose. Most interestingly, expansin A1, which plays a critical role in stomatal movements (Wei et al., 2011; Zhang et al., 2011), is one of the most abundant protein (rank 29) in the GCE fraction.

In other respects, Leonhardt et al. (2004) identified 63 genes preferentially expressed in guard cells, 25 being present in our analysis. Table S4 shows that only one protein encoded by this set of genes is more represented in the leaf fraction, and that 20 are more abundant in the GCE fraction, eight being specific of this sample. Finally, to further figure out the validity of the GCE fraction regarding stomatal functions, we scrutinized the protein list to find out candidates previously described as key players in stomatal movements or development (Table 1). Hence, 56 of these proteins were pinpointed, 43 being more abundant ( $R$ value $>1.5$ ) in the GCE fraction than in leaf. Consistently, a large majority of genes encoding these proteins are more expressed in guard cells than in mesophyll cells (Table S4) (Yang et al., 2008), and 22 were identified in Arabidopsis GC protoplasts (Zhao et al., 2008, 2010). Among the 56 proteins, we identified 12 kinases and phosphatases, 14 ion channels, pumps and transporters, 3 ABA receptors, and 19 enzymes and other proteins acting in osmoregulation in guard cells, in addition to eight effectors involved in stomatal development and patterning. We also identified GRF6 (14-3-3 $\lambda$ ) that is involved in blue light-mediated stomatal opening (Tseng et al., 2012), and present in the GCE fraction at a high level (top 5\%). 14-3-3 proteins (GRFs) are regulators of stomatal movements (Cotelle and Leonhardt, 2016), through the binding of phosphorylated client proteins such as phototropins, plasma membrane $\mathrm{H}^{+}$-ATPases or ion channels. In our 
analysis, we detected 10 out of the 13 members of this family, all being more abundant in the GCE fraction (Table S5). Taken together, these data indicate that grinding and extensively washing epidermis is as an easy way to concentrate guard cell proteins as evidenced by the high enrichment factor and the exclusive presence in the GCE fraction of numerous proteins known to function in stomatal movements. This approach can be thus used for identifying new proteins, the activity of which could be determinant for guard cell functioning.

\section{Abundance of TRs in the GCE fraction}

We thus analyzed the protein list from the GCE fraction to retrieve all TRs, and ranked them according to extracted abundance (Table 2). Thirty-nine TRs, out of the approximately 100 genes belonging to these enzyme families in Arabidopsis thaliana, were identified. Most interestingly, we observed the presence of various PRXs (PRXQ, 2-CysPRXA, PRXII-B, PRXII-F) in the first decile, and of other TR types (NTRA, PRXII-E, TRX h3, GPX6, 2CysPRXB, MSRA2, NRX1) in the first quartile. Numerous TRs (NTRB, MSRA4, GPX1, GPX2, TRX z, TRX h2, TRX m2, NTRC, TRX f1) were present in the first half of the ranking list. Then, we compared the relative abundance of TRs in GCE and leaf fractions using the R parameter (Table 2). When selecting those displaying a $\mathrm{R}$ value superior to 1.5 , we pointed 19 TRs, many being much more abundant in the GCE fraction than in leaf, notably PRXII-B, NTRA, TRX h3, MSRA2, NRX1, NTRB, GPX2, TRX h2, GPX3 and TRX CxxS1. Of note, five TRs were only detected in the GCE fraction, namely TRX z, TRXh9, GRXS15, TDX and TRX Lilium 6. In other respects, we also searched for the TRs relatively more abundant in the leaf fraction. We found that all those having a very low $\mathrm{R}$ value $(<0.1)$ are involved in the regulation of photosynthesis or in the maintenance of plastidial redox homeostasis. This is the case of TRXs m1, m2, m4, f1, CDSP32, HCF164, and MSRB2. By crossing transcriptomic and proteomic data (Fig. S1, Table 2), we observed good consistency between the two approaches. 
Indeed, among the $17 T R$ genes displaying preferential expression in GC, 11 were identified by proteomics and nine encode proteins more abundant in the GCE fraction. Finally, by comparing with the pioneer proteomic works on guard cell protoplasts, in which a much lower number of proteins ( $\mathrm{ca}$ 1000) was identified, we noticed that all TRs detected in these reports (Zhao et al., $2008 ; 2010$ ) are present in the GCE fraction (Table 2). Altogether, these findings lead us to conclude that numerous TRs are present in guard cells, several of them being very abundant.

\section{Western blot analysis of TR abundance in the GCE fraction}

We then assessed the abundance of some TRs in the GCE and leaf fractions by Western blot analysis (Fig. 1B). We noticed a much higher amount of TRX h3 in the GCE fraction than in leaf, and observed relative abundances of 2-CysPRXs, PRXQ, PRX-IIE and PRXII-B in the two fractions consistent with proteomic data. Further, we noticed comparable abundance in the two fractions of GRXS14, which was not detected in the proteomic analysis. Most interestingly, substantial changes in the redox status of 2-CysPRXs and GRXS14 were detected in the GCE fraction. Indeed, while the level of hyperoxidized 2-CysPRXs was relatively low in leaf, as already observed (Cerveau et al. 2016b; Cerveau et al. 2019), this form was much more abundant in the GCE fraction. Regarding GRXS14, we previously reported that the GRX has two redox forms showing differential migration (Rey et al., 2017). Whereas only one redox GRXS14 form was detected in leaf proteins, two specific bands were revealed in the GCE fraction. These data reveal that TRs could display specific redox features in guard cells compared to photosynthetic cells.

\section{Phenotype of mutants impaired in the expression of $T R$ genes}

To gain further insights about TR functions in stomatal biology, we investigated the phenotype of mutants modified for the expression of $P R X Q, 2-C y s P R X s, N T R A$ and NTRB, 
TRXh3, TRXo1, GRXS17, GRXS14 or GRXS16. These lines were selected based on protein abundance in guard cells, mutant availability (Reichheld et al., 2007; Knuesting et al., 2015; Cerveau et al., 2016b; Rey et al., 2017; Calderon et al., 2018), bibliographical data (Hu et al, 2017; Calderon et al, 2018; Mao et al, 2018), and preliminary experiments. Regarding prxq and trxh3 mutants, gene disruption was validated at the protein level (Fig. S3).

First, we investigated the growth of mutants in standard short-day, light, temperature and watering conditions, in which stomata function in an optimal manner. Growth was characterized by measuring the rosette fresh weight of 5- to 6-week old plants (Fig. S4). We previously reported that Arabidopsis plants impaired for both GRXS14 and GRXS16 expression displayed reduced growth (Fig. S5), whereas those over-expressing GRXS14 exhibited higher rosette weight (Rey et al., 2017). Plants deficient in GRXS17 expression did not exhibit any growth phenotype in short photoperiod (Fig. S4C) as already observed (Knuesting et al., 2015). Regarding lines affected in plastidial PRXs, we did not observe any difference for prxq as reported for another mutant (Lamkemeyer et al. 2006), but noticed that 2-cysprxa 2-cysprxb plants displayed substantially reduced growth (Figs. S4A, S5), consistently with the reports of Pulido et al., (2010) and Awad et al., (2015). A somewhat reduced growth was noticed for $n$ tra ntrb plants (Figs. S4B, S5) as in Reichheld et al., (2007), and trxh3 and trxol plants displayed slightly higher, but non-significantly different, rosette weights in agreement with Park et al. (2009) on one trxh3 line, and Ortiz-Espin et al. (2017) on two trxo1 mutants (Fig. S4D-E).

In addition, we measured the chlorophyll content and observed that most lines displayed a level similar to that in WT (Fig. S6), except the 2-cysprxa 2-cysprxb mutant, which exhibited pale green leaf phenotype (Fig. S5) and chlorophyll content reduced by ca $20 \%$ (Fig. S6) as observed by Pulido et al., (2010). In other respects, the two lines over-expressing GRXS14 were previously reported to display a somewhat reduced pigment content (Rey et al., 2017). 


\section{Stomatal phenotype of mutants impaired in the cytosolic NTR/TRX system}

We then characterized TR-modified lines with regard to stomatal functioning, and first

431

432 investigated the phenotype of those deficient in cytosolic NADPH-thioredoxin reductases A and $\mathrm{B}, \mathrm{TRXs} \mathrm{h} 3$ or $\mathrm{o} 1$. Beforehand, we determined the density and number of stomata in relation with the number of epidermal cells (stomatal index), since variations in these parameters can lead to differences in leaf capacity for gas exchange. We observed very close values of density (ca 270 per $\mathrm{mm}^{2}$ ) and index (0.16) in WT, ntra ntrb plants, trxh3 and trxol mutants (Fig. 3AB; Fig S7A-B), indicating no change in stomatal differentiation and development in the absence of cytosolic NTRs, TRXs h3 or o1.

Porometry measurements were conducted to evaluate the stomatal conductance by measuring the rate of water efflux from the leaf abaxial side of plants grown in optimal conditions. We observed that the mutant lacking both cytosolic NTRA and NTRB displayed a significantly higher conductance compared to WT (182.4 \pm 10.5 mmoles $\mathrm{H}_{2} \mathrm{O} . \mathrm{m}^{-2} . \mathrm{s}^{-1}$ vs 162.7 \pm 16.9 ) (Fig. 3C). No variation in stomatal conductance was detected in trxh3 and trx ol plants (Fig S8A-C). We then approached the stomatal functioning in 6-week old plants cultivated in standard conditions by evaluating leaf temperature using infrared (IR) imaging, since leaf cooling is ensured by opening of stomata. To validate the approach, we used the ost $2-2 D$ (open stomata 2) dominant mutant that displays stomatal closure defects due to constitutive $\mathrm{H}^{+}$ATPase activity (Merlot et al., 2007). IR imaging revealed a strong difference in the leaf temperature of this mutant compared to WT. In the ost2-2D mutant, most leaves appear purple/blue corresponding to a temperature in the range of 16 to $16.5^{\circ} \mathrm{C}$, whereas in the WT the leaf color (green to yellow) reflected a temperature in the range of 17.2 to $17.8^{\circ} \mathrm{C}$ (Fig. 3D). This is consistent with constitutive wide stomatal opening and constant cooling in ost $2-2 D$ plants. Regarding mutants lacking either TRX h3 or TRX o1, no difference in leaf temperature was observed (data not shown). When examining ntra ntrb plants, we observed that their 
temperature was lower than that of WT, as evidenced by the much higher number of red to yellow leaves in the latter (Fig. 3E). Based on the color scale, the difference could be evaluated to $c a 0.5^{\circ} \mathrm{C}$. Taken collectively, these data reveal that cytosolic NTRs that are highly abundant in the GCE fraction (Table 2) participate in stomatal functioning.

\section{Stomatal phenotype of lines deficient in plastidial PRXs}

As previously shown (Table 2), plastidial PRXs are well represented in the GCE fraction, PRXQ being the most abundant TR and 2-CysPRXA and B present in the top-ten proteins. We thus investigated the phenotype of lines lacking these PRXs. Compared to WT, no difference was observed in either stomatal density or index in both 2cysprxa 2 cysprxb and prxq plants (Fig. 4A-B). In standard watering conditions, a significantly lower stomatal conductance was measured in those deficient in 2-Cys-PRXs ( ca 220 mmoles $\mathrm{H}_{2} \mathrm{O} \cdot \mathrm{m}^{-2} \cdot \mathrm{s}^{-1}$ vs 260 in WT), while a slight non-significant decrease was noticed in prxq plants (Fig. 4C). When using thermal infrared imaging, we noticed that many leaves of the mutant lacking both 2-CysPRXs displayed red to yellow color corresponding to a temperature between 17 and $18^{\circ} \mathrm{C}$, whereas most WT leaves were green to red with a temperature between 16.5 and $17.5^{\circ} \mathrm{C}$ (Fig. 4D). With regard to prxq plants, we noticed no substantial temperature difference compared to WT (Fig. 4E).

\section{Stomatal phenotype of lines deficient in type-II GRXs}

We then investigated the phenotype of Arabidopsis lines affected in the expression of typeII GRXs based on the presence of cytosolic GRXS17 and plastidial GRXS16 in the GCE fraction (Table 2), and on the report of $\mathrm{Hu}$ et al. (2017) showing a stomatal phenotype in GRXS17-silenced rice plants. The Arabidopsis line deficient in GRXS17 did not exhibit any variation in stomatal density and index (Fig. S7A-B) in short-day conditions, in which the 
mutant has no obvious phenotype (Knuesting et al., 2015). No noticeable change in either stomatal conductance (Fig. S8D) or leaf temperature (data not shown) was observed.

We performed the analysis of lines modified for the expression of the two genes encoding plastidial type-II GRXs, GRXS14 and GRXS16 (Rey et al., 2017). First, we examined knockout mutants for GRXS14, lines co-suppressed for GRXS16 (Rey et al., 2017), and lines overexpressing one of the two GRXs. No change was observed in the density and stomatal index of any of these lines (Fig. 5A-B: Fig. S7C-D), nor in the stomatal conductance (Fig. 5C; Fig. S8E-G) and leaf temperature (Fig. 5D, data not shown).

Finally, we analyzed the phenotype in standard growth conditions of two independent lines, termed KI1 and KI2, knockout for GRXS14 and impaired for GRXS16 expression due to RNAinterference (Rey et al., 2017). Compared to WT, both lines did not exhibit any significant variation in stomatal density and index (Fig. 5A-B). Interestingly, substantially reduced stomatal conductance was recorded in the two KI1 and KI2 lines compared to WT ( $c a 230$ and 240 mmoles $\mathrm{H}_{2} \mathrm{O} \cdot \mathrm{m}^{-2} . \mathrm{s}^{-1}$, respectively, vs 280 in WT) (Fig. 5C). Consistently, when imaging leaf temperature, we observed higher temperature in both lines (Fig. 5D-E). This was particularly obvious in the KI1 line, where all leaves, particularly the youngest ones, displayed a red to yellow color corresponding to a temperature in the range of or higher than $18^{\circ} \mathrm{C}$, whereas most WT leaves exhibited green to red color with a temperature lower than $17.5^{\circ} \mathrm{C}$.

\section{Stomatal responses to $\mathrm{ABA}$ and $\mathrm{H}_{2} \mathrm{O}_{2}$ in lines deficient in thiol reductases}

Considering that ABA and $\mathrm{H}_{2} \mathrm{O}_{2}$ are major actors promoting stomatal closure, we investigated whether mutants deficient in thiol reductases showed altered sensitivity to these compounds. Stomatal apertures were measured in light-pretreated epidermal peels, incubated for $2.5 \mathrm{~h}$ on buffer containing 0.5 to $100 \mu \mathrm{M} \mathrm{ABA}$ or 0.01 to $1 \mathrm{mM} \mathrm{H}_{2} \mathrm{O}_{2}$ (Fig. 6). We observed that at the lowest ABA concentration $(0.5 \mu \mathrm{M}), 2$ cysprxa 2cysprxb, KI1 and KI2 plants were 
503

504

505

506

507

508

509

510

511

512

513

514

515

516

517

518

519

520

521

522

523

524

525

526

527

much more reactive compared to WT and ntra ntrb plants. Indeed, whereas the latter displayed no change compared to light treatment alone, stomatal aperture was significantly decreased by ca $24 \%$ in 2 cysprxa 2 cysprxb, KI1 and KI2 (Fig. 6A-B). At $1 \mu \mathrm{M}$, this differential behavior tended to diminish since a significant difference was observed only between WT and 2cysprxa 2 cysprxb, with aperture decreases of 20 and 40\%, respectively. No difference among all lines was noticed at higher hormone concentrations. When epidermal peels were exposed to $\mathrm{H}_{2} \mathrm{O}_{2}$, substantial differences were observed for 2cysprxa 2cysprxb, KI1 and KI2 lines, which clearly displayed enhanced sensitivity. In the three lines, stomatal aperture at $10 \mu \mathrm{M} \mathrm{H}_{2} \mathrm{O}_{2}$ was reduced by ca $35 \%$ and significantly lower compared to that recorded in WT and ntra ntrb plants (10\%) (Fig. 6 C-D). Higher susceptibility was also recorded at $100 \mu \mathrm{M} \mathrm{H}_{2} \mathrm{O}_{2}$ for the three mutant lines, but not at the highest concentration $(1 \mathrm{mM})$. Altogether, these data indicate that plastidial thiol reductases modulate $\mathrm{ABA}-$ and $\mathrm{H}_{2} \mathrm{O}_{2}$-dependent signaling pathways controlling stomatal closure.

\section{Discussion}

\section{Presence and abundance of TRs in guard cells}

So far, the knowledge about the abundance of TRs in guard cells is limited and based on the proteome of guard cell protoplasts in Arabidopsis thaliana and Brassica napus (Zhao et al., 2008; 2010; Zhu et al, 2009; 2010). We attempted to strengthen this knowledge by taking advantage of the great advance in mass spectrometry-based proteomics made since. To avoid redox biases and changes due to protoplast preparation, we implemented another approach using broken and extensively washed epidermis to get a fraction highly enriched in guard cells. The enrichment of this fraction was validated by the relatively high abundance of numerous key actors involved in stomatal functioning (Table 1). With regard to TRs, the proteomic analysis of the GCE fraction highlighted several findings: i) among about 4700 proteins 
identified, 39 TRs belonging to the TRX, GRX, PRX, GPX and MSR families are present; ii) $c a$ half of them are relatively more abundant in the GCE fraction than in leaf. iii) NADPHthioredoxin reductases A and B, the electron source for extra-plastidial TRXs, are present in the first quartile when ranking proteins as a function of abundance within the GCE fraction (Table 2); iv) six PRXs (PRXQ the most abundant TR, the two 2-CysPRXs and three PRX-IIs: $\mathrm{B}, \mathrm{E}$ and F) out of the nine in Arabidopsis are also present in the first quartile of the list. Most importantly, these proteomic data are in accordance with transcriptomics of guard cell protoplasts, that revealed higher transcript levels for various TR types compared to mesophyll cells (Fig. S1). Further, all the TRs (13) identified in the first proteomic analyses of guard cell protoplasts in Arabidopsis thaliana and Brassica napus (Zhao et al., 2008; 2010; Zhu et al., 2009) are present in the GCE fraction, notably four PRXs (2-CysPRXA and B, PRXII-E and PRXII-F). Thereby, these reports and the present work strongly support a key contribution of TRs in the functioning of guard cells. Numerous TRs are present in both GCE and leaf fractions (Table S2), indicating that they might also participate in long-distance signaling pathways originating from mesophyll and controlling stomatal movements in relation with photosynthesis level (Lawson, 2009). Nonetheless, our data revealing high abundance of many TRs in guard cells and phenotypes for mutants impaired for several of them, give strong reliability to essential roles of these reductases within the stomatal signaling network and machinery.

\section{Participation of cytosolic TRs in stomatal functioning}

We observed that plants deficient in NTRA and NTRB display increased stomatal opening in standard growth conditions as evidenced by porometry measurements and thermal infrared imaging (Fig. 3). In other respects, bioassay experiments carried out on epidermal peels did not reveal any substantial aperture change in this line compared to WT in response to $\mathrm{ABA}$ or $\mathrm{H}_{2} \mathrm{O}_{2}$ treatments applied over a relatively short period of time (2.5 h) (Fig. 6). Both NTRs ensure the 
reduction of cytosolic and mitochondrial TRXs, such as $\mathrm{h}$ and o isoforms. Nonetheless, Arabidopsis mutant plants lacking either cytosolic TRX h3 or mitochondrial TRX o1 did not show any noticeable change in stomatal functioning (Fig. S8). Interestingly, da Fonseca-Pereira et al., (2019) reported that ntra ntrb and trxol plants displayed faster recovery after two cycles of drought episodes in relation with higher stomatal conductance. This is consistent with our data unveiling higher conductance in the mutant lacking cytosolic and mitochondrial NTR systems. Therefore, the role of the NTR/TRX system in stomata might be of importance following drought stress. In other respects, Calderon et al. (2018) reported higher stomatal density and index in the two trxol mutant lines compared to WT, revealing a possible role of these TRXs in stomatal development. When characterizing these mutants, we did not notice such a phenotype. (Fig. S7). It is worth mentioning that in this study, the density and index ranges ( $\mathrm{ca} 120 . \mathrm{mm}^{-2}$ and 0.45$)$ are very different from ours. This might originate from different culture conditions and measurements performed at distinct developmental stages in the two works. Of note, the trxol lines also displayed reduced water loss upon high salinity, possibly due to altered stomatal functioning (Calderon et al., 2018). Finally, da Fonseca-Pereira et al., (2020) reported that Arabidopsis mutants lacking TRX h2, which is located in both cytosol and mitochondria, do not exhibit any growth phenotype in short day and low light intensity, but decreased stomatal conductance and higher water use efficiency. These data indicate that the cytosolic NTR/TRX system could fine tune guard cell functioning in relation with light parameters via pathways remaining to be unveiled (Fig. 7).

This system is likely to fulfill several functions through redox interaction with known actors of the signaling network regulating stomatal movements. Thus, cytosolic TRs might control the redox status of OST1/SnRK2.6, BAK1, SnRK2.4 and CPK21, which are likely prone to thiol-based modifications as they display cysteine thiol redox switches modifying their activity in vitro, or interact in vitro with TRs (Bender et al. 2015; Wang et al. 2015; Zhu et al. 
2017; Ma et al. 2018). This hypothesis is further supported by the identification of $c a 80$ potential TRX targets in a fraction enriched in guard cells (Zhang et al., 2016), and of numerous proteins harboring redox sensitive Cys in Brassica napus guard cells (Zhu et al., 2014). One major challenge will consist of identifying their reductants among TRs and determining their physiological functions in stomatal movements (Fig. 7).

\section{Participation of plastidial TRs in stomatal functioning}

Plants deficient in type-II GRXs or 2-Cys PRXs exhibited decreased stomatal opening in optimal growth conditions as shown by porometry and thermal infrared imaging (Figs. 4-5), and enhanced stomatal closure in epidermal peels treated with $\mathrm{ABA}$ or $\mathrm{H}_{2} \mathrm{O}_{2}$ (Fig. 6). $\mathrm{H}_{2} \mathrm{O}_{2}$ is an essential redox signaling messenger promoting closure, and likely enters the cytoplasm of guard cells (Rodrigues et al., 2017) following the ABA-induced ROS burst in apoplast (Kwak et al., 2003). Our data clearly reveal that GRXS14, GRXS16 and 2-CysPRXs limit ABA- and ROS-induced stomatal closure (Fig. 6). Strikingly, these reductases are located in plastids, highlighting the involvement of this compartment in stomatal functioning. This is fully consistent with the hypothesis of redox signals originating from chloroplasts in the network controlling stomatal movements (Chen and Gallie, 2004; Song et al, 2014), $\mathrm{H}_{2} \mathrm{O}_{2}$ accumulation in chloroplasts of guard cells being even considered as one of the earliest hallmarks of stomatal closure (Sierla et al, 2016). The involvement of subcellular compartments is further supported by the participation of mitochondrial TRX o1 in guard cell functioning (Calderon et al., 2018), and the presence of numerous organelle TRs in the GCE fraction (Table 2). Plastidial and mitochondrial TRs play master roles in energy generation and consumption (Schurmann and Buchanan, 2008; Daloso et al., 2015), and are thus probably needed in the regulation and coordination of the highly active metabolism in guard cells during stomatal movements. 
Plastidial GRXS14 and S16 might modulate stomatal movements via the control of Cys

603

604

605

606

607

608

609

610

611

612

613

614

615

616

617

618

619

620

621

622

623

624

625

626

redox status in partner proteins that participate in ROS-related transduction pathways inducing closure (Fig. 7). Consistent with this hypothesis, another GRX is able to inhibit in vitro the activity of BAK1 via glutathionylation (Bender et al., 2015). So far, very little is known in vivo about the participation of GRXs in stomatal functioning, except for GRXS17, which also belongs to class-II and is located in cytosol and nucleus. Silencing of its expression in rice is associated with increased stomatal closure (Hu et al., 2017). Moreover, GRXS17-deficent lines are more tolerant to water deficit (Hu et al., 2017). However, when investigating the stomatal phenotype of an Arabidopsis grxs17 line using porometry and thermal imaging, we did not notice any difference with WT in standard conditions (Fig. S8 and data not shown), indicating environmental and/or species influence on the role of the GRX.

The Arabidopsis line lacking plastidial 2-CysPRXs exhibited a marked stomatal phenotype (Figs. 4, 6), which might underlie, at least partially, its decreased growth (Fig. S4) due to reduced $\mathrm{CO}_{2}$ supply to photosynthetic cells. It is worth mentioning that this pleiotropic mutant also displays less chlorophyll (Figs. S5-S6) and increased susceptibility to photooxidative stress (Awad et al., 2015). Note that deficiency and overexpression of 2-CysPRX in rice lead to enhanced and decreased stomatal opening, respectively (Mao et al., 2017), suggesting that this peroxidase plays distinct roles in stomata of monocotyledons and dicotyledons. 2-Cys PRXs are considered as a central redox buffer in plastid since they are efficient scavengers of hydrogen and organic peroxides (Liebthal et al., 2018; Cerveau et al., 2019). Thus, they are prime candidates to sense local changes in $\mathrm{H}_{2} \mathrm{O}_{2}$ content in guard cells. This function could take place in the transduction pathway involving $\mathrm{H}_{2} \mathrm{O}_{2}$ and promoting stomatal closure. Since $\mathrm{H}_{2} \mathrm{O}_{2}$ induced closure is strongly enhanced in the mutant lacking both 2-Cys PRXs (Fig. 6), we can hypothesize that these peroxidases directly mitigate, via scavenging, the peroxide signal intensity leading to closure (Fig. 7). Further, many recent lines of evidence revealed that these 
enzymes achieve essential roles in redox signaling processes through the control of thiol switch in partner proteins (Rhee and Woo, 2011; Liebthal et al., 2018). Accordingly, Stöcker at al. (2017) reported that 2-CysPRXs enable rapid and sensitive thiol oxidation in various protein types at the expense of $\mathrm{H}_{2} \mathrm{O}_{2}$. In plants, 2-CysPRXs play a key role in Calvin cycle deactivation at night via oxidation of TRX partners (Yoshida et al., 2018). Further, 2-Cys PRXs interact with a large number of potentially redox-regulated proteins (Cerveau et al., 2016a; Liebthal et al., 2020). Some such as $\beta$-amylases, which are redox-regulated enzymes involved in starch degradation, very likely participate in osmotic adjustment during stomata opening (Valerio et al., 2011; Horrer et al., 2016). Thus, we can presume that similarly to their role in photosynthesis regulation, 2-Cys PRXs participate in the daytime control of starch degradation, which drives light-induced stomatal opening (Horrer et al., 2016). Such a function might underlie the phenotype observed in whole plants (Fig. 4). To conclude, plastidial 2-Cys PRXs are likely to accomplish several signaling functions in relation with $\mathrm{H}_{2} \mathrm{O}_{2}$ level in guard cells (Fig. 7). This hypothesis is further supported by the much higher level of protein hyperoxidation in the GCE fraction compared to leaf (Fig. 1B). Cys hyperoxidation to a sulfinic acid form is reversible thanks to the action of sulfiredoxin (Rey et al., 2007), and leads based on the floodgate theory to local $\mathrm{H}_{2} \mathrm{O}_{2}$ accumulation and initiation of signaling pathways (Poole et al., 2011). Finally, 2-CysPRXs possess several phosphorylation sites (Liebthal et al., 2018) susceptible to modulate peroxidase activity as shown in its human counterpart (Woo et al., 2010) and possibly underlying interplays between redox and phosphorylation transduction pathways, which are essential in stomatal movements (Kim et al., 2010).

\section{Conclusions}

The present work provides evidence of altered stomatal functioning in plants deficient for several TR types. In Arabidopsis lines lacking class-II GRXs or 2-CysPRXs, the lower stomatal 
652

653

654

655

656

657

658

659

660

661

662

663

664

665

666

667

668

669

670

671

672

673

674

675

676

conductance is associated with reduced growth. However, this cannot be regarded as a general rule since plants deficient in NTRs A and B concomitantly exhibit reduced growth (Fig. S4) and more open stomata (Fig. 3). Taking collectively, the few works reporting a stomatal phenotype resulting from TR deficiency (Hu et al, 2017; Calderon et al, 2018; Mao et al, 2018) and our data highlight the complexity of TR roles in stomata that very likely depend on environmental conditions, developmental stage, and species. This work clearly unveils the participation of plastidial TRs in signaling transduction pathways controlling stomatal closure, and opens new avenues of research to investigate the roles of thiol redox switch in stomatal functioning. In particular, it will be essential to identify TR physiological partners in guard cells, and unravel their integration within the hormone- and ROS-related transduction pathways regulating stomatal movements in response to abiotic environmental stimuli, but also biotic ones, since stomata participate in immune defense mechanisms (Melotto et al., 2006; Montillet and Hirt, 2013). Consistently Pang et al., (2020) recently reported changes in the expression of several $T R X$ and $P R X$ genes in a GCE fraction following treatment with a bacterial pathogen.

\section{Acknowledgements}

We are very grateful to the "Phytotec" platform (CEA, DRF, BIAM) for technical assistance with growth chambers, S. CHIARENZA and N. BROUSSE-POCHON for assistance in growing plants, W. SAINT-AUBIN for technical assistance in experiments, N. BECUWE for molecular characterization of mutants, Dr. I. REITER (CNRS, ECCOREV, O3HP) for equipment supply and advice in porometry experiments, Dr. V. HINOUX (University of Perpignan) for participation in the trxh3 mutant characterization, Prof. N. ROUHIER (University of Lorraine) for valuable project discussion and M.L. REY for help in formatting the manuscript. D. RONDET acknowledges financial support for a PhD grant (CIFRE contract $\mathrm{n}^{\circ}$ 2014/0798) between CEA and the NIXE Company (Sophia-Antipolis, France), and is 
677 grateful to Dr. R. CANAGUIER for helpful discussion. This study is set within the framework 678 of the "Laboratoires d'Excellence (LabEx)" TULIP (ANR-10-LABX-41). Proteomic 679 experiments were partly supported by the Agence Nationale de la Recherche (ProFI grant ANR680 10-INBS-08-01). 
681

682

683

684

685

686

687

688

689

690

691

692

693

694

695

696

697

698

699

700

701

702

703

704

705

706

707

708

\section{References}

Awad J., Stotz H.U., Fekete A., Krischke M., Engert C., Havaux M., Berger S. \& Mueller M.J. (2015). 2-cysteine peroxiredoxins and thylakoid ascorbate peroxidase create a water-water cycle that is essential to protect the photosynthetic apparatus under high light stress conditions. Plant Physiology, 167, 1592-1603.

Bashandy T., Guilleminot J., Vernoux T., Caparros-Ruiz D., Ljung K., Meyer Y. \& Reichheld J.P. (2010). Interplay between the NADP-linked thioredoxin and glutathione systems in Arabidopsis auxin signaling. The Plant Cell, 22, 376-391.

Bender K.W., Wang X., Cheng G.B., Kim H.S., Zielinski R.E. \& Huber S.C. (2015). Glutaredoxin AtGRXC2 catalyses inhibitory glutathionylation of Arabidopsis BRI1-associated receptor-like kinase 1 (BAK1) in vitro. Biochemical Journal, 467, 399-413.

Berry J.A., Beerling D.J. \& Franks P.J. (2010). Stomata: key players in the earth system, past and present. Current Opinion in Plant Biology, 13, 233-240.

Bréhélin C., Meyer E.H., de Souris J.P., Bonnard G. \& Meyer Y. (2003). Resemblance and dissemblance of Arabidopsis type II peroxiredoxins: similar sequences for divergent gene expression, protein localization, and activity. Plant Physiology, 132, 2045-2057.

Broin M., Cuiné S., Eymery F. \& Rey P. (2002). The plastidic 2-cysteine peroxiredoxin is a target for a thioredoxin involved in the protection of the photosynthetic apparatus against oxidative damage. The Plant Cell, 14, 1417-1432.

Calderón A., Sánchez-Guerrero A., Ortiz-Espín A., Martínez-Alcalá I., Camejo D., Jiménez A. \& Sevilla F. (2018). Lack of mitochondrial thioredoxin 01 is compensated by antioxidant components under salinity in Arabidopsis thaliana plants. Physiologia Plantarum, 164, 251267.

Cerveau D., Henri P., Blanchard L. \& Rey P. (2019). Variability in the redox status of plant 2Cys peroxiredoxins in relation to species and light cycle. Journal of Experimental Botany, 70, 5003-5016.

Cerveau D., Kraut A., Stotz H.U., Mueller M.J., Couté Y. \& Rey P. (2016a). Characterization of the Arabidopsis thaliana 2-Cys peroxiredoxin interactome. Plant Science, 252, 30-41. 
Cerveau D., Ouahrani D., Marok M.A., Blanchard L. \& Rey P. (2016b). Physiological relevance of plant 2-Cys peroxiredoxin overoxidation level and oligomerization status. Plant, Cell and Environment, 39, 103-119.

Chen Z. \& Gallie D.R. (2004). The ascorbic acid redox state controls guard cell signaling and stomatal movement. The Plant Cell, 16, 1143-1162.

Costa J.M., Monnet F., Jannaud D., Leonhardt N., Ksas B., Reiter I.M., Pantin F. \& Genty B. (2015). Open all night long: the dark side of stomatal control. Plant Physiology, 167, 289-294.

Cotelle V. \& Leonhardt N. (2016). 14-3-3 Proteins in Guard Cell Signaling. Frontiers in Plant Science, 6, 1210. doi: 10.3389/fpls.2015.01210

Courteille A., Vesa S., Sanz-Barrio R., Cazalé A.C., Becuwe-Linka N., Farran I., Havaux M., Rey P. \& Rumeau D. (2013). Thioredoxin $\mathrm{m} 4$ controls photosynthetic alternative electron pathways in Arabidopsis. Plant Physiology, 161, 508-520.

Daloso D. M., Müller K., Obata T., Florian A., Tohge T., Bottcher A., Riondet C., Bariat L., Carrari F., Nunes-Nesi A., Buchanan B.B., Reichheld J.P., Araújo W.L., \& Fernie A.R. (2015). Thioredoxin, a master regulator of the tricarboxylic acid cycle in plant mitochondria. Proceedings of the National Academy of Sciences USA, 112, E1392-E1400. https://doi.org/10.1073/pnas.1424840112

Day A.M., Brown J.D., Taylor S.R., Rand J.D., Morgan B.A. \& Veal E.A. (2012). Inactivation of a peroxiredoxin by hydrogen peroxide is critical for thioredoxin-mediated repair of oxidized proteins and cell survival. Molecular Cell, 45, 398-408.

Delaunay A., Pflieger D., Barrault M.B., Vinh J. \& Toledano M.B. (2002). A thiol peroxidase is an $\mathrm{H}_{2} \mathrm{O}_{2}$ receptor and redox-transducer in gene activation. Cell, 111, 471-481.

Duruflé H., Ranocha P., Balliau T., Dunand C. \& Jamet E. (2019). Transcriptomic \& cell wall proteomic datasets of rosettes and floral stems from five Arabidopsis thaliana ecotypes grown at optimal or sub-optimal temperature. Data Brief. 27, 104581. doi: 10.1016/j.dib.2019.104581

Farhat D.C., Swale C., Dard C., Cannella D., Ortet P., Barakat M., Sindikubwabo F., Belmudes L., De Bock P.J., Couté Y., Bougdour A. \& Hakimi M.A. (2020). A MORC-driven transcriptional switch controls Toxoplasma developmental trajectories and sexual commitment. Nature Microbiology, 5, 570-583. 
da Fonseca-Pereira P., Daloso D.M., Gago J., de Oliveira Silva F.M., Condori-Apfata J.A., Florez-Sarasa I., Tohge T., Reichheld J.P., Nunes-Nesi A., Fernie A.R. \& Araújo W.L. (2019). The mitochondrial thioredoxin system contributes to the metabolic response under drought episodes in Arabidopsis. Plant Cell Physiology, 60 213-229. doi: 10.1093/pcp/pcy194

da Fonseca-Pereira P., Souza P.V.L., Hou L.Y., Schwab S., Geigenberger P., Nunes-Nesi A., Timm S., Fernie A.R., Thormählen I., Araújo W.L. \& Daloso D.M. (2020). Thioredoxin h2 contributes to the redox regulation of mitochondrial photorespiratory metabolism. Plant, Cell and Environment, 43, 188-208. doi: 10.1111/pce.13640

Foyer C.H. \& Noctor G. (2016). Stress-triggered redox signalling: what's in pROSpect? Plant, Cell and Environment, 39, 951-964.

Geigenberger P., Thormählen I., Daloso D.M. \& Fernie A.R. (2017). The unprecedented versatility of the plant thioredoxin system. Trends Plant Science, 22, 249-262.

Hägglund P., Finnie C., Yano H., Shahpiri A., Buchanan B.B., Henriksen A. \& Svensson B. (2016). Seed thioredoxin h. Biochimica et Biophysica Acta, 1864, 974-982.

Hetherington A.M. \& Woodward F.I. (2003). The role of stomata in sensing and driving environmental change. Nature, 424, 901-908.

Horrer D., Flütsch S., Pazmino D., Matthews J.S., Thalmann M., Nigro A., Leonhardt N., Lawson T. \& Santelia D. (2016). Blue light induces a distinct starch degradation pathway in guard cells for stomatal opening. Current Biology, 26, 362-370. doi: 10.1016/j.cub.2015.12.036

Hu Y., Wu Q., Peng Z., Sprague S.A., Wang W., Park J., Akhunov E., Jagadish K.S.V., Nakata P.A., Cheng N., Hirschi K.D. White F.F. \& Park S. (2017). Silencing of OsGRXS17 in rice improves drought stress tolerance by modulating ROS accumulation and stomatal closure. Scientific Reports, 7, 15950. doi: 10.1038/s41598-017-16230-7

Irshad M., Canut H., Borderies G., Pont-Lezica R. \& Jamet E. (2008). A new picture of cell wall protein dynamics in elongating cells of Arabidopsis thaliana: confirmed actors and newcomers. BMC Plant Biology, 8, 94. doi: 10.1186/1471-2229-8-94

Jahan M.S., Ogawa K., Nakamura Y., Shimoishi Y., Mori I.C. \& Murata Y. (2008). Deficient glutathione in guard cells facilitates abscisic acid-induced stomatal closure but does not affect light-induced stomatal opening. Bioscience, Biotechnology and Biochemistry, 72, 2795-2798. 
767 Kim T.H., Böhmer M., Hu H., Nishimura N. \& Schroeder J.I. (2010). Guard cell signal 768 transduction network: advances in understanding abscisic acid, $\mathrm{CO}_{2}$, and $\mathrm{Ca}^{2+}$ signaling. Annual Review of Plant Biology, 61, 561-591.

770

Knuesting J., Riondet C., Maria C., Kruse I., Bécuwe N., König N., Berndt C., Tourrette S., Guilleminot-Montoya J., Herrero E., Gaymard F., Balk J., Belli G., Scheibe R., Reichheld J.P., Rouhier N. \& Rey P. (2015). Arabidopsis glutaredoxin S17 and its partner NF-YC11/NC2 $\alpha$ contribute to maintenance of the shoot apical meristem under long-day photoperiod. Plant Physiology, 167, 1643-1658.

Kollist H., Nuhkat, M. \& Roelfsema M.R. (2014). Closing gaps: linking elements that control stomatal movement. New Phytology, 203, 44-62.

Kwak J.M., Mori I.C., Pei Z.M., Leonhardt N., Torres M.A., Dangl J.L., Bloom R.E., Bodde S., Jones J.D. \& Schroeder J.I. (2003). NADPH oxidase AtrbohD and AtrbohF genes function in ROS-dependent ABA signaling in Arabidopsis. EMBO Journal, 22, 2623-2633.

Lai C.P., Huang L.M., Chen L.O., Chan M.T. \& Shaw J.F. (2017). Genome-wide analysis of GDSL-type esterases/lipases in Arabidopsis. Plant Molecular Biology, 95,181-197.

Lamkemeyer P., Laxa M., Collin V., Li W., Finkemeier I., Schöttler M.A., Holtkamp V., Tognetti V.B., Issakidis-Bourguet E., Kandlbinder A., Weis E., Miginiac-Maslow M. \& Dietz K.J. (2006). Peroxiredoxin Q of Arabidopsis thaliana is attached to the thylakoids and functions in context of photosynthesis. The Plant Journal, 45, 968-981.

Lawson T. (2009). Guard cell photosynthesis and stomatal function. New Phytologist, 181, 1334.

Lee Y., Choi D. \& Kende H. (2001). Expansins: ever-expanding numbers and functions. Current Opinion in Plant Biology, 4, 527-532.

Leonhardt N., Kwak J.M., Robert N., Waner D., Leonhardt G. \& Schroeder J.I. (2004). Microarray expression analyses of Arabidopsis guard cells and isolation of a recessive abscisic acid hypersensitive protein phosphatase 2C mutant. The Plant Cell, 16, 596-615.

Li L., Xu X., Chen C. \& Shen Z. (2016). Genome-Wide Characterization and Expression Analysis of the Germin-Like Protein Family in Rice and Arabidopsis. International Journal of Molecular Sciences, 17, 10. pii: E1622. doi: 10.3390/ijms17101622 
796

797

798

799

800

801

802

803

804

805

806

807

808

809

810

811

812

813

814

815

816

817

818

819

820

821

822

823

Lichtenthaler H.K. (1987). Chlorophylls and carotenoids: pigments of photosynthetic biomembranes. Methods in Enzymology, 148, 350-382.

Liebthal M., Maynard D. \& Dietz K.J. (2018). Peroxiredoxins and Redox Signaling in Plants. Antioxydants \& Redox Signaling, 28, 609-624.

Liebthal M., Schuetze J., Dreyer A., Mock H.P., \& Dietz K.J. (2020). Redox conformationspecific protein-protein interactions of the 2-ysteine peroxiredoxin in Arabidopsis. Antioxidants, 9, 515.

Ma T., Yoo M.J., Zhang T., Liu L., Koh J., Song W.Y., Harmon A.C., Sha W. \& Chen S. (2018). Characterization of thiol-based redox modifications of Brassica napus SNF1-related protein kinase 2.6-2C. FEBS Open Biology, 8, 628-645.

Mao X., Zheng, Y., Xiao K., Wei Y., Zhu Y., Cai Q., Chen L., Xie H. \& Zhang, J. (2018). OsPRX2 contributes to stomatal closure and improves potassium deficiency tolerance in rice. Biochemical and Biophysical Research Communications, 495, 461-467.

Melotto M., Underwood W., Koczan J., Nomura K. \& He S.Y. (2006). Plant stomata function in innate immunity against bacterial invasion. Cell, 126, 969-980.

Merlot S., Leonhardt N., Fenzi F., Valon C., Costa M., Piette L., Vavasseur A., Genty B., Boivin K., Müller A., Giraudat J. \& Leung J. (2007). Constitutive activation of a plasma membrane $\left.\mathrm{H}^{+}\right)$-ATPase prevents abscisic acid-mediated stomatal closure. EMBO Journal, 26, 3216-3226.

Meyer Y., Belin C., Delorme-Hinoux V., Reichheld J.P. \& Riondet C. (2012). Thioredoxin and glutaredoxin systems in plants: molecular mechanisms, crosstalks, and functional significance. Antioxidants \& Redox Signaling, 17, 1124-1160.

Miao Y., Lv D., Wang P., Wang X.C., Chen J., Miao C. \& Song C.P. (2006). An Arabidopsis glutathione peroxidase functions as both a redox transducer and a scavenger in abscisic acid and drought stress responses. The Plant Cell, 18, 2749-2766.

Montillet J.L. \& Hirt H. (2013). New check points in stomatal defense. Trends in Plant Science, 18, 295-297. doi: 10.1016/j.tplants.2013.03.007

Montrichard F., Alkhalfioui F., Yano H., Vensel W.H., Hurkman W.J. \& Buchanan B.B. (2009). Thioredoxin targets in plants: the first 30 years. Journal of Proteomics, 72, 452-474. 
Murata Y., Mori I.C. \& Munemasa S. (2015). Diverse stomatal signaling and the signal integration mechanism. Annual Review of Plant Biology, 66, 369-392.

Naranjo B., Diaz-Espejo A., Lindahl M. \& Cejudo F.J. (2016). Type-f thioredoxins have a role in the short-term activation of carbon metabolism and their loss affects growth under short-day conditions in Arabidopsis thaliana. Journal of Experimental Botany, 67, 1951-1964.

Navrot N., Collin V., Gualberto J., Gelhaye E., Hirasawa M., Rey P., Knaff D.B, Issakidis E., Jacquot J.P. \& Rouhier N. (2006). Plant glutathione peroxidases are functional peroxiredoxins distributed in several subcellular compartments and regulated during biotic and abiotic stresses. Plant Physiology, 142, 1364-1379.

Ortiz-Espín A., Iglesias-Fernández R., Calderón A., Carbonero P., Sevilla F. \& Jiménez. A. (2017). Mitochondrial AtTrxo1 is transcriptionally regulated by AtbZIP9 and AtAZF2 and affects seed germination under saline conditions. Journal of Experimental Botany, 68, 10251038.

Pang Q., Zhang T., Zhang A., Lin C., Kong W. \& Chen S. (2020). Proteomics and phosphoproteomics revealed molecular networks of stomatal immune responses. Planta, 252, 66. doi: 10.1007/s00425-020-03474-3.

Papadakis A.K. \& Roubelakis-Angelakis K.A. (1999). The generation of active oxygen species differs in Nicotiana and Vitis plant protoplasts. Plant Physiology, 121,197-205.

Park S.K., Jung Y.J., Lee J.R., Lee Y.M., Jang H.H., Lee S.S., Park J.H., Kim S.Y., Moon J.C., Lee S.Y., Chae H.B., Shin M.R., Jung J.H., Kim M.G., Kim W.Y., Yun D.J., Lee K.O. \& Lee S.Y. (2009). Heat-shock and redox-dependent functional switching of an h-type Arabidopsis thioredoxin from a disulfide reductase to a molecular chaperone. Plant Physiology, 150, 552561.

Poole L.B., Hall A. \& Nelson K.J. (2011). Overview of peroxiredoxins in oxidant defense and redox regulation. Current Protocols in Toxicology, 7, 9. doi: 10.1002/0471140856.tx0709s49.

Pulido P., Spínola M.C., Kirchsteiger K., Guinea M., Pascual M.B., Sahrawy M., Sandalio L.M., Dietz K.J., González M. \& Cejudo F.J. (2010). Functional analysis of the pathways for 2-Cys peroxiredoxin reduction in Arabidopsis thaliana chloroplasts. Journal of Experimental Botany, 61, 4043-4054. 
853

854

855

856

857

858

859

860

861

862

863

864

865

866

867

868

869

870

871

872

873

874

875

876

877

878

879

880

881

882

Reichheld J.P., Khafif M., Riondet C., Droux M., Bonnard G. \& Meyer Y. (2007). Inactivation of thioredoxin reductases reveals a complex interplay between thioredoxin and glutathione pathways in Arabidopsis development. The Plant Cell, 19, 1851-1865.

Reichheld J.P., Mestres-Ortega D., Laloi C. \& Meyer Y. (2002). The multigenic family of thioredoxin $h$ in Arabidopsis thaliana: specific expression and stress response. Plant Physiology and Biochemistry, 40, 685-690.

Rey P., Becuwe N., Barrault M.B., Rumeau D., Havaux M., Biteau B. \& Toledano M.B. (2007). The Arabidopsis thaliana sulfiredoxin is a plastidic acid reductase involved in the photooxidative stress response. The Plant Journal, 49, 505-514.

Rey P., Becuwe N., Tourrette S. \& Rouhier N. (2017). Involvement of Arabidopsis glutaredoxin S14 in the maintenance of chlorophyll content. Plant, Cell and Environment, 40, 2319-2332.

Rey P., Cuiné S., Eymery F., Garin J., Court M., Jacquot J.P., Rouhier N. \& Broin M. (2005). Analysis of the proteins targeted by CDSP32, a plastidic thioredoxin participating in oxidative stress responses. The Plant Journal, 41, 31-42.

Rey P. \& Tarrago L. (2018). Physiological roles of plant methionine sulfoxide reductases in redox homeostasis and signaling. Antioxidants (Basel), 7(9). pii: E114. doi: 10.3390/antiox 7090114

Rhee S.G. \& Woo H.A. (2011). Multiple functions of peroxiredoxins: peroxidases sensors and regulators of the intracellular messenger $\mathrm{H}_{2} \mathrm{O}_{2}$ and protein chaperones. Antioxidants \& Redox Signaling, 15, 781-794.

Rodrigues O., Reshetnyak G., Grondin A., Saijo Y., Leonhardt N., Maurel C. \& Verdoucq L. (2017). Aquaporins facilitate hydrogen peroxide entry into guard cells to mediate ABA- and pathogen-triggered stomatal closure. Proceedings of the National Academy of Sciences USA, $114,9200-9205$.

Rouhier N., Cerveau D., Couturier J., Reichheld J.P. \& Rey P. (2015). Involvement of thiolbased mechanisms in plant development. Biochemical et Biophysical Acta, 1850, 1479-1496.

Rouhier N., Gelhaye E., Gualberto J.M., Jordy M.N., De Fay E., Hirasawa M., Duplessis S., Lemaire S.D., Frey P., Martin F., Manieri W., Knaff D.B. \& Jacquot J.P. (2004). Poplar peroxiredoxin Q. A thioredoxin-linked chloroplast antioxidant functional in pathogen defense. Plant Physiology, 134, 1027-1038. 
883

884

885

886

887

888

889

890

891

892

893

894

895

896

897

898

899

900

901

902

903

904

905

906

907

908

909

910

Rouhier N., Lemaire S.D. \& Jacquot J.P. (2008). The role of glutathione in photosynthetic organisms: emerging functions for glutaredoxins and glutathionylation. Annual Review of Plant Biology, 59, 143-166.

Rouhier N., Villarejo A., Srivastava M., Gelhaye E., Keech O., Droux M., Finkemeier I., Samuelsson G., Dietz K.J., Jacquot J.P. \& Wingsle G. (2005). Identification of plant glutaredoxin targets. Antioxidants \& Redox Signaling, 7, 919-929.

Roux B. \& Leonhardt N. (2018). The regulation of ion channels and transporters in the guard cell. Advances in Botanical Research, 87, 171-214. doi.org/10.1016/bs.abr.2018.09.013.

Salvetti A., Couté Y., Epstein A., Arata L., Kraut A., Navratil V., Bouvet P. \& Greco A. (2016). Nuclear functions of nucleolin through global proteomics and interactomic approaches. Journal of Proteome Research, 15, 1659-1669.

Schürmann P. \& Buchanan B.B. (2008) The ferredoxin/thioredoxin system of oxygenic photosynthesis. Antioxidants \& Redox Signaling, 10, 1235-1274.

Schwanhaüsser B., Busse D., Li N., Dittmar G., Schuchhardt J., Wolf J., Chen W. \& Selbach M. (2011). Global quantification of mammalian gene expression control. Nature, 473, 337-342.

Shimazaki K., Doi. M., Assmann S.M. \& Kinoshita T. (2007). Light regulation of stomatal movement. Annual Review of Plant Biology, 58, 219-47.

Showalter A.M., Keppler B., Lichtenberg J., Gu D. \& Welch L.R. (2010). A bioinformatics approach to the identification, classification, and analysis of hydroxyproline-rich glycoproteins. Plant Physiology, 153, 485-513.

Sierla M., Waszczak C., Vahisalu T. \& Kangasjärvi J. (2016). Reactive oxygen species in the regulation of stomatal movements. Plant Physiology, 171, 1569-1580.

Song Y., Miao Y. \& Song C.P. (2014). Behind the scenes: the roles of reactive oxygen species in guard cells. New Phytologist, 201, 1121-1140.

Stöcker S., Maurer M., Ruppert T. \& Dick T.P. (2017). A role for 2-Cys peroxiredoxins in facilitating cytosolic protein thiol oxidation. Nature Chemical Biology, 14, 148-155.

Sweat T.A. \& Wolpert T.J. (2007). Thioredoxin h5 is required for victorin sensitivity mediated by a CC-NBS-LRR gene in Arabidopsis. The Plant Cell, 19, 673-687. 
Tada Y., Spoel S.H., Pajerowska-Mukhtar K., Mou Z., Song J., Wang C., Zuo J. \& Dong X. (2008). Plant immunity requires conformational changes of NPR1 via S-nitrosylation and thioredoxins. Science, 321, 952-956.

Tarrago L., Laugier E. \& Rey P. (2009). Protein-repairing methionine sulfoxide reductases in photosynthetic organisms: gene organization, reduction mechanisms, and physiological roles. Molecular Plant, 2, 202-217.

Tseng T.S., Whippo C., Hangarter R.P. \& Briggs W.R. (2012). The role of a 14-3-3 protein in stomatal opening mediated by PHOT2 in Arabidopsis. The Plant Cell, 24, 1114-1126.

Tyanova S., Temu T. \& Cox J. (2016). The MaxQuant computational platform for mass spectrometry-based shotgun proteomics. Nature Protocols, 11, 2301-2319.

Valerio C., Costa A., Marri L., Issakidis-Bourguet E., Pupillo P., Trost P. \& Sparla F. (2011). Thioredoxin-regulated beta-amylase (BAM1) triggers diurnal starch degradation in guard cells, and in mesophyll cells under osmotic stress. Journal of Experimental Botany, 62, 545-555.

Vieira Dos Santos C. \& Rey P. (2006). Plant thioredoxins are key actors in oxidative stress response. Trends in Plant Science, 11, 329-334.

Wang P., Du Y., Hou Y.J., Zhao Y., Hsu C.C., Yuan F., Zhu X., Tao W.A., Song C.P. \& Zhu J.K. (2015). Nitric oxide negatively regulates abscisic acid signaling in guard cells by Snitrosylation of OST1. Proceedings of the National Academy of Sciences USA, 112, 613-618.

Wang W., Vignani R., Scali M. \& Cresti M. (2006). A universal and rapid protocol for protein extraction from recalcitrant plant tissues for proteomic analysis. Electrophoresis, 27, 27822786.

Wei P.C., Zhang X.Q., Zhao P. \& Wang X.C. (2011). Regulation of stomatal opening by the guard cell expansin AtEXPA1. Plant Signaling Behavior, 6, 740-742.

Wieczorek S., Combes F., Lazar C., Giai Gianetto Q., Gatto L., Dorffer A., Hesse A.M., Couté Y., Ferro M., Bruley C. \& Burger T. (2017). DAPAR \& ProStaR: software to perform statistical analyses in quantitative discovery proteomics. Bioinformatics, 33, 135-136. 
938 Winter D., Vinegar B., Nahal H., Ammar R., Wilson G.V. \& Provart N.J. (2007). An 939 "Electronic Fluorescent Pictograph" browser for exploring and analyzing large-scale biological 940 data sets. PLoS One, 2, e718. doi: 10.1371/journal.pone.0000718.

941 Woo H.A., Yim S.H., Shin D.H., Kang D., Yu D.Y. \& Rhee S.G. (2010). Inactivation of 942 peroxiredoxin $\mathrm{I}$ by phosphorylation allows localized $\mathrm{H}_{2} \mathrm{O}_{2}$ accumulation for cell signaling. Cell, $943140,517-528$.

944 Wu F.H., Shen S.C., Lee L.Y., Lee S.H., Chan M.T. \& Lin C.S. (2009). Tape-Arabidopsis Sandwich - a simpler Arabidopsis protoplast isolation method. Plant Methods, 5, 16.

Yang Y., Costa A., Leonhardt N., Siegel R.S. \& Schroeder J.I. (2008). Isolation of a strong Arabidopsis guard cell promoter and its potential as a research tool. Plant Methods, 4, 6.

Yoshida K., Hara A., Sugiura K., Fukaya Y. \& Hisabori T. (2018). Thioredoxin-like2/2-Cys peroxiredoxin redox cascade supports oxidative thiol modulation in chloroplasts. Proceedings of the National Academy of Sciences USA, 115, E8296-E8304.

Zhang X.Q., Wei P.C., Xiong Y.M., Yang Y., Chen J. \& Wang X.C. (2011). Overexpression of Arabidopsis alpha-expansin gene AtEXPA1 accelerates stomatal opening by decreasing the volumetric elastic modus. Plant Cell Reports, 30, 27-36.

Zhang T., Zhu M., Zhu N., Strul J.M., Dufresne C.P., Schneider J.D., Harmon A.C. \& Chen S. (2016). Identification of thioredoxin targets in guard cell enriched epidermal peels using cysTMT proteomics. Journal of Proteomics, 133, 48-53.

Zhao Z., Stanley B.A., Zhang W. \& Assmann S.M. (2010). ABA-regulated G protein signaling in Arabidopsis guard cells: a proteomic perspective. Journal of Proteome Research, 9, 16371647.

960 Zhao Z., Zhang W., Stanley B.A. \& Assmann S.M. (2008). Functional proteomics of 961 Arabidopsis thaliana guard cells uncovers new stomatal signaling pathways. The Plant Cell, 12, $962 \quad 3210-3226$. napus guard cells and mesophyll cells revealed by comparative proteomics. Molecular Cell Proteomics, 8, 752-766. 
966 Zhu M., Simons B., Zhu N., Oppenheimer D.G. \& Chen S. (2010). Analysis of abscisic acid 967 responsive proteins in Brassica napus guard cells by multiplexed isobaric tagging. Journal of 968 Proteomics, 73, 790-805.

969 Zhu M., Zhang T., Ji W., Silva-Sanchez C., Song W.Y., Assmann S.M., Harmon A.C. \& Chen 970 S. (2017). Redox regulation of a guard cell SNF1-related protein kinase in Brassica napus, an 971 oilseed crop. Biochemical Journal, 474, 2585-2599.

972 Zhu M., Zhu N., Song W.Y., Harmon A.C., Assmann S.M. \& Chen S. (2014). Thiol-based 973 redox proteins in abscisic acid and methyl jasmonate signaling in Brassica napus guard cells. 974 The Plant Journal, 78, 491-515. 


\begin{tabular}{|c|c|c|c|c|c|c|c|c|c|}
\hline $\begin{array}{c}\text { AGI } \\
\text { Number }\end{array}$ & $\begin{array}{l}\text { Protein } \\
\text { ID }\end{array}$ & Description & GCE & $\mathbf{L}$ & $\underset{\mathrm{L}}{\text { GCE- }}$ & $\mathbf{R}$ & $\begin{array}{c}\text { GC } \\
\text { proteomics }\end{array}$ & $\begin{array}{c}\mathbf{G C} / \mathbf{M} \\
\text { transcript } \\
\text { ratio }>2\end{array}$ & Reference \\
\hline AT5G26000 & P37702 & Myrosinase $1 *$ & 31,43 & 29,21 & 2,22 & 4,66 & $\mathbf{X}$ & $\bullet$ & {$[54]$} \\
\hline AT1G69530 & Q9C554 & Expansin-A1 * & 29,30 & 24,39 & 4,91 & 30,1 & & - & [48]; [53] \\
\hline AT3G53420 & P43286 & Aquaporin PIP2-1 \# & 29,05 & 29,17 & $-0,12$ & 0,92 & $\mathbf{X}$ & & {$[43]$} \\
\hline AT2G18960 & P20649 & ATPase $1 \#$ & 27,77 & 24,99 & 2,78 & 6,87 & $\mathbf{X}$ & - & [21] \\
\hline AT5G56030 & P55737 & Heat shock protein $90-2 *$ & 27,46 & 27,15 & 0,32 & 1,25 & $\mathbf{X}$ & - & [6] \\
\hline AT5G10450 & F4KGV2 & G-box regulating factor $6 *$ & 27,36 & 23,98 & 3,38 & 10,4 & & & [39] \\
\hline AT5G67500 & Q9FJX3 & Voltage-dependent anion channel $2 \#$ & 27,23 & 24,61 & 2,62 & 6,15 & $\mathbf{X}$ & $\bullet$ & [27] \\
\hline AT1G70410 & Q94CE4 & Beta carbonic anhydrase $4 *$ & 27,08 & 25,87 & 1,21 & 2,31 & $\mathbf{X}$ & & {$[15]$} \\
\hline AT3G15730 & Q38882 & Phospholipase D alpha $1 *$ & 26,60 & 25,83 & 0,77 & 1,71 & $\mathbf{X}$ & - & [41] \\
\hline AT5G02500 & F4KCE5 & Heat shock cognate $70 \mathrm{kDa}$ protein $1 *$ & 26,53 & 27,09 & $-0,57$ & 0,68 & $\mathbf{X}$ & $\bullet$ & [6] \\
\hline AT1G12840 & Q9SDS7 & V-type proton ATPase subunit C \# & 26,17 & 24,86 & 1,31 & 2,48 & & $\bullet$ & [1]; [18] \\
\hline AT1G15690 & P31414 & Vacuolar membrane proton pump $1 \#$ & 25,96 & 26,85 & $-0,89$ & 0,54 & $\mathbf{X}$ & & [3] \\
\hline AT1G11260 & P23586 & Sugar transport protein $1 \#$ & 25,70 & 21,16 & 4,54 & 23,3 & $\mathbf{X}$ & $\bullet$ & {$[35] ;[31]$} \\
\hline AT4G29130 & Q42525 & Hexokinase- $1 \S$ & 25,00 & 24,43 & 0,57 & 1,48 & & $\bullet$ & {$[24]$} \\
\hline AT3G18490 & Q9LS40 & Aspartic protease in guard cell $1^{*}$ & 24,98 & 23,42 & 1,57 & 2,96 & & $\bullet$ & [51] \\
\hline AT1G04110 & O64495 & Subtilisin-like protease SBT1.2 $\propto$ & 24,83 & 15,90 & 8,93 & 489 & & & [42] \\
\hline AT4G05590 & Q8L7H8 & Mitochondrial pyruvate carrier $3 *$ & 24,73 & 15,18 & 9,55 & GCE & & & {$[52] ;[35]$} \\
\hline AT5G57110 & Q9LF79 & Calcium-transporting ATPase 8 \# & 24,37 & 22,47 & 1,89 & 3,72 & $\mathbf{X}$ & & {$[50]$} \\
\hline AT4G03560 & Q94KI8 & Two pore calcium channel protein $1 \#$ & 24,31 & 20,57 & 3,74 & 13,4 & & $\bullet$ & [34] \\
\hline AT3G02880 & Q9M8T0 & Probable inactive receptor kinase $\S$ & 23,81 & 23,47 & 0,33 & 1,26 & $\bar{X}$ & & {$[18]$} \\
\hline AT5G46790 & Q8VZS8 & Abscisic acid receptor PYL1! & 23,59 & 22,21 & 1,38 & 2,60 & & $\bullet$ & {$[45]$} \\
\hline AT1G13320 & Q38951 & Protein phosphatase $2 \mathrm{~A}$ subunit $\mathrm{A} 3 \S$ & 23,57 & 20,06 & 3,51 & 11,4 & & & [26] \\
\hline AT4G23650 & Q42479 & Calcium-dependent protein kinase $3 \S$ & 23,32 & 24,62 & $-1,30$ & 0,41 & $\mathbf{X}$ & & [30] \\
\hline AT4G30190 & P19456 & ATPase 2, plasma membrane-type \# & 23,25 & 20,95 & 2,30 & 4,92 & $\mathbf{X}$ & $\bullet$ & [46] \\
\hline AT2G26040 & O80992 & Abscisic acid receptor PYL2! & 22,92 & 15,18 & 7,74 & GCE & $\mathbf{X}$ & $\bullet$ & {$[45]$} \\
\hline AT1G55020 & Q06327 & Linoleate 9S-lipoxygenase $1 *$ & 22,91 & 20,35 & 2,56 & 5,90 & & $\bullet$ & [29] \\
\hline AT1G52340 & Q9C826 & Xanthoxin dehydrogenase $*$ & 22,89 & 21,21 & 1,68 & $\mathbf{3 , 2 0}$ & & $\bullet$ & [49] \\
\hline AT2G46070 & Q8GYQ5 & Mitogen-activated protein kinase $12 \S$ & 22,81 & 17,65 & 5,16 & 35,8 & $\mathbf{X}$ & $\bullet$ & [20] \\
\hline AT5G50000 & Q9FGB1 & Protein kinase superfamily protein $\S$ & 22,80 & 21,03 & 1,76 & 3,39 & $\mathbf{X}$ & $\bullet$ & {$[14]$} \\
\hline AT4G17870 & O49686 & Abscisic acid receptor PYR1! & 22,73 & 21,86 & 0,87 & 1,83 & & $\bullet$ & [33] \\
\hline AT4G35790 & Q9C5Y0 & Phospholipase D delta * & 22,46 & 20,88 & 1,58 & 2,99 & $\mathbf{X}$ & $\bullet$ & [41] \\
\hline AT5G13630 & Q9FNB0 & Magnesium-chelatase subunit $\mathrm{ChlH} *$ & 21,77 & 24,15 & $-2,38$ & 0,19 & & & {$[40]$} \\
\hline AT2G43350 & $\mathrm{O} 22850$ & Glutathione peroxidase $3 *$ & 21,56 & 15,18 & 6,38 & GCE & & $\bullet$ & {$[28]$} \\
\hline AT2G43790 & Q39026 & Mitogen-activated protein kinase $6 \S$ & 21,29 & 19,99 & 1,30 & 2,46 & & $\bullet$ & {$[29]$} \\
\hline AT2G13540 & Q9SIU2 & Nuclear cap-binding protein subunit $1 *$ & 21,21 & 18,32 & 2,89 & 7,41 & & & [17] \\
\hline AT3G53720 & Q9M353 & Cation/H(+) antiporter 20 \# & 21,21 & 15,18 & 6,03 & GCE & $\mathbf{X}$ & $\bullet$ & [32] \\
\hline AT1G32080 & Q9FVQ4 & $\begin{array}{l}\text { Plastidal glycolate/glycerate } \\
\text { translocator\# }\end{array}$ & 21,19 & 23,68 & $-2,48$ & 0,18 & & & [7] \\
\hline AT5G40890 & P92941 & Chloride channel protein CLC-a \# & 20,92 & 19,53 & 1,40 & 2,63 & $\mathbf{X}$ & $\bullet$ & [47] \\
\hline AT5G24520 & Q9XGN1 & TRANSPARENT TESTA GLABRA 1 a & 20,81 & $\underline{18,93}$ & 1,87 & 3,66 & & $\bullet$ & [9] \\
\hline AT1G28490 & Q946Y7 & Syntaxin-61* & 20,64 & 18,52 & 2,12 & 4,35 & & $\bullet$ & [55] \\
\hline AT4G14480 & $\mathrm{O} 23304$ & Serine/threonine-protein kinase BLUS1 $\S$ & 20,56 & 15,18 & 5,38 & 41,6 & $\mathbf{X}$ & $\bullet$ & [38] \\
\hline AT5G49890 & Q96282 & Chloride channel protein CLC-c \# & 20,22 & 15,18 & 5,04 & GCE & & $\bullet$ & {$[22]$} \\
\hline AT4G04720 & Q9ZSA2 & Calcium-dependent protein kinase $21 \S$ & 20,15 & 20,73 & $-0,57$ & 0,67 & & & [10] \\
\hline AT1G23200 & O49298 & Pectinesterase/pectinesterase inhibitor $6 *$ & 19,84 & 15,18 & 4,66 & GCE & & $\bullet$ & [2] \\
\hline AT3G08550 & Q9C9Z9 & Glycosyltransferase-like KOBITO $1 *$ & 19,46 & 19,62 & $-0,15$ & 0,90 & & $\bullet$ & [25] \\
\hline AT4G08920 & Q43125 & Cryptochrome-1 $\mathrm{a}$ & 19,35 & 18,73 & 0,63 & $\mathbf{1 , 5 5}$ & & & [23] \\
\hline AT4G17615 & Q9LTB8 & Calcineurin B-like protein $1 *$ & 19,31 & 15,18 & 4,13 & GCE & & & [5] \\
\hline AT5G63870 & Q9FN02 & Serine/threonine-protein phosphatase $7 \S$ & 19,12 & 19,04 & 0,07 & 1,05 & & $\bullet$ & {$[37]$} \\
\hline
\end{tabular}




\begin{tabular}{|l|c|l|c|c|c|c|c|c|c|} 
AT1G04400 & Q96524 & Cryptochrome-2 $\propto$ & 19,01 & $\mathbf{1 5 , 1 8}$ & 3,83 & GCE & & $\bullet$ & {$[4]$} \\
\hline AT1G12110 & Q05085 & Nitrate transporter 1.1 \# & 18,76 & $\underline{17,50}$ & 1,26 & $\mathbf{2 , 3 9}$ & & $\bullet$ & {$[11]$} \\
\hline AT2G36850 & Q9SJM0 & Callose synthase 10 $\propto$ & 18,77 & 16,02 & 2,75 & $\mathbf{6 , 7 2}$ & & $\bullet$ & {$[12]$} \\
\hline AT1G49040 & Q8RXA7 & DENN-domain WD-repeat protein $\propto$ & 18,69 & 17,87 & 0,82 & $\mathbf{1 , 7 7}$ & $\mathbf{X}$ & & {$[8]$} \\
\hline AT3G45640 & Q39023 & Mitogen-activated protein kinase 3 $\S$ & 17,93 & 17,01 & 0,92 & $\mathbf{1 , 8 9}$ & & & {$[44]$} \\
\hline AT1G35670 & Q39016 & Calcium-dependent protein kinase 2 $\S$ & 17,83 & $\underline{16,81}$ & 1,03 & $\mathbf{2 , 0 4}$ & & & {$[16]$} \\
\hline AT1G62400 & Q2MHE4 & Serine/threonine-protein kinase HT1 $\S$ & 17,44 & $\mathbf{1 5 , 1 8}$ & 2,26 & $\mathbf{G C E}$ & & $\bullet$ & {$[13]$} \\
\hline AT2G18790 & P42497 & Phytochrome $\propto$ & 17,43 & 19,21 & $-1,78$ & 0,29 & & $\bullet$ & {$[23]$} \\
\hline
\end{tabular}

976

977

978

979

980

981

982

983

984

985

986

987

988

989

990

991

992

993

994

995

996

997

998

999

1000

1001

1002

1003

1004

1005

1006

1007

1008
Table 1. List of proteins present in the guard cell-enriched fraction and playing a role in stomatal functioning and development.

Proteins are ranked from the most abundant to the less in the GCE fraction. Bold lines separate quartiles. In GCE and L columns are reported $\log _{2}$ of imputed normiBAQ that reflect relative abundance of each protein in guard cell-enriched and leaf fractions, respectively. $\mathrm{R}$ represents protein abundance ratio in the GC-enriched fraction epidermis relative to leaf fraction and is equal to $2^{(\mathrm{E}-\mathrm{L})}$. Bold $\mathrm{R}$ value, protein having a value $>1.5$ and thus more abundant in the GCE fraction than in the L fraction. GCE, protein found only in the guard cell-enriched fraction Underlined L value, only 1 peptide detected; bold L value, no peptide detected. $\mathbf{X}$, Protein identified in Arabidopsis guard cell proteomics by Zhao et al., (2008; 2010). •, Transcript ratio, GC protoplast level/mesophyll protoplast level, higher than 2 (Yang et al., 2008). Classification of proteins: $\S$, kinases and phosphatases involved in stomatal movements; \#, Ion channels, transporters and pumps involved in stomatal movements;!, ABA receptors;, , Proteins involved in regulation of stomatal development and patterning; *, Enzymes and other protein functions. References are listed in Table S6. 


\begin{tabular}{|c|c|c|c|c|c|c|c|c|}
\hline $\begin{array}{c}\text { AGI } \\
\text { Number }\end{array}$ & $\begin{array}{l}\text { Protein } \\
\text { ID }\end{array}$ & Description & Name & GCE & $\mathbf{L}$ & $\begin{array}{l}\text { GCE- } \\
\mathbf{L}\end{array}$ & $\mathbf{R}$ & $\begin{array}{c}\text { GC } \\
\text { proteomics }\end{array}$ \\
\hline AT3G26060 & Q9LU86 & Peroxiredoxin Q & PRXQ & 28,20 & 29,82 & $-1,62$ & 0,33 & \\
\hline AT3G11630 & Q96291 & 2-Cys peroxiredoxin A & 2-CysPrxA & 27,71 & 27,09 & 0,63 & 1,55 & $\mathbf{X}$ \\
\hline AT1G65980 & Q9XEX2 & Peroxiredoxin IIB & Prx IIB & 26,14 & 23,27 & 2,87 & 7,29 & \\
\hline AT3G06050 & Q9M7T0 & Peroxiredoxin IIF & Prx IIF & 25,99 & 25,28 & 0,71 & 1,64 & $\mathbf{X}$ \\
\hline AT2G17420 & Q39242 & NADPH-thioredoxin reductase A & NTRA & 25,94 & 24,01 & 1,92 & 3,79 & \\
\hline AT3G52960 & Q949U7 & Peroxiredoxin IIE & Prx IIE & 25,61 & 27,37 & $-1,76$ & 0,30 & $\mathbf{X}$ \\
\hline AT5G42980 & Q42403 & Thioredoxin h3 & TRX h3 & 25,00 & 22,90 & 2,10 & 4,29 & $\mathbf{X}$ \\
\hline AT4G11600 & $\mathrm{O} 48646$ & Glutathione peroxidase 6 & GPX6 & 24,44 & 23,79 & 0,65 & 1,56 & $\mathbf{X}$ \\
\hline AT5G06290 & Q9C5R8 & 2-Cys peroxiredoxin $\mathrm{B}$ & 2-CysPrxB & 24,19 & 25,08 & $-0,88$ & 0,54 & $\mathbf{X}$ \\
\hline AT5G07460 & Q9LY15 & Peptide methionine sulfoxide reductase A2 & MSRA2 & 24,17 & 22,55 & 1,62 & 3,08 & $\mathbf{X}$ \\
\hline AT1G60420 & O80763 & Nucleoredoxin 1 & NRX1 & 23,95 & 21,82 & 2,13 & 4,38 & \\
\hline AT4G35460 & Q39243 & NADPH-thioredoxin reductase B & NTRB & 23,93 & 20,25 & 3,69 & 12,9 & \\
\hline AT4G25130 & P54150 & Peptide methionine sulfoxide reductase A4 & MSRA4 & 23,87 & 26,50 & $-2,63$ & 0,16 & $\mathbf{X}$ \\
\hline AT2G25080 & P52032 & Glutathione peroxidase 1 & GPX1 & 23,20 & 23,81 & $-0,61$ & 0,65 & \\
\hline AT2G31570 & O04922 & Glutathione peroxidase 2 & GPX2 & 22,76 & 20,98 & 1,78 & 3,43 & $\mathbf{X}$ \\
\hline AT3G06730 & Q9M7X9 & Thioredoxin $\mathrm{z}$ & TRX z & 22,71 & 15,18 & 7,53 & GCE & \\
\hline AT5G39950 & Q38879 & Thioredoxin h2 & TRX h2 & 22,43 & 19,63 & 2,80 & 6,96 & \\
\hline AT4G03520 & Q9SEU8 & Thioredoxin $\mathrm{m} 2$ & TRX m2 & 22,17 & 26,87 & $-4,70$ & 0,04 & $\mathbf{X}$ \\
\hline AT2G38270 & Q8H7F6 & Glutaredoxin S16 & GRXS16 & 22,14 & 24,32 & $-2,18$ & 0,22 & $\mathbf{X}$ \\
\hline AT2G41680 & $\mathrm{O} 22229$ & NADPH-thioredoxin reductase C & NTRC & 22,09 & 26,15 & $-4,06$ & 0,06 & \\
\hline AT3G02730 & Q9XFH8 & Thioredoxin $\mathrm{fl}$ & TRX f1 & 21,96 & 25,88 & $-3,93$ & 0,07 & \\
\hline AT3G08710 & Q9C9Y6 & Thioredoxin h9 & TRX h9 & 21,81 & 15,18 & 6,63 & GCE & \\
\hline AT3G15660 & Q8LBK6 & Glutaredoxin S15, & GRXS15 & 21,80 & 15,18 & 6,62 & GCE & \\
\hline AT4G04950 & Q9ZPH2 & Glutaredoxin S17 & GRXS17 & 21,72 & 20,97 & 0,75 & 1,68 & \\
\hline AT3G15360 & Q9SEU6 & Thioredoxin m4 & TRX m4 & 21,72 & 26,37 & $-4,66$ & 0,04 & $\mathbf{X}$ \\
\hline AT1G03680 & $\mathrm{O} 48737$ & Thioredoxin $\mathrm{m} 1$ & TRX m1 & 21,65 & 25,86 & $-4,21$ & 0,05 & \\
\hline AT3G63080 & Q9LYB4 & Glutathione peroxidase 5 & AtGPX5 & 21,59 & 22,49 & $-0,89$ & 0,54 & \\
\hline AT2G43350 & $\mathrm{O} 22850$ & Glutathione peroxidase 3 & AtGPX3 & 21,56 & 15,18 & 6,38 & 355 & \\
\hline AT1G76080 & Q9SGS4 & Chloroplastic Drought Stress 32-kDa Protein & $\begin{array}{c}\text { TRX } \\
\text { CDSP32 }\end{array}$ & 21,41 & 25,66 & $-4,25$ & 0,05 & \\
\hline AT4G29670 & Q8LCT3 & Atypical cysteine/histidine-rich thioredoxin 2 & ACHT2 & 21,39 & 23,63 & $-2,24$ & 0,21 & \\
\hline AT4G28730 & Q8GWS0 & Glutaredoxin C5 & GRXC5 & 21,26 & 23,56 & $-2,30$ & 0,20 & \\
\hline AT2G35010 & O64764 & Thioredoxin o1 & TRX o1 & 20,99 & 20,43 & 0,55 & 1,47 & $\mathbf{X}$ \\
\hline AT1G11530 & Q8LDI5 & Thioredoxin-like, Mono-cysteine 1 & TRX CxxS1 & 20,89 & 18,83 & 2,06 & 4,21 & \\
\hline AT4G21860 & Q9C5C8 & Methionine sulfoxide reductase B2 & MSRB2 & 20,78 & 24,26 & $-3,48$ & 0,09 & \\
\hline AT3G17880 & Q8VWG7 & Tetratricoredoxin & TDX & 20,61 & 15,18 & 5,43 & GCE & \\
\hline AT5G08410 & Q8LBP6 & Ferredoxin/thioredoxin reductase subunit A2 & FTRA2 & 20,27 & 21,52 & $-1,25$ & 0,42 & \\
\hline AT1G07700 & Q9C5C5 & Thioredoxin-like, Lilium-type thioredoxin 6 & Lilium6 & 20,08 & 15,18 & 4,90 & GCE & \\
\hline AT2G18030 & Q9SL43 & Methionine sulfoxide reductase A5 & MSRA5 & 20,07 & 20,31 & $-0,24$ & 0,84 & \\
\hline AT4G37200 & $\mathrm{O} 23166$ & $\begin{array}{l}\text { Thioredoxin High Chlorophyll } \\
\text { Fluorescence } 164\end{array}$ & $\begin{array}{c}\text { TRX } \\
\text { HCF164 }\end{array}$ & 19,72 & 23,43 & $-3,71$ & 0,08 & \\
\hline
\end{tabular}


Table 2. List of thiol reductases identified in the guard cell-enriched fraction

Proteins are ranked from the most abundant to the less in the GCE fraction. Bold lines separate quartiles. In GCE and L columns are reported $\log _{2}$ of imputed normiBAQ that reflect relative abundance of each protein in guard cell-enriched and leaf fractions, respectively. $\mathrm{R}$ represents protein abundance ratio in the GC-enriched fraction epidermis relative to leaf fraction and is equal to $2^{\text {(E-L) }}$. Bold $\mathrm{R}$ value, protein having a value $>1.5$ and thus more abundant in the GCE fraction than in the L fraction. GCE, protein found only in the guard cell enriched-fraction. Bold L value, no peptide detected. X, Protein identified in Arabidopsis guard cell proteomics by Zhao et al., (2008; 2010). 
Figure 1. Western blot analysis of the abundance of thiol reductases in extracts from a guard cellenriched fraction

A. Coomassie Blue-stained gel of SDS-PAGE separated proteins from leaf blades (L) and GCE fractions. The arrows indicate proteins noticeably more abundant in the GCE fraction. LSU and SSU, large and small RubisCO subunits, respectively. B. Western blot analysis of RubisCO subunits and of various types of thiol reductases in L and GCE fractions. Blots (20 to $30 \mu \mathrm{g}$ proteins per lane, depending on the serum used, for both fractions) were probed using antibodies raised against RubisCO $(1: 10,000)$, TRX h3 (1:20,000), 2-CysPRX (1:10,000) 2-CysPRX-Ox, hyperoxidized 2-CysPRX (1:4000), PRXQ (1:1000), PRX-IIE $(1: 10,000)$ PRXII-B $(1: 20,000)$ and GRXS14 (1:800). For the latter, the asterisk points to a non-specific band and the two arrows indicate two GRX redox forms.

Figure 2. Functional categorization (GO Cellular Component) of proteins identified in guard cellenriched and leaf fractions.

Functional categorization was performed using of the GO annotation retrieval tool available on the site TAIR: https://www.arabidopsis.org/tools/bulk/go/index.jsp. Analysis was performed on genes encoding the $25 \%$ most abundant proteins of each sample (in GCE fraction, 1102 proteins having a Log2(iBAQ) $\geq 24.06$ and in leaf fraction 913 proteins with $\log 2(\mathrm{BAQ}) \geq 23.97)$.

\section{Figure 3. Stomatal phenotype of the Arabidopsis ntra ntrb mutant}

A. Stomatal density. B. Stomatal index. Data for A and B are means \pm SD of 12 independent values using peeled epidermis from three leaves per genotype. Plants were grown for 4 weeks in control conditions: moderate light $\left(200 \mu \mathrm{mol}\right.$ photons. $\left.\mathrm{m}^{-2} \cdot \mathrm{s}^{-1}\right)$ and short photoperiod $(8 \mathrm{~h})$ at $22^{\circ} \mathrm{C}$. C. Stomatal conductance measurements using porometry. Measurements of the water efflux from leaf abaxial side were performed on plants grown for 6 weeks in control conditions. Conductance values are means $\pm \mathrm{SD}$ of twelve average values per genotype originating from independent plants ( 8 measurements per plant for each genotype per experiment). ${ }^{* * *}$, significantly different from the WT value with $\mathrm{P}<0.001$ ( $t$ test). D. and E. Infrared thermal imaging. Plants were dark-adapted. False colored infrared images of 6week-old plants grown in control conditions. The color scale on the right shows increasing temperature from purple to yellow. Pictures were taken at the end of the night period two hours before the light period. As a control, the ost2-2D mutant was used and shown to exhibit lower leaf temperature due to 
Figure 4. Stomatal phenotype of Arabidopsis mutants deficient in plastidial PRXs

A. Stomatal density. B. Stomatal index. Data for A and B are means \pm SD of 12 independent values using peeled epidermis from three leaves per genotype. Plants were grown for 4 weeks in control conditions: moderate light $\left(200 \mu \mathrm{mol}\right.$ photons. $\left.\mathrm{m}^{-2} \cdot \mathrm{s}^{-1}\right)$ and short photoperiod $(8 \mathrm{~h})$ at $22^{\circ} \mathrm{C}$. C. Stomatal conductance measurements using porometry. Measurements of the water efflux from leaf abaxial side were performed on plants grown for 6 weeks in control conditions. Conductance values are means $\pm \mathrm{SD}$ of eight average values per genotype originating from independent plants ( 8 measurements per plant for each genotype per experiment). ${ }^{* *}$, significantly different from the WT value with $\mathrm{P}<0.01$ ( $t$-test). $\mathbf{D}$. and E. Infrared thermal imaging. Plants were dark-adapted. False colored infrared images of 6-weekold plants grown in control conditions. The color scale on the right shows increasing temperature from purple to yellow. Pictures were taken at the end of the night period two hours before the light period. 2cprx, double 2cysprxa 2cysprxb mutant plants; prxq, knockout PRXQ plants.

Figure 5. Stomatal phenotype of Arabidopsis lines modified for plastidial type-II GRXs. A. Stomatal density. B. Stomatal index. Data for $\mathbf{A}$ and $\mathbf{B}$ are means \pm SD of 12 independent values using peeled epidermis from three leaves per genotype. Plants were grown for 4 weeks in control conditions: moderate light $\left(200 \mu \mathrm{mol}\right.$ photons. $\left.\mathrm{m}^{-2} \cdot \mathrm{s}^{-1}\right)$ and short photoperiod $(8 \mathrm{~h})$ at $22^{\circ} \mathrm{C}$. C. Stomatal conductance measurements using porometry. Measurements of the water efflux from leaf abaxial side were performed on plants grown for 6 weeks in control conditions. Conductance values are means \pm SD of at least 17 average values per genotype originating from independent plants ( 8 measurements per plant for each genotype per experiment). ${ }^{* * *}$, significantly different from the WT value with $\mathrm{P}<0.001$ ( $t$-test). D. and E. Infrared thermal imaging. Plants were dark-adapted. False colored infrared images of 6-weekold plants grown in control conditions. Pictures were taken at the end of the night period two hours before the light period. The color scale on the right shows increasing temperature from purple to yellow. As a control, the ost2-2D mutant was used and shown to exhibit lower leaf temperature due to open stomata in the dark (Merlot et al., 2007). KI1 and KI2, independent grxS14 GRXS16-RNAi lines; OE1 and OE2, independent GRXS14-overexpressing lines.

Figure 6. Effect of $\mathrm{ABA}$ and $\mathrm{H}_{2} \mathrm{O}_{2}$ on stomatal aperture in Arabidopsis mutants deficient in cytosolic NTRs, plastidial 2Cys-PRXs or plastidial type-II GRXs.

Stomatal aperture measurements in response to ABA concentrations of $0.5,1,10$ and $100 \mu \mathrm{M}$ (A-B) or to $\mathrm{H}_{2} \mathrm{O}_{2}$ concentrations of 10,100 and $1000 \mu \mathrm{M}$ (C-D) in light-treated epidermis. Data in panels $\mathbf{B}$ and $\mathbf{D}$ were calculated from the original raw data reported in panels $\mathbf{A}$ and $\mathbf{C}$, respectively, and represent the inhibitions of stomatal aperture due to the treatments expressed in percents of that measured in light alone. Data represent means \pm SD of 2 independent experiments with 60 measurements per genotype and treatment. Means were compared with 
1110 the ANOVA test, and letters represent groups of means not statistically different $(\mathrm{P}<0.05)$. 1111 2cprx, double 2cysprxa 2cysprxb mutant plants; KI1 and KI2, independent grxS14 GRXS161112 RNAi lines; ntra ntrb, double ntra ntrb mutant plants.

Figure 7. Model for positioning putative roles of plastidial 2-CysPRXs and type-II GRXs in the signaling network governing stomatal closure. Based on the results gained on epidermal peels showing modified responses of mutants to $\mathrm{ABA}$ and $\mathrm{H}_{2} \mathrm{O}_{2}$ and the known biochemical functions of these enzymes, we propose that they participate in $\mathrm{H}_{2} \mathrm{O}_{2}$-related transduction pathways. 2-CysPRXs might scavenge $\mathrm{H}_{2} \mathrm{O}_{2}$ within plastid or promote oxidation of partners that remain to be identified and are involved, when oxidized, in a pathway mitigating stomatal closure. Type II-GRXs might prevent oxidation of partners, the oxidized form of which could trigger closure. The roles of cytosolic NTRs and other TRs in guard cells remain to be determined.

\section{Supporting information}

Table S1. Leaf characteristics of 6 week-old plants and guard cell characteristics for evaluating the enrichment in guard cells in the broken and washed epidermal fraction.

Table S2: Proteins identified and quantified in guard cell-enriched and leaf fractions by mass spectrometry-based proteomics.

Table S3. List of cell wall and extracellular proteins identified in the guard cell-enriched fraction.

Table S4. List of proteins having transcript preferentially expressed in guard cell protoplasts (Leonhard et al., 2004) identified in the guard cell-enriched fraction.

Table S5. List of 14-3-3 proteins identified in the guard cell-enriched fraction.

Table S6. List of references cited in Table 1.

Figure S1: Transcriptomic analysis of $T R$ expression in guard and mesophyll cell protoplasts. Data were retrieved from the microarray analyses described by Yang et al., (2008). RNA was isolated from protoplasts prepared from guard or mesophyll cells and hybridized to the ATH1 GeneChip. Two independent hybridization experiments per cell type were performed. Means and SD of expression levels 
were retrieved using the Arabidopsis eFP Browser at bar-utoronto.ca (Winter et al., 2007). A, NADPHThioredoxin reductase A (NTRA) and thioredoxins h2, h3, h4, h5, h9, TDX, o1, o2, Clot, m3, Lillium1 and CDSP32; B, Glutaredoxins S15 and ROXY10, peroxiredoxin II-B (II-B), glutathione peroxidase 2 (GPX2), and methionine sulfoxide reductases A1 and A4.

Figure S2. Gene expression in guard cells. $T R X h 2(\mathbf{A}), T R X h 3(\mathbf{B}), N T R B(\mathbf{C})$ and $P R X-I I B(\mathbf{D})$ gene promoters were fused to $\beta$-glucuronidase $(G U S)$ as a reporter gene and gene expression was monitored in 15 day-old plants by histochemical analysis. Inset: focus on one single stomata.

Figure S3. Characterization of mutants deficient in the expression of $P R X Q$ and $T R X h 3$ genes. A. Genotyping of SAIL_742_G10 plants (prxq) using primers corresponding to 5' and 3' ends of $P R X Q$ coding sequence. B. Genotyping of SAIL_314_G04 (trxh3-1) using primers corresponding to 5' and 3' ends of TRXh3 coding sequence. WT: wild type. C. Western blot analysis of PRXQ abundance in WT and prxq plants. D. Western blot analysis of TRX h3 abundance in WT, trxh3-1 (homozygous SAIL_742_G10) and trxh3-2 (homozygous SALK_111160) plants.

Figure S4. Growth of plants modified for the expression of various $T R$ genes. Plants were grown for 5 or 6 weeks in control conditions: moderate light $\left(200 \mu \mathrm{mol}\right.$ photons. $\left.\mathrm{m}^{-2} \cdot \mathrm{s}^{-1}\right)$ and short photoperiod $(8 \mathrm{~h})$ at $22^{\circ} \mathrm{C}$. Rosette weight values are means $\pm \mathrm{SD}$ of four to six average values originating from independent experiments (at least 6 plants for each genotype per experiment). * and $* * *$, significantly different from the WT value with $\mathrm{P}<0.05$ and $\mathrm{P}<0.001$, respectively ( $t$-test). 2 cprx, double 2cysprxa 2cysprxb mutant plants (A); ntra ntrb, double ntra ntrb mutant plants (B); prxq (A), grxs17 (C), trxh31, trxh3-2 (D) and trxo1-1, trxo1-2 (E) mutants lacking PRXQ, GRXS17, TRXh3 and TRXo1, respectively.

\section{Figure S5. Photograph of wild type (WT) plants and of plants modified for the expression of} various $\boldsymbol{T R}$ genes. Plants were grown for 5 weeks in control conditions: moderate light $(200 \mu \mathrm{mol}$ photons. $\left.\mathrm{m}^{-2} \cdot \mathrm{s}^{-1}\right)$ and short photoperiod $(8 \mathrm{~h})$ at $22^{\circ} \mathrm{C} .2$ cprx , double 2 cysprxa 2 cysprxb mutant plant; ntra ntrb, double ntra ntrb mutant plant; KI1 and KI2, independent grxS14 GRXS16-RNAi lines.

\section{Figure S6. Leaf chlorophyll content of plants modified for the expression of various $T R$ genes.}

Plants grown for 6 weeks in control conditions: moderate light $\left(200 \mu \mathrm{mol}\right.$ photons. $\left.\mathrm{m}^{-2} . \mathrm{s}^{-1}\right)$ and short photoperiod $(8 \mathrm{~h})$ at $22^{\circ} \mathrm{C}$. Data are means $\pm \mathrm{SD}$ of at least 5 values originating from adult leaves from independent plants. ${ }^{* * *}$, significantly different from the WT value with $\mathrm{P}<0.001$, (t-test). 2 cprx , double 2cysprxa 2cysprxb mutant plants; ntra ntrb, double ntra ntrb mutant plants; prxq, grxs 17, trxh3 and trxo1, mutants lacking PRXQ, GRXS17, TRXh3 and TRXo1, respectively. 
1181 Figure S7. Stomatal density (A and C) and stomatal index (B and D) of Arabidopsis lines affected

1182 in the expression of genes coding for various types of thiol reductases. Data are means \pm SD of 12

1183 independent values using peeled epidermis from three leaves per genotype. Plants were grown for 4

1184 weeks in control conditions: moderate light $\left(200 \mu \mathrm{mol}\right.$ photons. $\left.\mathrm{m}^{-2} \cdot \mathrm{s}^{-1}\right)$ and short photoperiod $(8 \mathrm{~h})$ at

$118522^{\circ} \mathrm{C}$. grxs 17, trxh3, trxol and grxs 14, mutants lacking GRXS17, TRXh3, TRXo1 and GRXS14, 1186 respectively; C-GRXS16 C2 and C4, two independent GRXS16-cosuppressed lines; OE-GRXS16 O4 1187 and $\mathrm{O} 5$, two independent GRXS16-overexpressing lines.

Figure S8. Stomatal conductance of Arabidopsis lines affected in the expression of genes coding for various types of thiol reductases. Measurements of the water efflux from leaf abaxial side were performed using porometry on plants grown for 6 weeks in control conditions. Conductance values are means \pm SD of six average values originating from independent plants $(8$ measurements per plant for each genotype per experiment); $\operatorname{trxh3}$ (A-B), trxo1 (C) and grxs17 (D), mutants lacking TRXh3, TRXo1 and GRXS17, respectively; grxs14 and OE-GRXS14 OE1 (E), lines lacking GRXS14 expression and overexpressing GRXS14, respectively; C-GRXS16 C2 and C4 (F), two independent GRXS16cosuppressed lines; OE-GRXS16 O4 and O5 (G), two independent GRXS16-overexpressing lines. 
Summary statement: The contribution of thiol reductases to the signaling network governing stomatal functioning remains poorly known. Using proteomics, we show that numerous thiol reductases are abundant in a guard cell-enriched fraction, and we unveil a stomatal phenotype in Arabidopsis mutants for thiol reductases. 


\section{Figure 1}

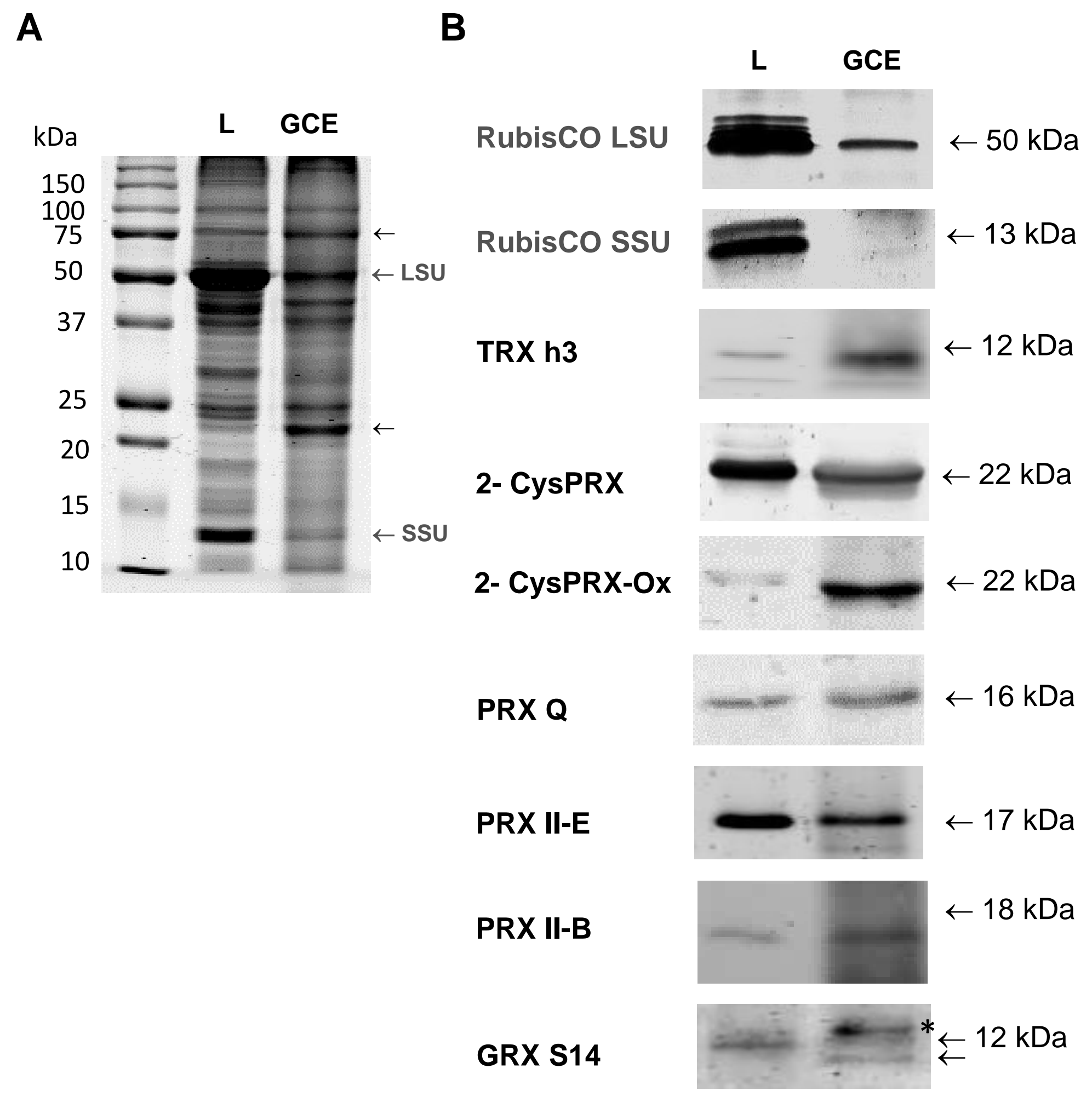

Figure 1 Western blot analysis of the abundance of thiol reductases in extracts from a guard cell-enriched fraction A. Coomassie Blue-stained gel of SDS-PAGE separated proteins from leaf blades (L) and GCE fractions. The arrows indicate proteins more abundant in the GCE fraction. LSU and SSU, large and small RubisCO subunits, respectively. B. Western blot analysis of RubisCO subunits and of various types of thiol reductases in L and GCE fractions. Blots (20 to $30 \mu \mathrm{g}$ proteins per lane, depending on the serum used, for both fractions) were probed using antibodies raised against RubisCO (1:10,000), TRX h3 (1:20,000), 2-CysPRX (1:10,000) 2-CysPRX-Ox, hyperoxidized 2-CysPRX (1:4000), PRXQ (1:1000), PRX-IIE (1:10,000) PRXII-B $(1: 20,000)$ and GRXS14 (1:800). For the latter, the asterisk points to a non-specific band and the two arrows indicate two GRX redox forms. 


\section{Figure 2}

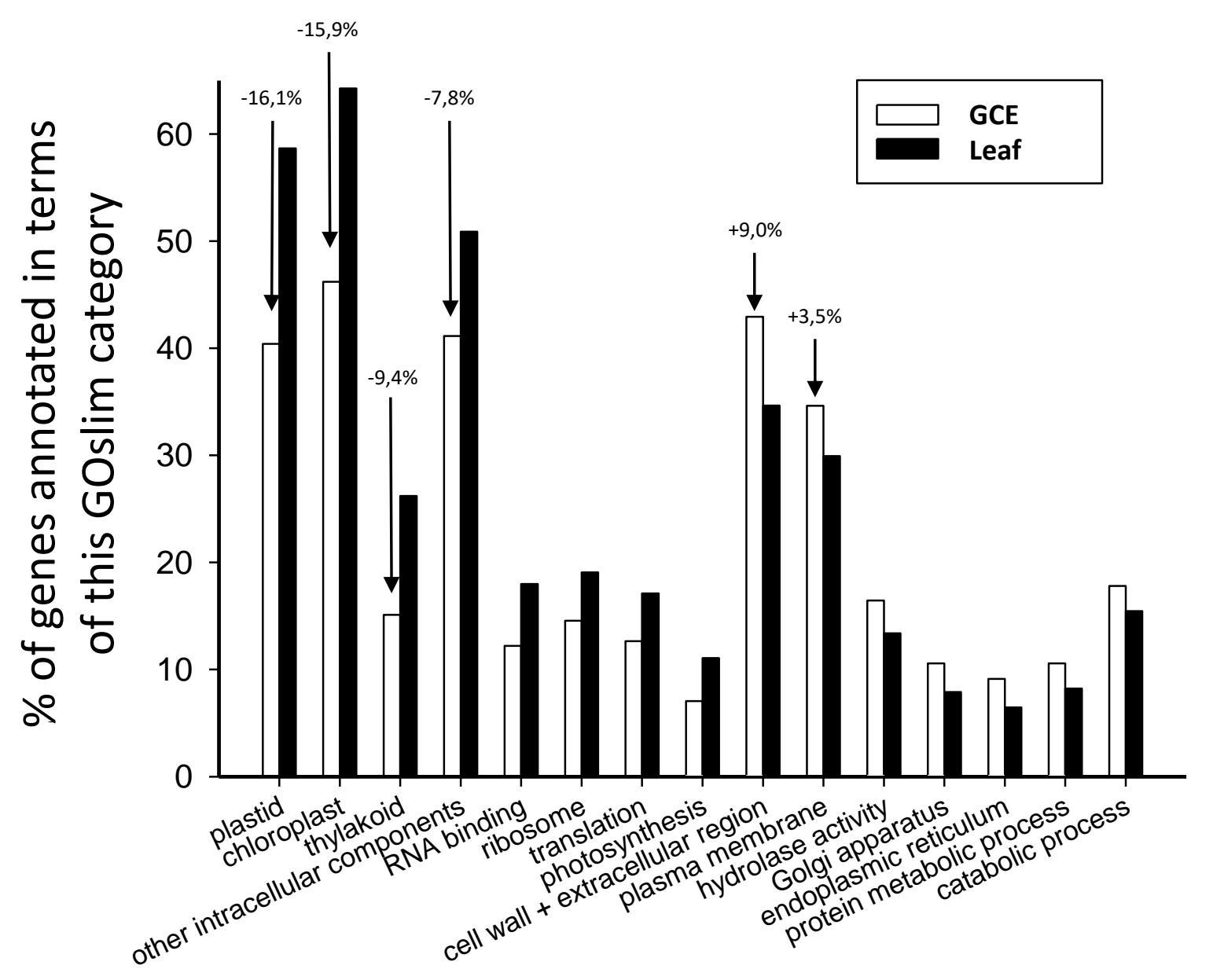

Functional Categorization (GO Cellular Component)

Figure 2: Functional categorization was performed by making use of the GO annotation retrieval tool available on the site TAIR: https://www.arabidopsis.org/tools/bulk/go/index.jsp. Analysis was retrieved on genes encoding the $25 \%$ most abundant proteins of each sample (in broken epidermis, 1174 proteins having a $\log _{2}$ of imputed normiBAQ $\geq 23,93$ and in leaf, 1063 proteins $\geq 23.66$ ) 


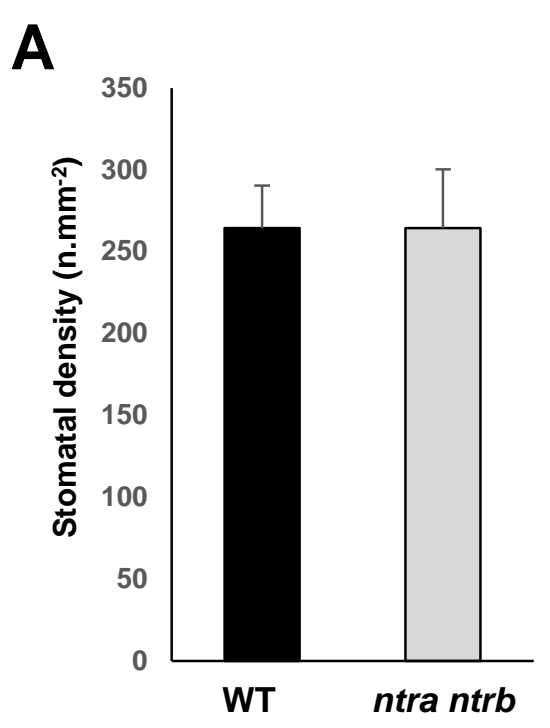

D

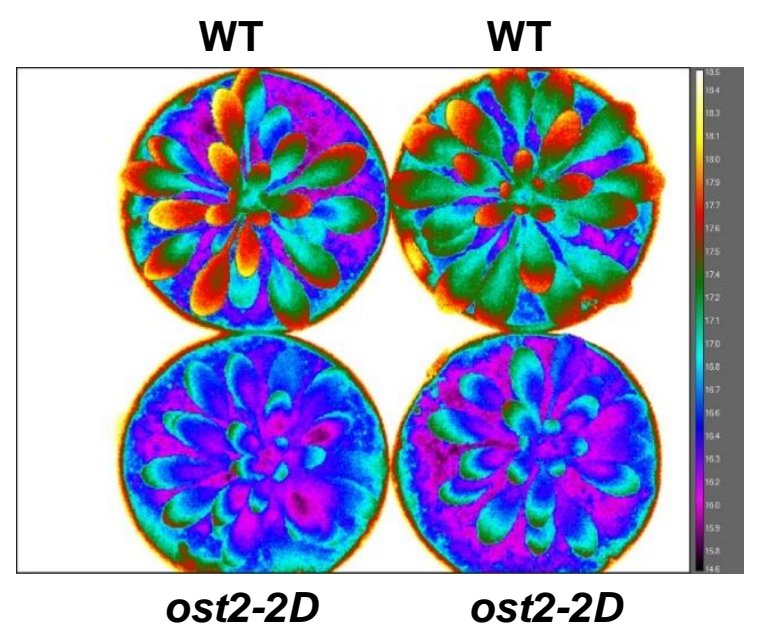

B

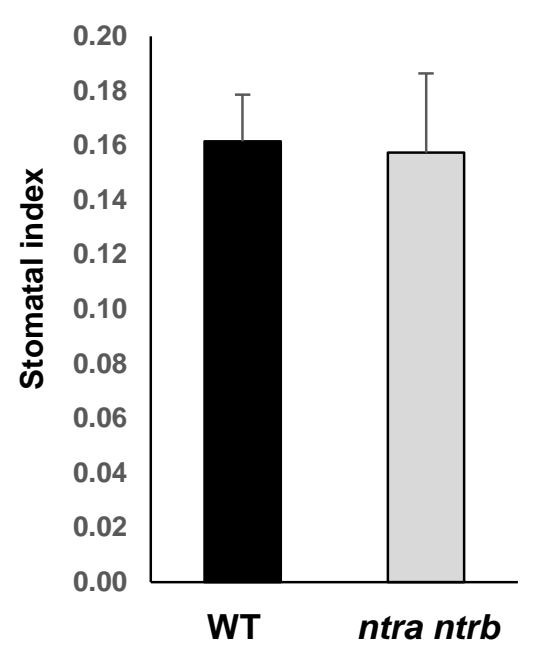

C

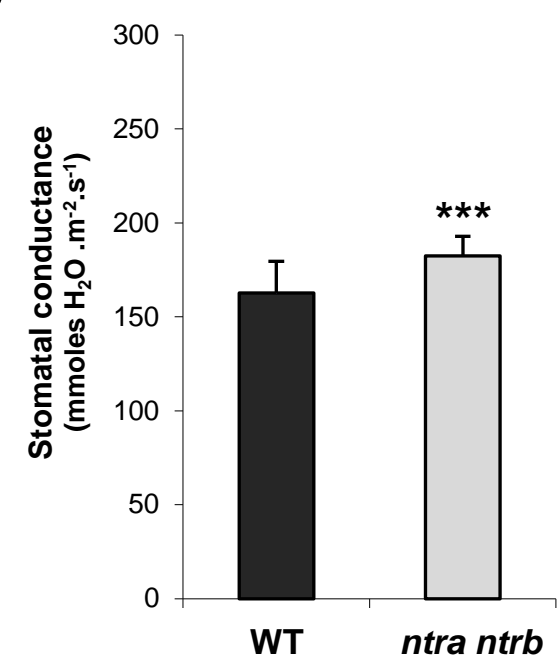

\section{$\mathbf{E}$}

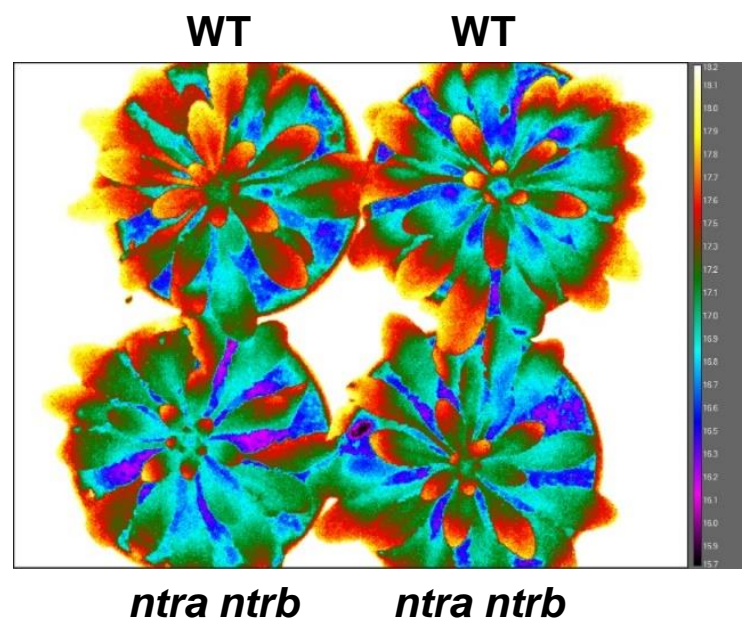

Figure 3. Stomatal phenotype of the Arabidopsis ntra ntrb mutant

A. Stomatal density. B. Stomatal index. Data for $\mathbf{A}$ and $\mathbf{B}$ are means \pm SD of 12 independent values using peeled epidermis from three leaves per genotype. Plants were grown for 4 weeks in control conditions: moderate light (200 $\mu \mathrm{mol}$ photons. $\left.\mathrm{m}^{-2} \cdot \mathrm{s}^{-1}\right)$ and short photoperiod $(8 \mathrm{~h})$ at $22^{\circ} \mathrm{C}$. C. Stomatal conductance measurements using porometry. Measurements of the water efflux from leaf abaxial side were performed on plants grown for 6 weeks in control conditions. Conductance values are means $\pm \mathrm{SD}$ of twelve average values per genotype originating from independent plants (8 measurements per plant for each genotype per experiment). ***, significantly different from the WT value with P $<0.001$ ( $t$-test). D. and E. Infrared thermal imaging. Plants were dark-adapted. False colored infrared images of 6week-old plants grown in control conditions. The color scale on the right shows increasing temperature from purple to yellow. Pictures were taken at the end of the night period two hours before the light period. As a control, the ost2-2D mutant was used and shown to exhibit lower leaf temperature due to open stomata in the dark (Merlot et al., 2007). ntra ntrb, double ntra ntrb mutant plants. 


\section{Figure 4}

A

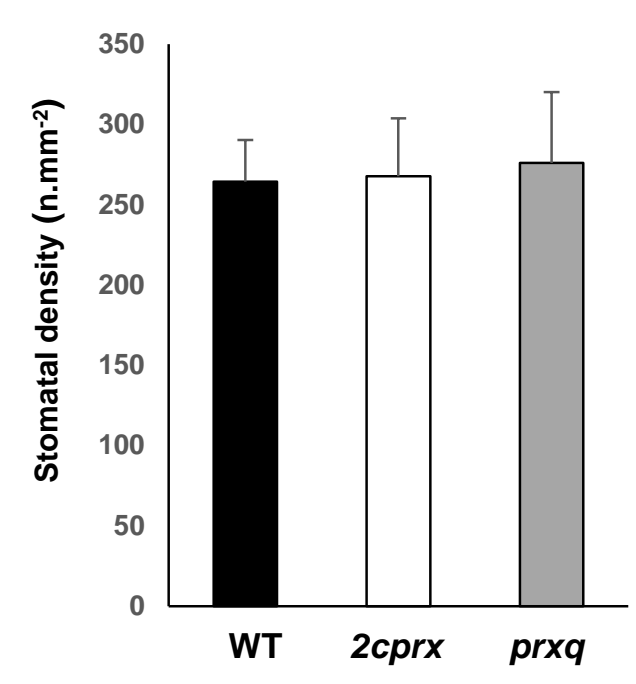

B

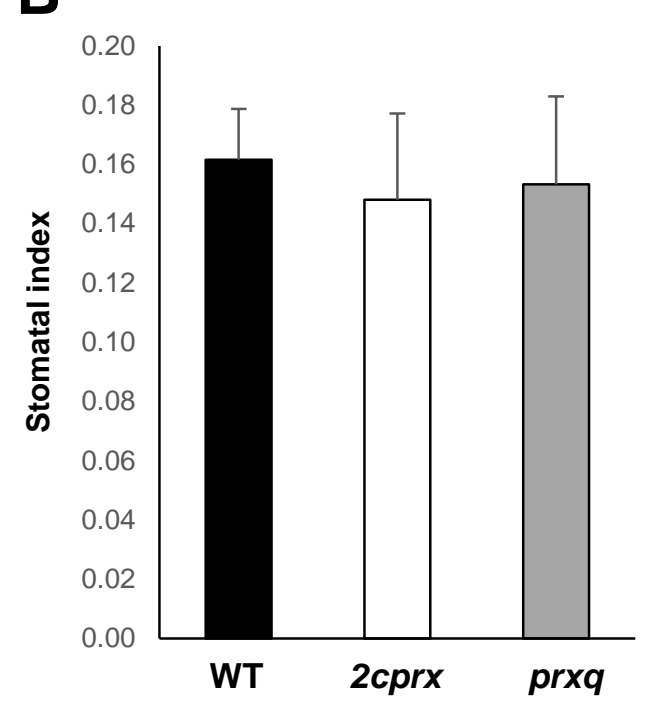

C

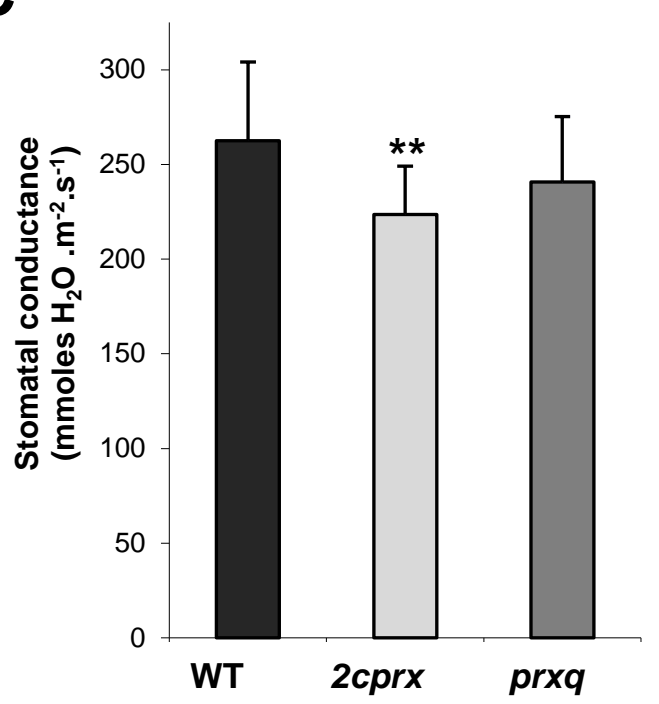

E
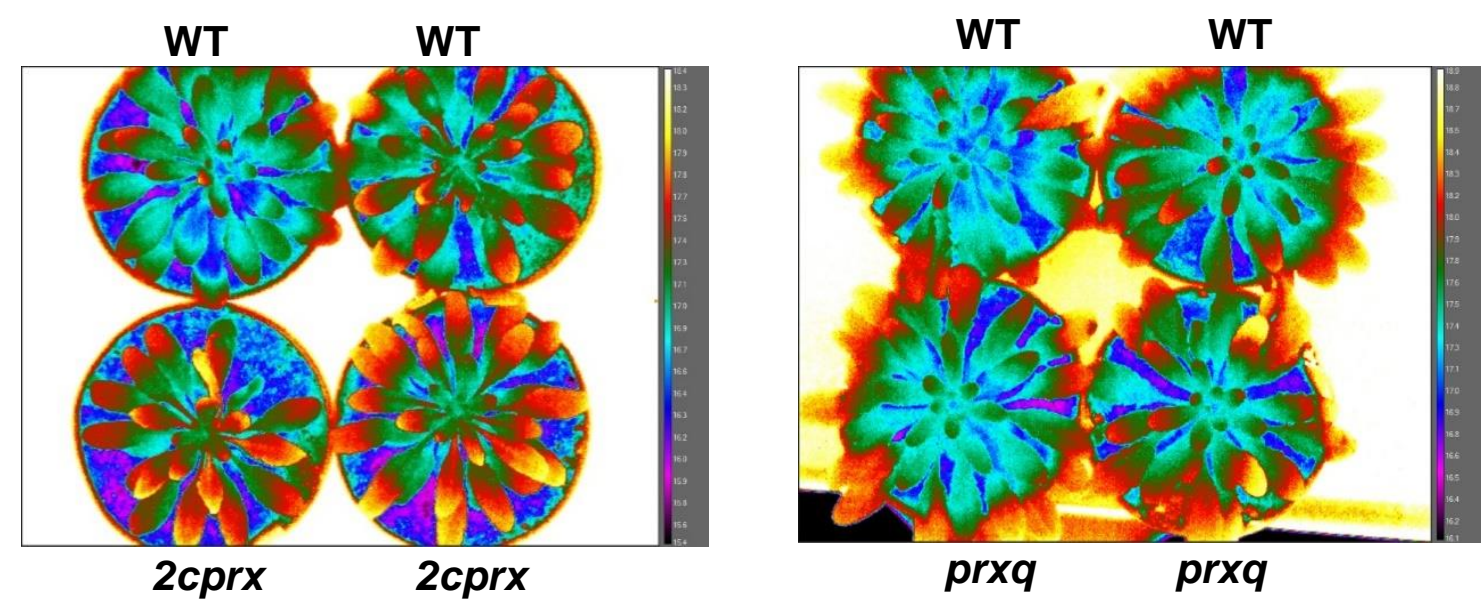

Figure 4. Stomatal phenotype of Arabidopsis mutants deficient in plastidial PRXs

A. Stomatal density. B. Stomatal index. Data for A and $\mathbf{B}$ are means \pm SD of 12 independent values using peeled epidermis from three leaves per genotype. Plants were grown for 4 weeks in control conditions: moderate light (200 $\mu$ mol photons. $\left.\mathrm{m}^{-2} \cdot \mathrm{s}^{-1}\right)$ and short photoperiod $(8 \mathrm{~h})$ at $22^{\circ} \mathrm{C}$. C. Stomatal conductance measurements using porometry. Measurements of the water efflux from leaf abaxial side were performed on plants grown for 6 weeks in control conditions. Conductance values are means \pm SD of eight average values per genotype originating from independent plants (8 measurements per plant for each genotype per experiment). **, significantly different from the WT value with $\mathrm{P}<0.01$ ( $t$-test). D. and E. Infrared thermal imaging. Plants were dark-adapted. False colored infrared images of 6-weekold plants grown in control conditions. The color scale on the right shows increasing temperature from purple to yellow. Pictures were taken at the end of the night period two hours before the light period. 2cprx, double 2 cysprxa 2 cysprxb mutant plants; prxq, knockout $P R X Q$ plants. 


\section{Figure 5}

A

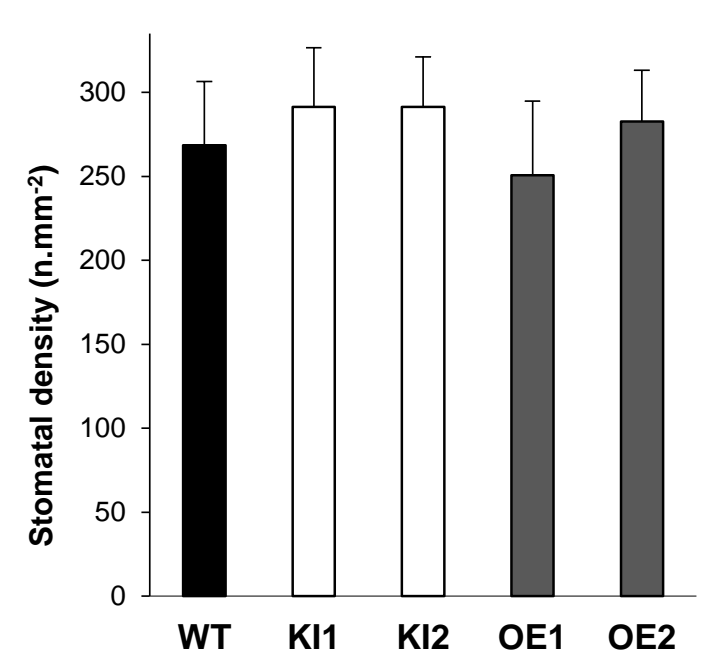

B

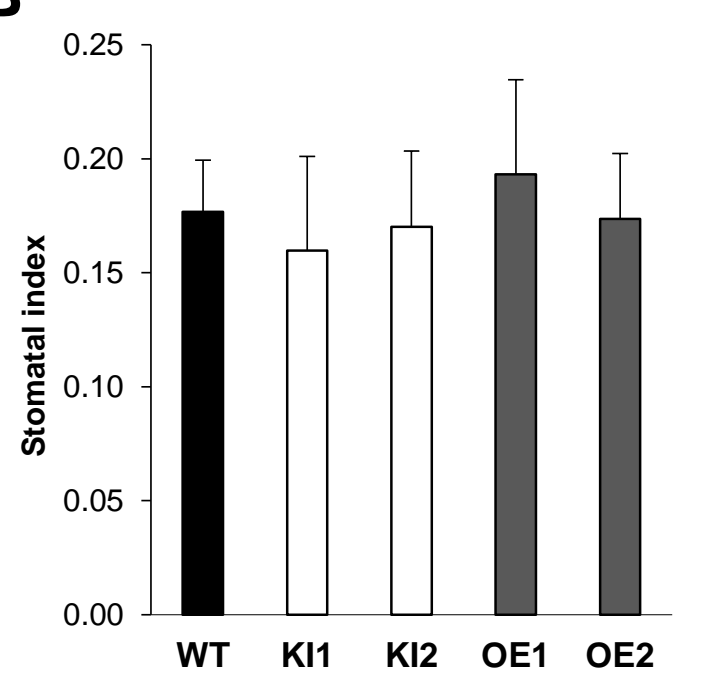

C

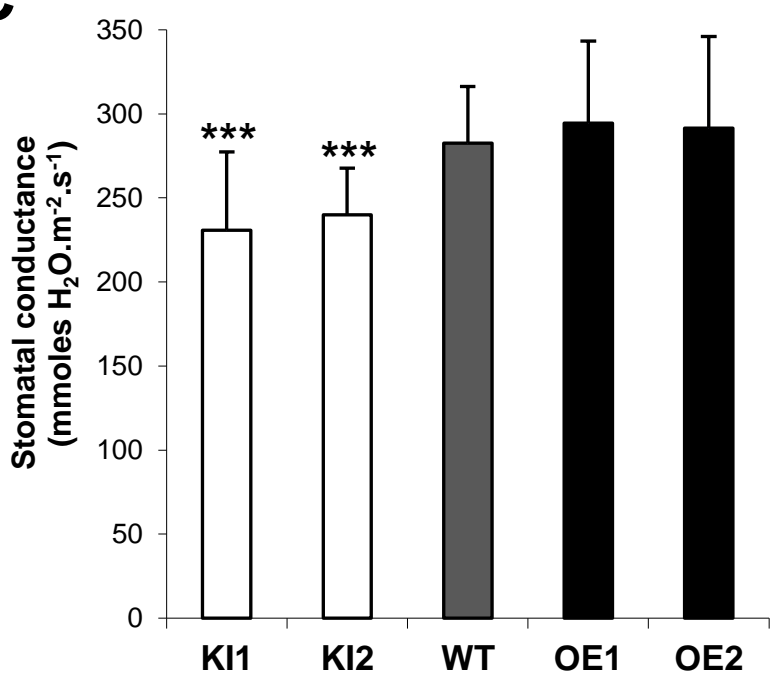

D

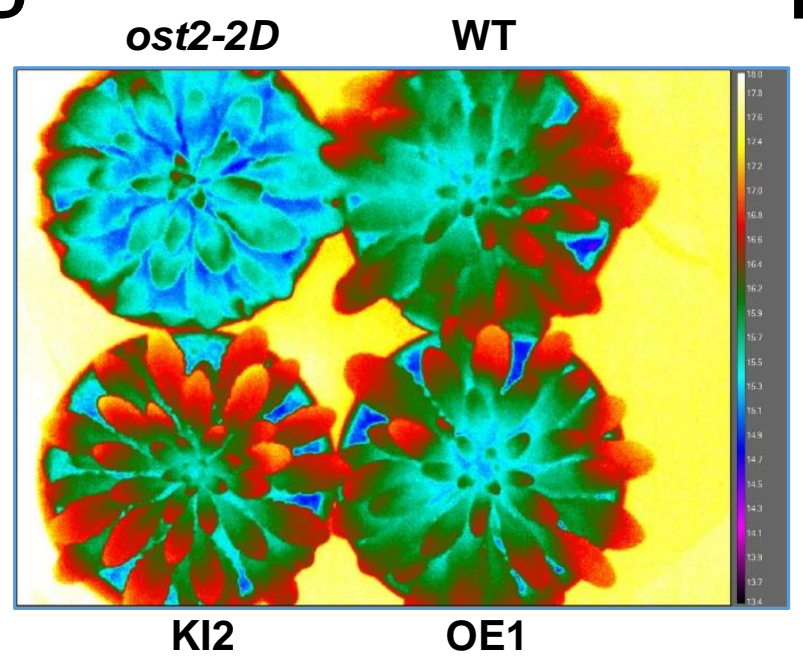

E

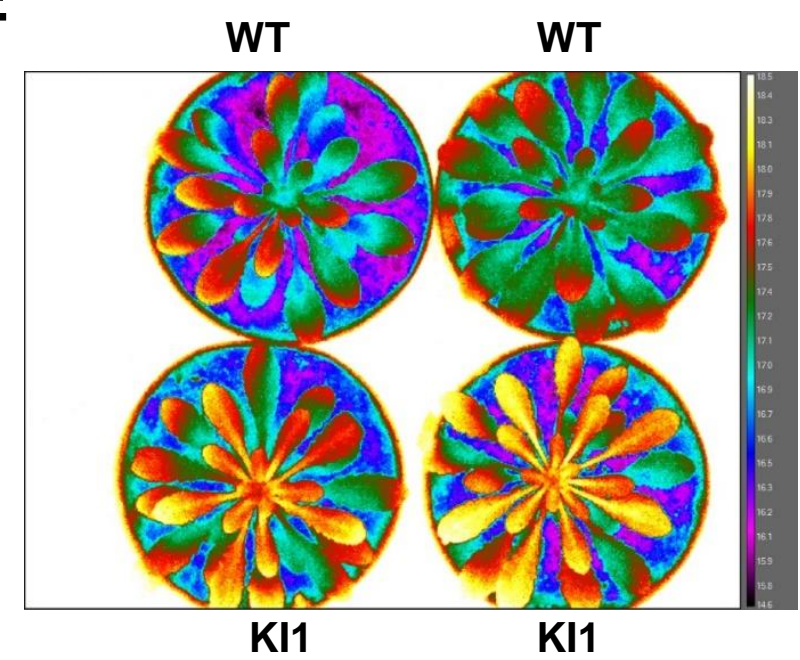

Figure 5. Stomatal phenotype of Arabidopsis lines modified for plastidial type-II GRXs. A. Stomatal density. B. Stomatal index. Data for $\mathbf{A}$ and $\mathbf{B}$ are means \pm SD of 12 independent values using peeled epidermis from three leaves per genotype. Plants were grown for 4 weeks in control conditions: moderate light $\left(200 \mu\right.$ mol photons. $\left.\mathrm{m}^{-2} \cdot \mathrm{s}^{-1}\right)$ and short photoperiod $(8 \mathrm{~h})$ at $22^{\circ} \mathrm{C}$. C. Stomatal conductance measurements using porometry. Measurements of the water efflux from leaf abaxial side were performed on plants grown for 6 weeks in control conditions. Conductance values are means \pm SD of at least 17 average values per genotype originating from independent plants ( 8 measurements per plant for each genotype per experiment). $* * *$, significantly different from the WT value with $\mathrm{P}<0.001(t$-test). D. and E. Infrared thermal imaging. Plants were dark-adapted. False colored infrared images of 6-week-old plants grown in control conditions. Pictures were taken at the end of the night period two hours before the light period. The color scale on the right shows increasing temperature from purple to yellow. As a control, the ost2-2D mutant was used and shown to exhibit lower leaf temperature due to open stomata in the dark (Merlot et al., 2007). KI1 and KI2, independent grxS14 GRXS16-RNAi lines; OE1 and OE2, independent GRXS14-overexpressing lines. 


\section{Figure 6}
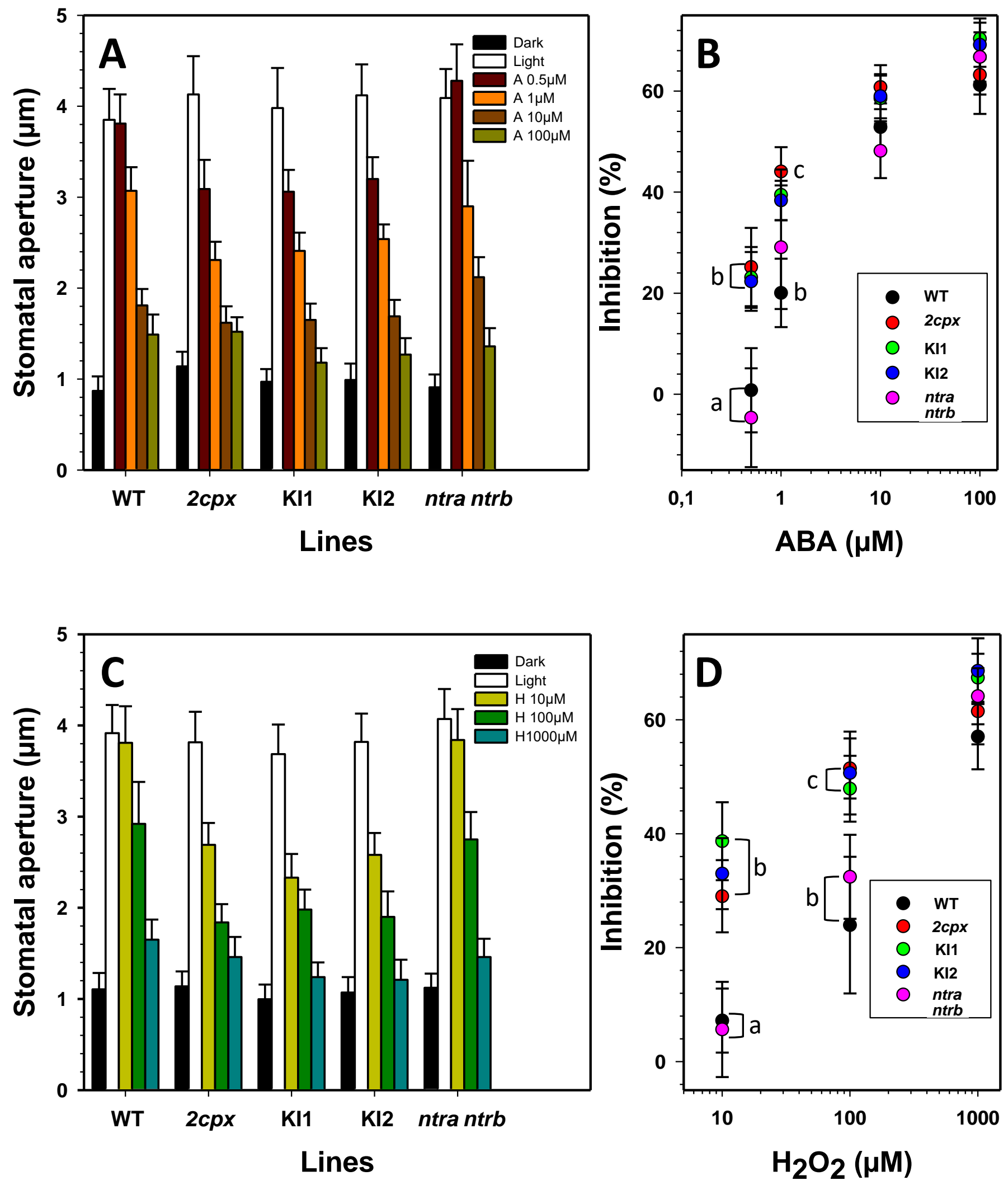

Figure 6. Effect of $\mathrm{ABA}$ and $\mathrm{H}_{2} \mathrm{O}_{2}$ on stomatal aperture in Arabidopsis mutants deficient in cytosolic NTRs, plastidial 2Cys-PRXs or plastidial type-II GRXs.

Stomatal aperture measurements in response to ABA concentrations of $0.5,1,10$ and $100 \mu \mathrm{M}(\mathbf{A}$ B) or to $\mathrm{H}_{2} \mathrm{O}_{2}$ concentrations of 10,100 and $1000 \mu \mathrm{M}(\mathbf{C}-\mathbf{D})$ in light-treated epidermis. Data in panels $\mathbf{B}$ and $\mathbf{D}$ were calculated from the original raw data reported in panels $\mathbf{A}$ and $\mathbf{C}$, respectively, and represent the inhibitions of stomatal aperture due to the treatments expressed in percents of that measured in light alone. Data represent means \pm SD of 2 independent experiments with 60 measurements per genotype and treatment. Means were compared with the ANOVA test, and letters represent groups of means not statistically different $(\mathrm{P}<0.05) .2 c p r x$, double 2cysprxa 2cysprxb mutant plants; KI1 and KI2, independent grxS14 GRXS16-RNAi lines; ntra ntrb, double ntra ntrb mutant plants. 


\section{Figure 7}

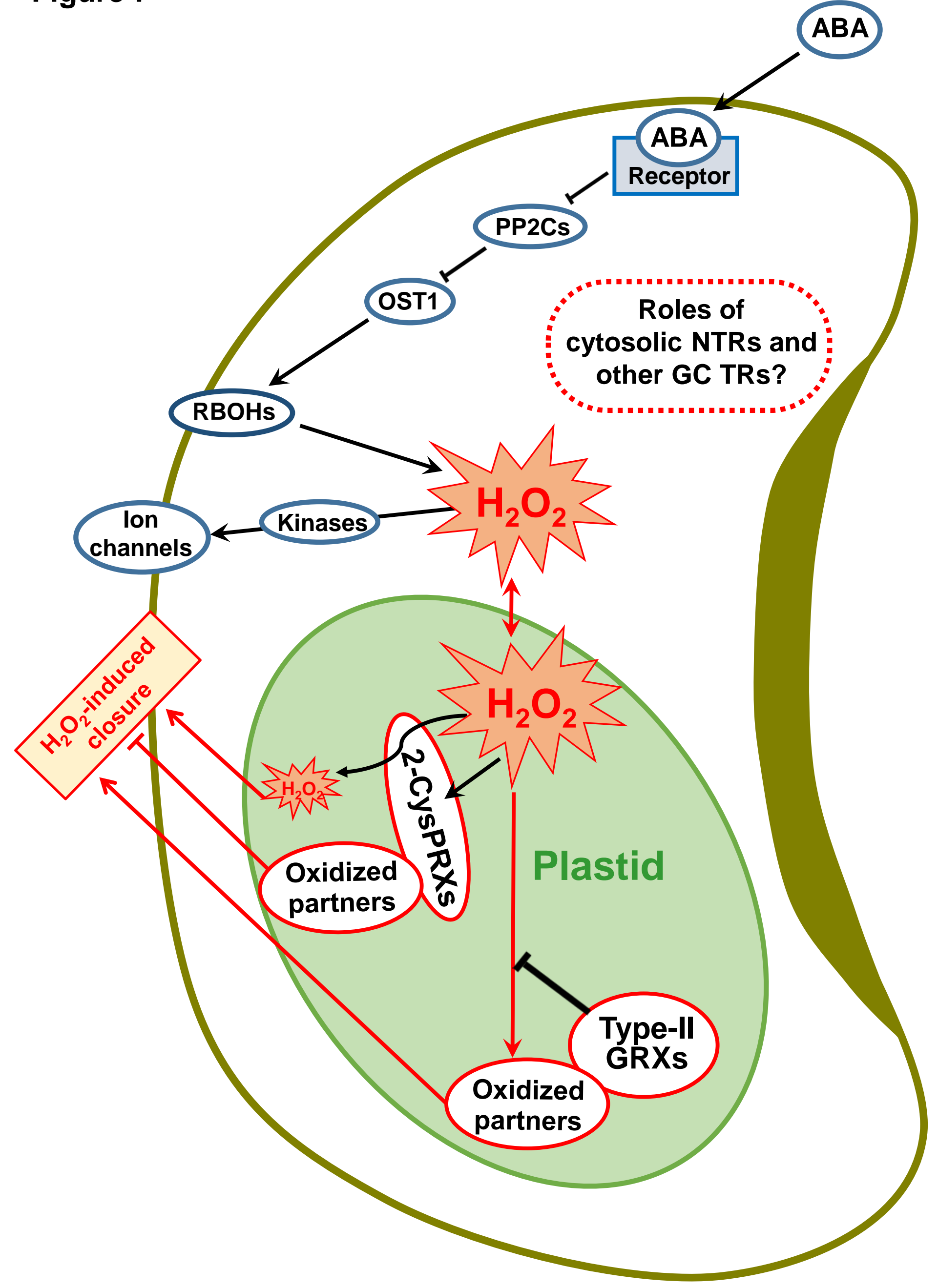

Figure 7. Model for positioning putative roles of plastidial 2-CysPRXs and type-II GRXs in the signaling network governing stomatal closure. Based on the results gained on epidermal peels showing modified responses of mutants to ABA and $\mathrm{H}_{2} \mathrm{O}_{2}$ and the known biochemical functions of these enzymes, we propose that they participate in $\mathrm{H}_{2} \mathrm{O}_{2}$-related transduction pathways. 2-CysPRXs might scavenge $\mathrm{H}_{2} \mathrm{O}_{2}$ within plastid or promote oxidation of partners that remain to be identified and are involved, when oxidized, in a pathway mitigating stomatal closure. Type II-GRXs might prevent oxidation of partners, the oxidized form of which could trigger closure. The roles of cytosolic NTRs and other TRs in guard cells remain to be determined. 


\section{Figure S1}

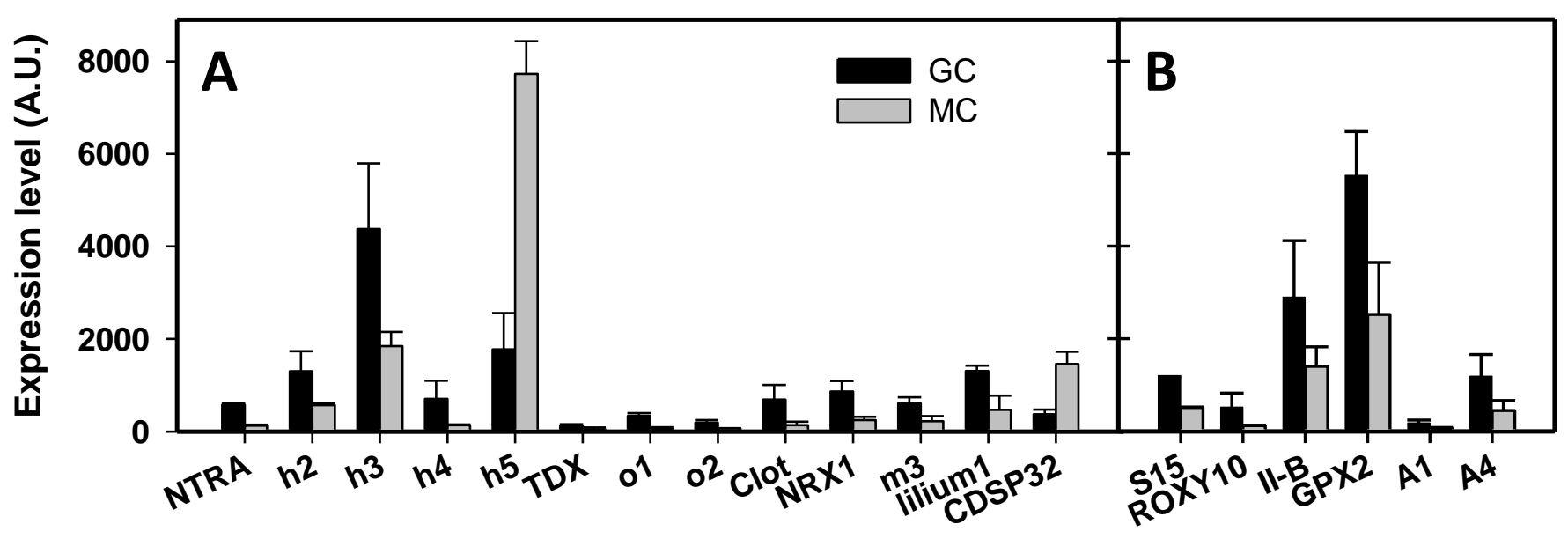

Figure S1: Transcriptomic analysis of $T R$ expression in guard and mesophyll cell protoplasts. Data were retrieved from the microarray analyses described by Yang et al., (2008). RNA was isolated from protoplasts prepared from guard or mesophyll cells and hybridized to the ATH1 GeneChip. Two independent hybridization experiments per cell type were performed. Means and SD of expression levels were retrieved using the Arabidopsis eFP Browser at bar-utoronto.ca (Winter et al., 2007). Only $T R$ genes displaying $\mathrm{GC} / \mathrm{MC}$ or $\mathrm{MC} / \mathrm{GC}$ ratios of expression $\geq 2$ were considered for this figure. $\mathbf{A}$, NADPH-Thioredoxin reductase A (NTRA) and thioredoxins h2, h3, h4, h5, TDX, o1, o2, Clot, m3, Lillium-1 and CDSP32; B, Glutaredoxins S15 and ROXY10, peroxiredoxin II-B (II-B), glutathione peroxidase 2 (GPX2), and methionine sulfoxide reductases A1 and A4. 


\section{Figure S2}
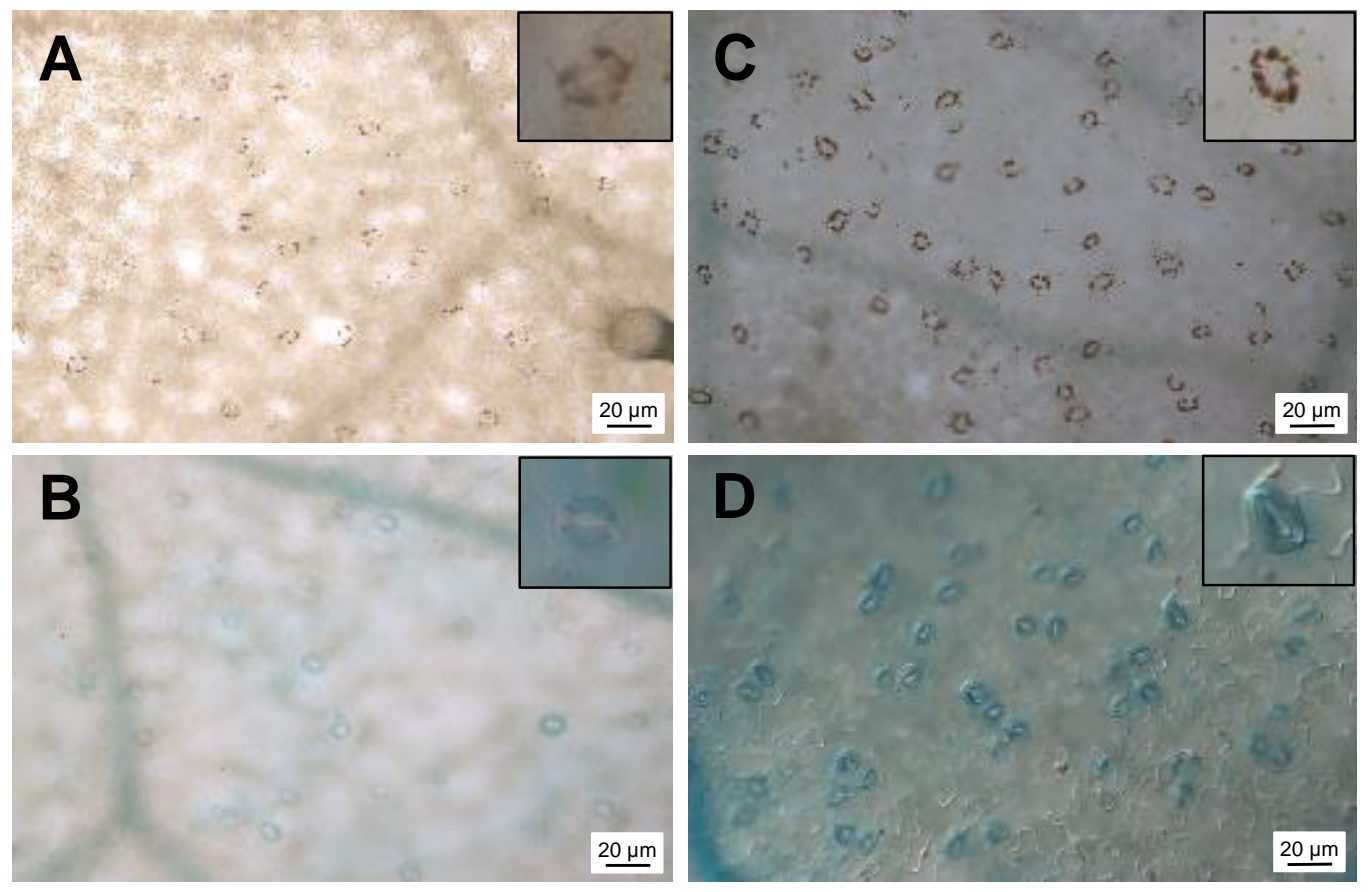

Figure S2. Gene expression in guard cells. $T R X h 2$ (A), $T R X h 3$ (B), NTRB (C) and $P R X-I I B$ (D) gene promoters were fused to $\beta$-glucuronidase $(G U S)$ as a reporter gene and gene expression was monitored in 15 day-old plants by histochemical analysis. Inset: focus on one single stomata. 


\section{Figure S3}

A

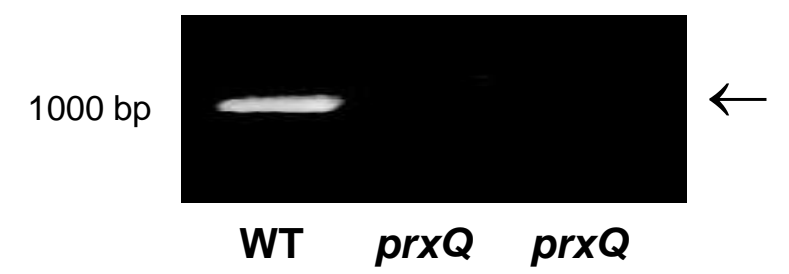

C

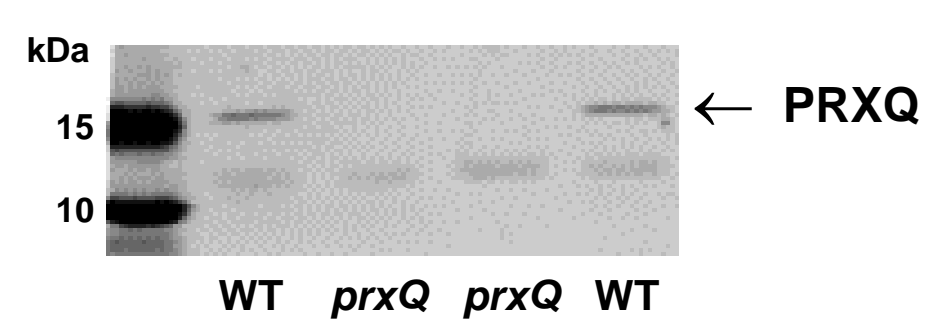

B

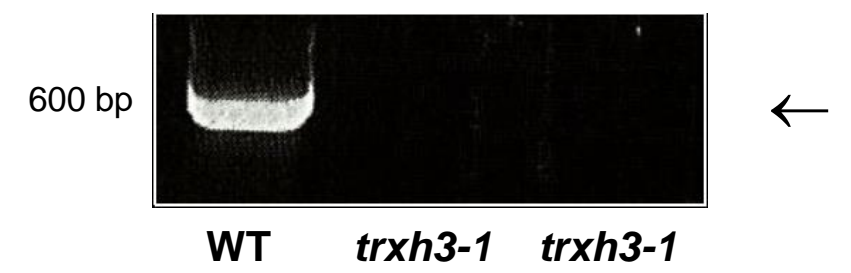

D

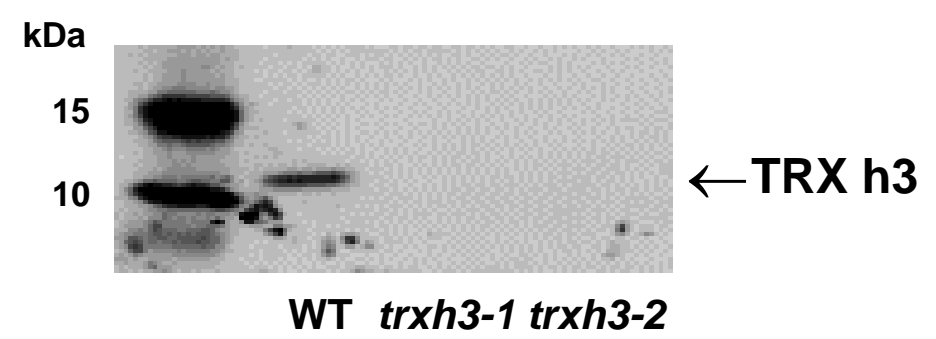

Figure S3. Characterization of mutants deficient in the expression of $P R X Q$ and $T R X h 3$ genes.

A. Genotyping of SAIL_742_G10 plants (prxq) using primers corresponding to 5' and 3' ends of $P R X Q$ coding sequence. B. Genotyping of SAIL_314_G04 (trxh3-1) using primers corresponding to 5' and 3' ends of TRXh3 coding sequence. WT: wild type. C. Western blot analysis of PRXQ abundance in WT and prxq plants. D. Western blot analysis of TRX h3 abundance in WT, trxh3-1 (homozygous SAIL_742_G10) and trxh3-2 (homozygous SALK_111160) plants. 


\section{Figure S4}

A

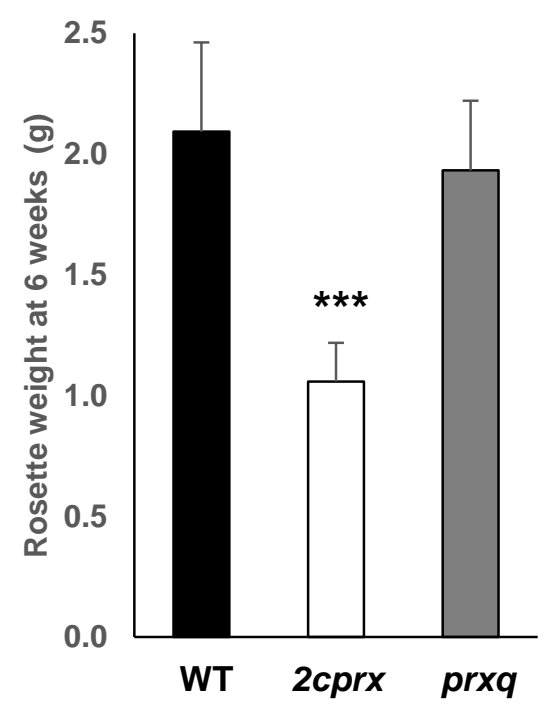

D

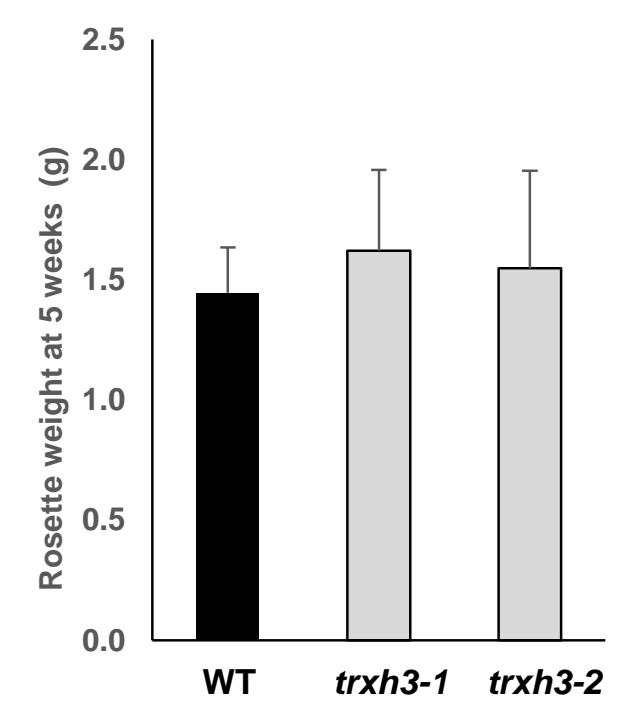

B

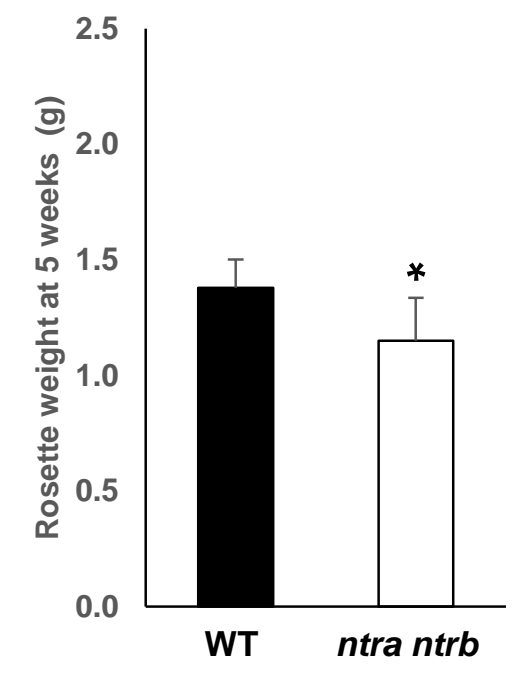

E

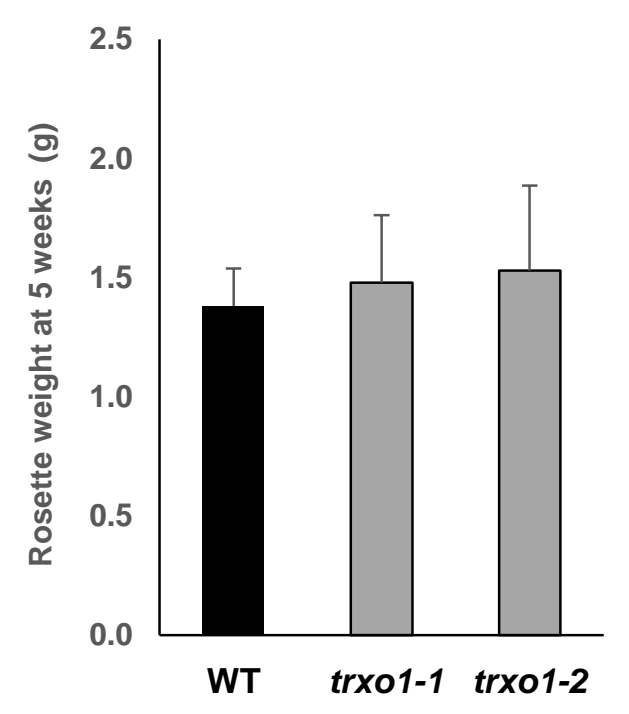

Figure S4. Growth of plants modified for the expression of various $\boldsymbol{T R}$ genes. Plants were grown for 5 or 6 weeks in control conditions: moderate light $\left(200 \mu \mathrm{mol}\right.$ photons. $\left.\mathrm{m}^{-2} \cdot \mathrm{s}^{-1}\right)$ and short photoperiod $(8 \mathrm{~h})$ at $22^{\circ} \mathrm{C}$. Rosette weight values are means \pm $\mathrm{SD}$ of four to six average values originating from independent experiments (at least 6 plants for each genotype per experiment). $*$ and $* * *$, significantly different from the WT value with $\mathrm{P}<0.05$ and $\mathrm{P}<0.001$, respectively ( $t$-test). 2 cprx, double 2 cysprxa 2cysprxb mutant plants (A); ntra ntrb, double ntra ntrb mutant plants (B); prxq (A), grxs17 (C), trxh3-1, trxh3-2 (D) and trxo11, trxo1-2 (E) mutants lacking PRXQ, GRXS17, TRXh3 and TRXo1, respectively. 


\section{Figure S5}

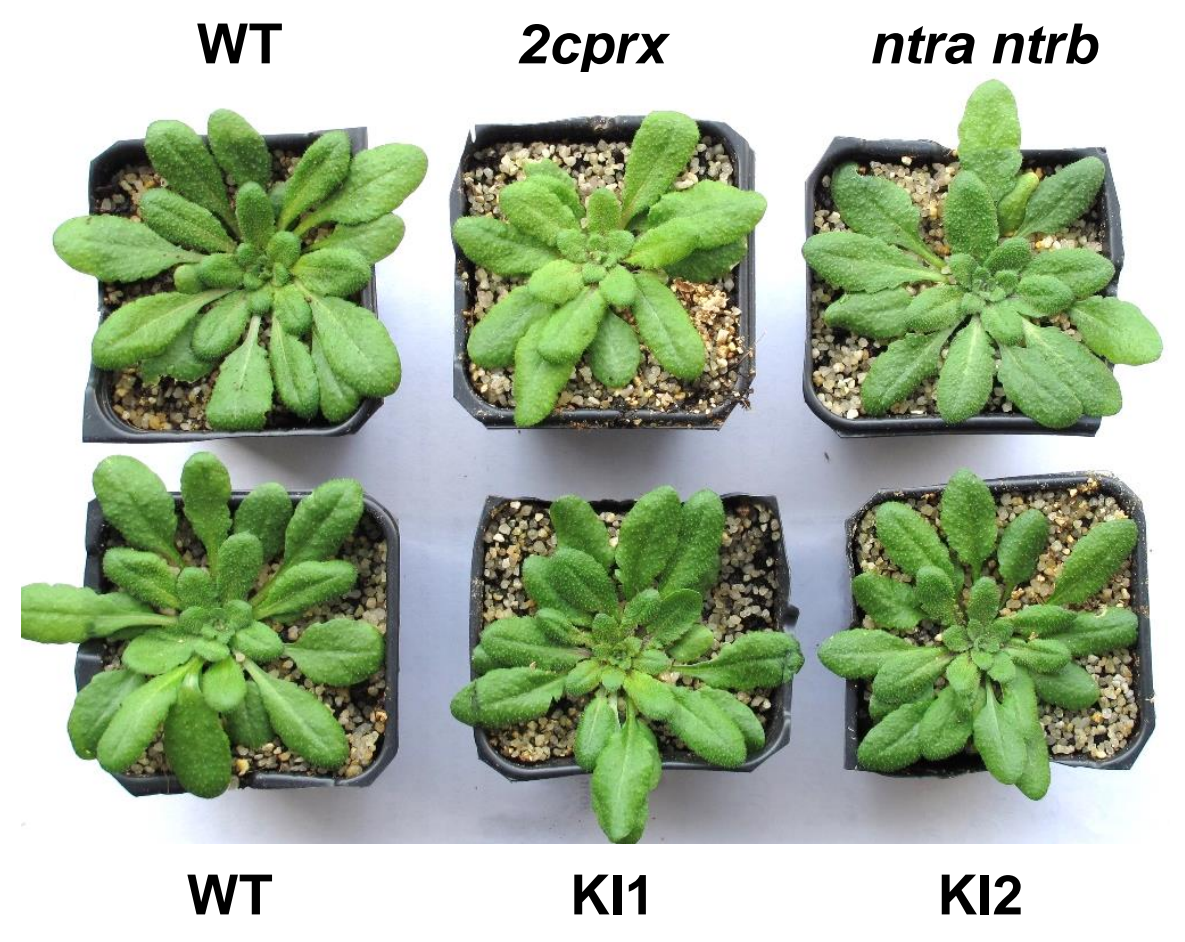

Figure S5. Photograph of wild type (WT) plants and of plants modified for the expression of various $T R$ genes. Plants were grown for 5 weeks in control conditions: moderate light $\left(200 \mu \mathrm{mol}\right.$ photons. $\left.\mathrm{m}^{-2} \cdot \mathrm{s}^{-1}\right)$ and short photoperiod $(8 \mathrm{~h})$ at $22^{\circ} \mathrm{C}$. $2 c p r x$, double 2cysprxa 2cysprxb mutant plant ; ntra ntrb, double ntra ntrb mutant plant; KI1 and KI2, independent grxS14 GRXS16-RNAi lines.. 


\section{Figure S6}

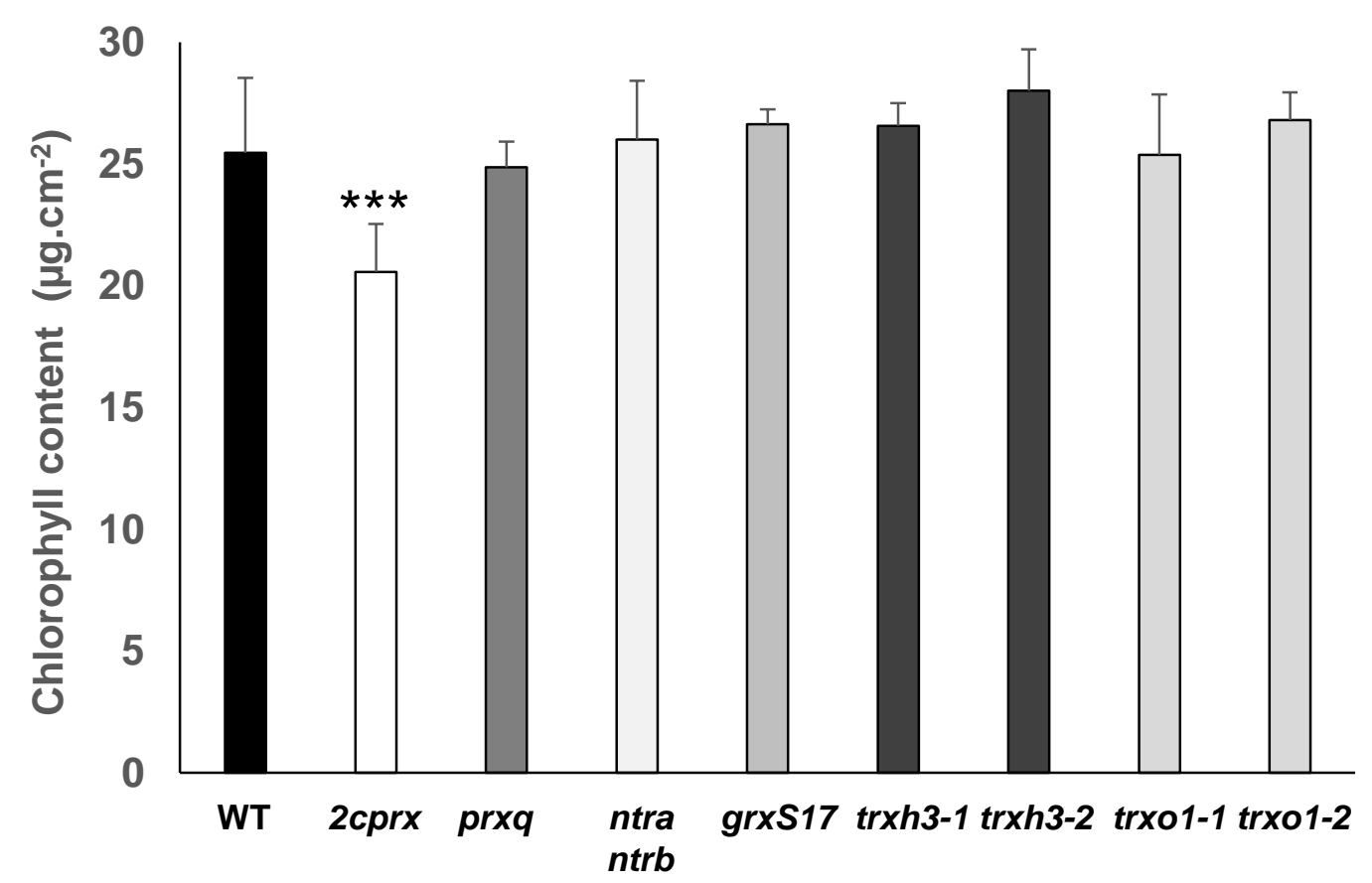

Figure S6. Leaf chlorophyll content of plants modified for the expression of various $T R$ genes.

Plants grown for 6 weeks in control conditions: moderate light $\left(200 \mu \mathrm{mol}\right.$ photons. $\left.\mathrm{m}^{-2} \cdot \mathrm{s}^{-1}\right)$ and short photoperiod $(8 \mathrm{~h})$ at $22^{\circ} \mathrm{C}$. Data are means $\pm \mathrm{SD}$ of at least 5 values originating from adult leaves taken from independent plants. $* * *$, significantly different from the WT value with $\mathrm{P}<0.001$, ( $t$-test). 2 cprx, double 2 cysprxa 2 cysprxb mutant plants; tra ntrb, double ntra ntrb mutant plants; prxq, grxs17, trxh3 and trxo1, mutants lacking PRXQ, GRXS17, TRXh3 and TRXo1, respectively. 


\section{Figure S7}

A

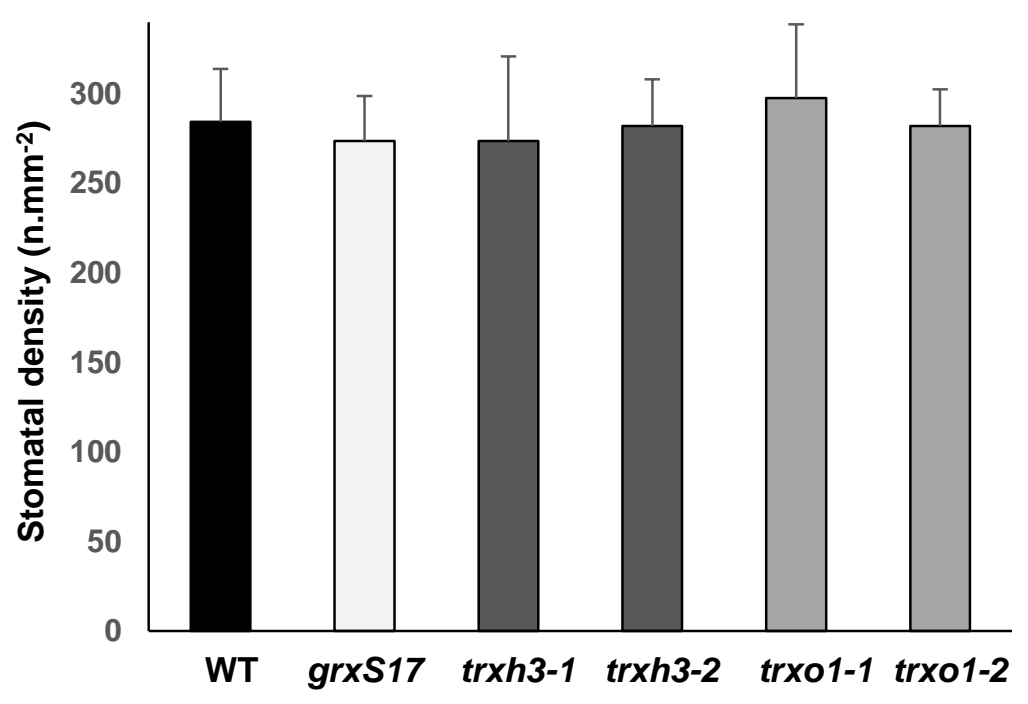

C

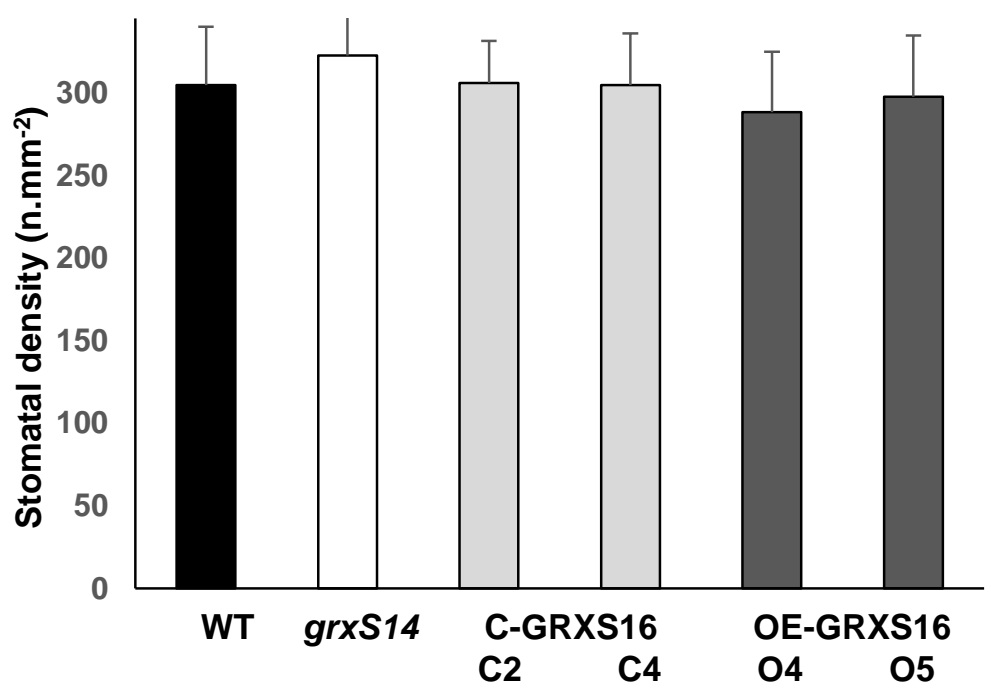

B

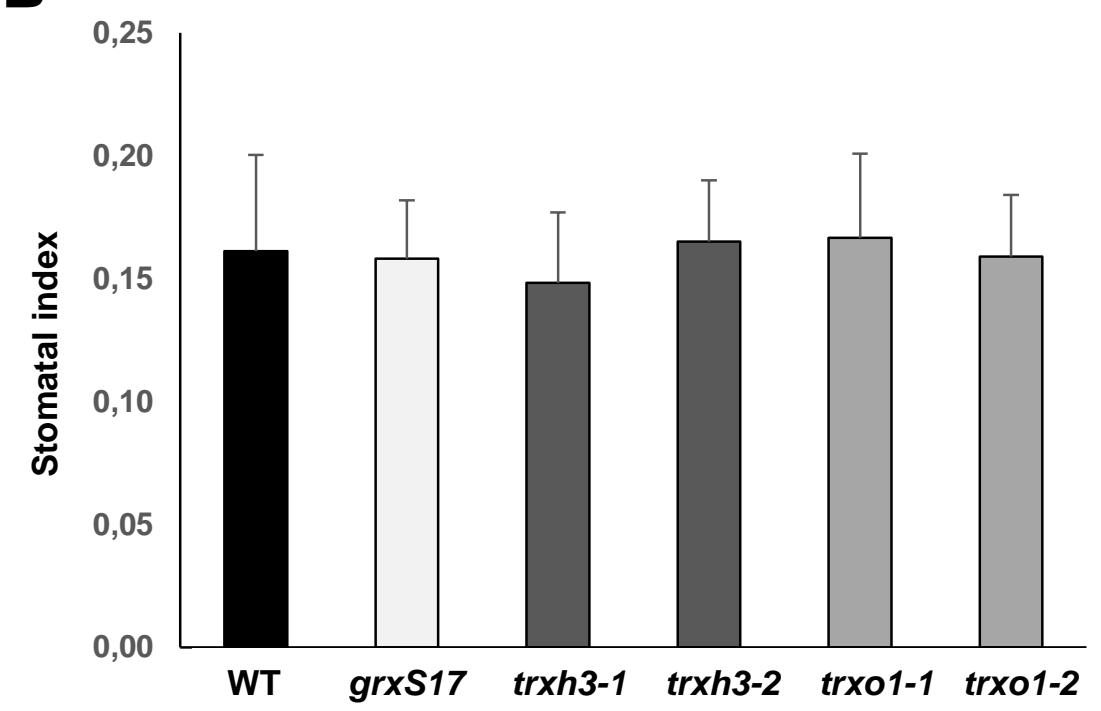

D

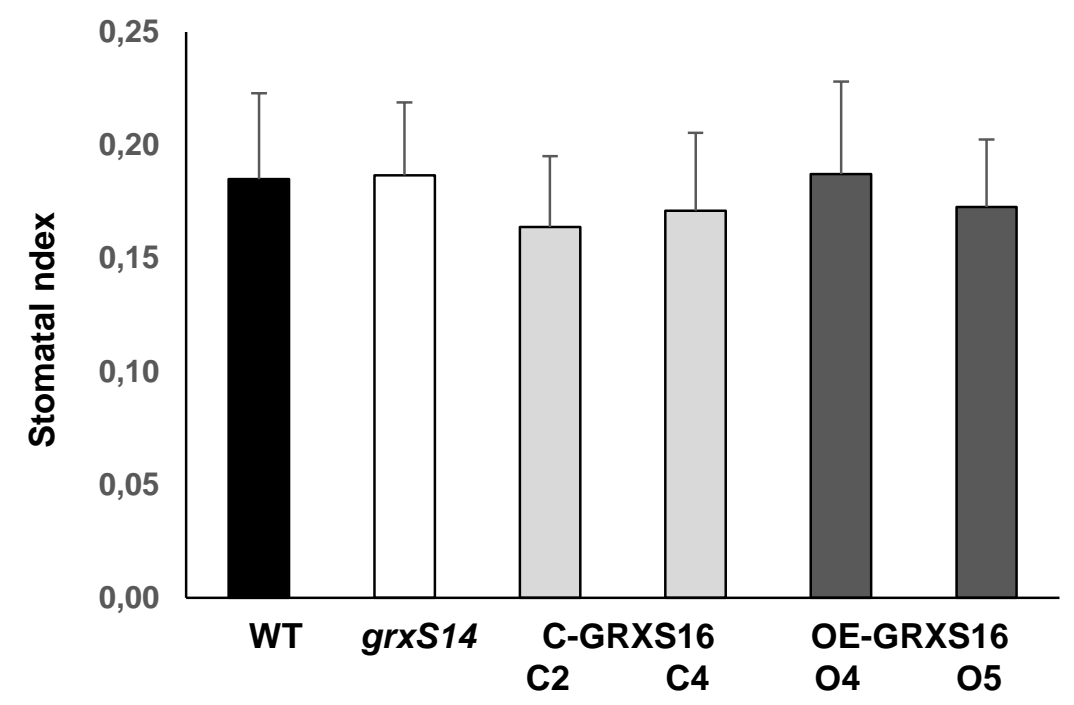

Figure S7. Stomatal density (A and C) and stomatal index (B and D) of Arabidopsis lines affected in the expression of genes coding for various types of thiol reductases. Data are means \pm SD of 12 independent values using peeled epidermis from three leaves per genotype. Plants were grown for 4 weeks in control conditions: moderate light $\left(200 \mu \mathrm{mol}\right.$ photons. ${ }^{-}$ $\left.{ }^{2} \cdot \mathrm{s}^{-1}\right)$ and short photoperiod $(8 \mathrm{~h})$ at $22^{\circ} \mathrm{C}$. grxs $17, \operatorname{trxh} 3$, trxol and grxs 14 , mutants lacking GRXS17, TRXh3, TRXo1 and GRXS14, respectively; C-GRXS16 C2 and C4, two independent GRXS16-cosuppressed lines; OE-GRXS16 O4 and O5, two independent GRXS16-overexpressing lines. 


\section{Figure S8}

A

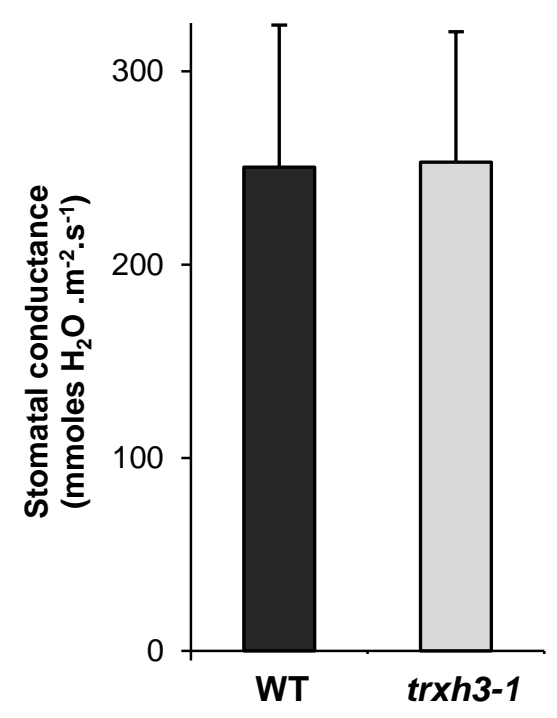

B

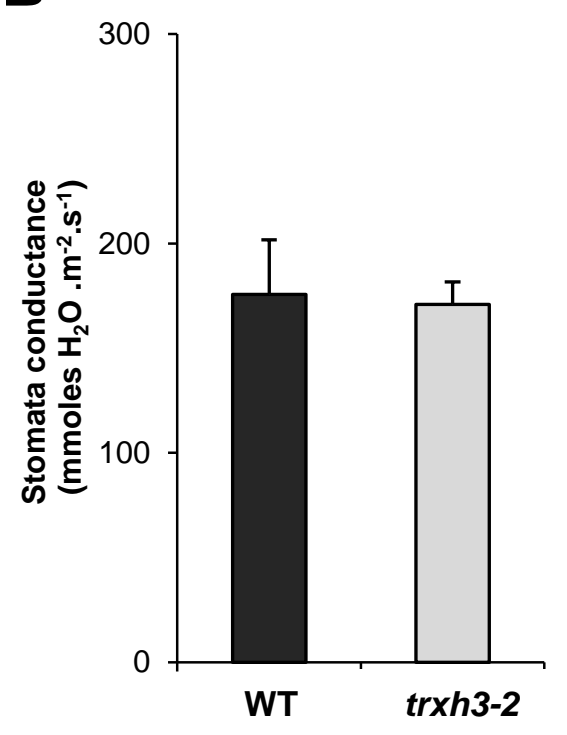

C

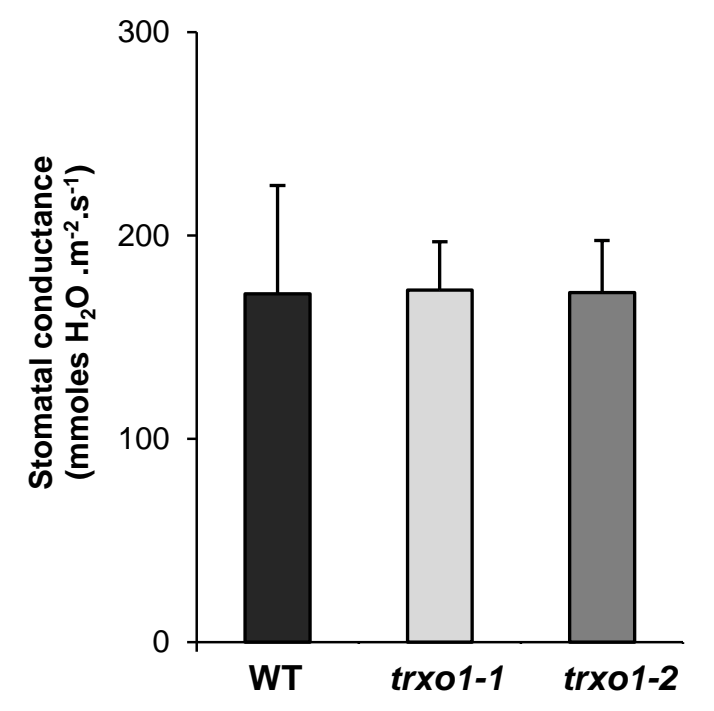

D

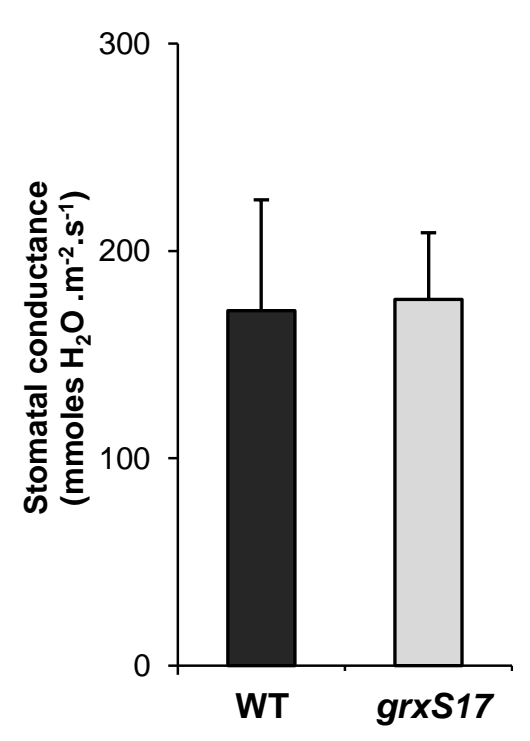

E

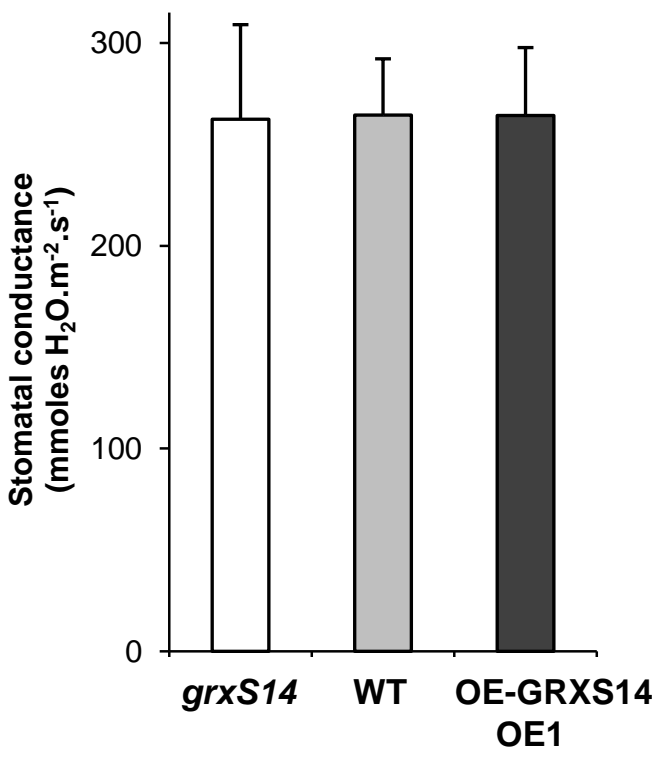

F

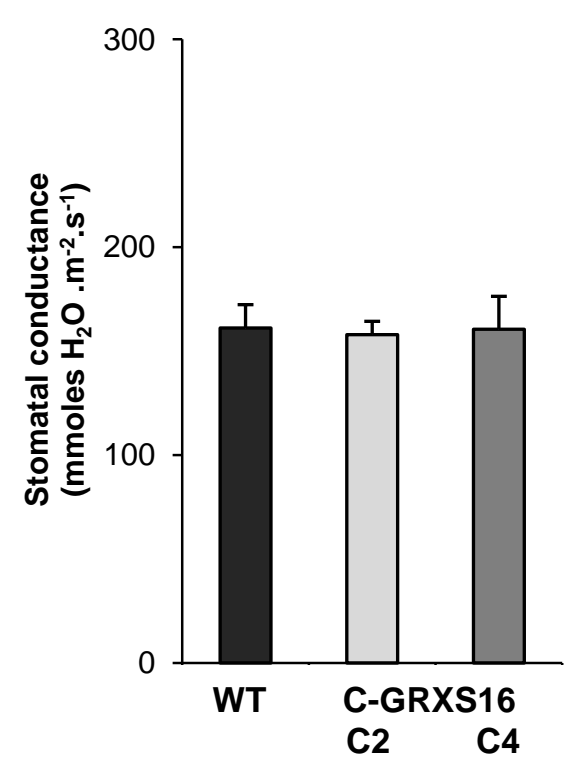

G

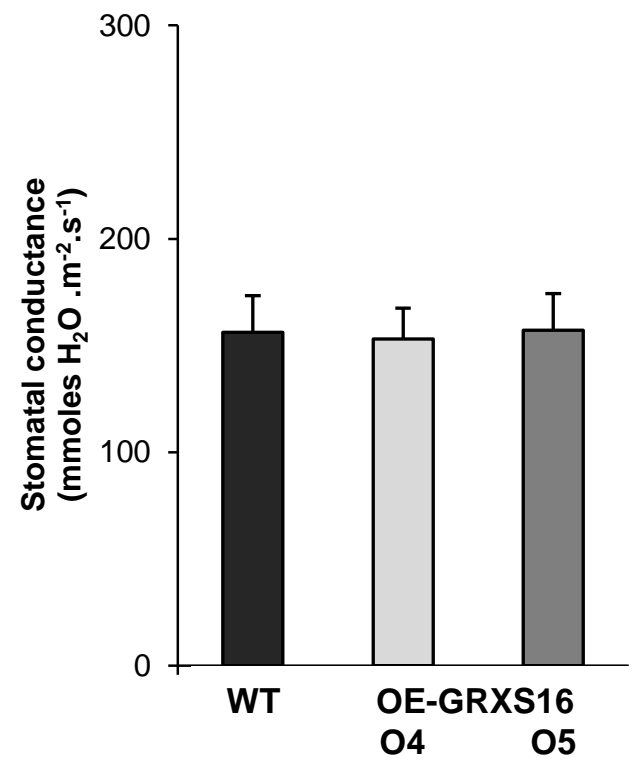

Figure S8. Stomatal conductance of Arabidopsis lines affected in the expression of genes coding for various types of thiol reductases. Measurements of the water efflux from the leaf abaxial side were performed using porometry on plants grown for 6 weeks in control conditions. Conductance values are means \pm SD of six average values originating from independent plants (8 measurements per plant for each genotype per experiment); trxh3 (A-B), trxol (C) and grxs17 (D), mutants lacking TRXh3, TRXo1 and GRXS17, respectively; grxs14 and OE-GRXS14 OE1 (E), lines lacking GRXS14 expression and overexpressing GRXS14, respectively; C-GRXS16 C2 and C4 (F), two independent GRXS16-cosuppressed lines; OE-GRXS16 O4 and O5 (G), two independent GRXS16-overexpressing lines. 